University of Massachusetts Amherst

ScholarWorks@UMass Amherst

Doctoral Dissertations 1896 - February 2014

$1-1-1975$

\title{
Assessing the vocational maturity of students in the East Central State of Nigeria.
}

Chinwe Achebe

University of Massachusetts Amherst

Follow this and additional works at: https://scholarworks.umass.edu/dissertations_1

\section{Recommended Citation}

Achebe, Chinwe, "Assessing the vocational maturity of students in the East Central State of Nigeria."

(1975). Doctoral Dissertations 1896 - February 2014. 2922.

https://doi.org/10.7275/05gz-n042 https://scholarworks.umass.edu/dissertations_1/2922

This Open Access Dissertation is brought to you for free and open access by ScholarWorks@UMass Amherst. It has been accepted for inclusion in Doctoral Dissertations 1896 - February 2014 by an authorized administrator of ScholarWorks@UMass Amherst. For more information, please contact scholarworks@library.umass.edu. 


\section{ASSESSING THE VOCATIONAL MATURITY OF STUDENTS IN THE EAST CENTRAL STATE OF NIGERIA}

A Dissertation Presented

By

Christie Chinwe Achebe

Submitted to the Graduate school of the University of Massachusetts in partial fulfillment of the requirements for the degree of DOCTOR OF EDUCATION
April
1975

Education, Guidance and Counseling 
(c) Christie Chinwe Achebe 1975

All Rights Reserved 


\section{ASSESSING THE VOCATIONAL MATURITY OF STUDENTS}

IN THE EAST CENTRAL STATE OF NIGERIA

A Dissertation

By

Christie Chinwe Achebe

Approved as to style and content by:
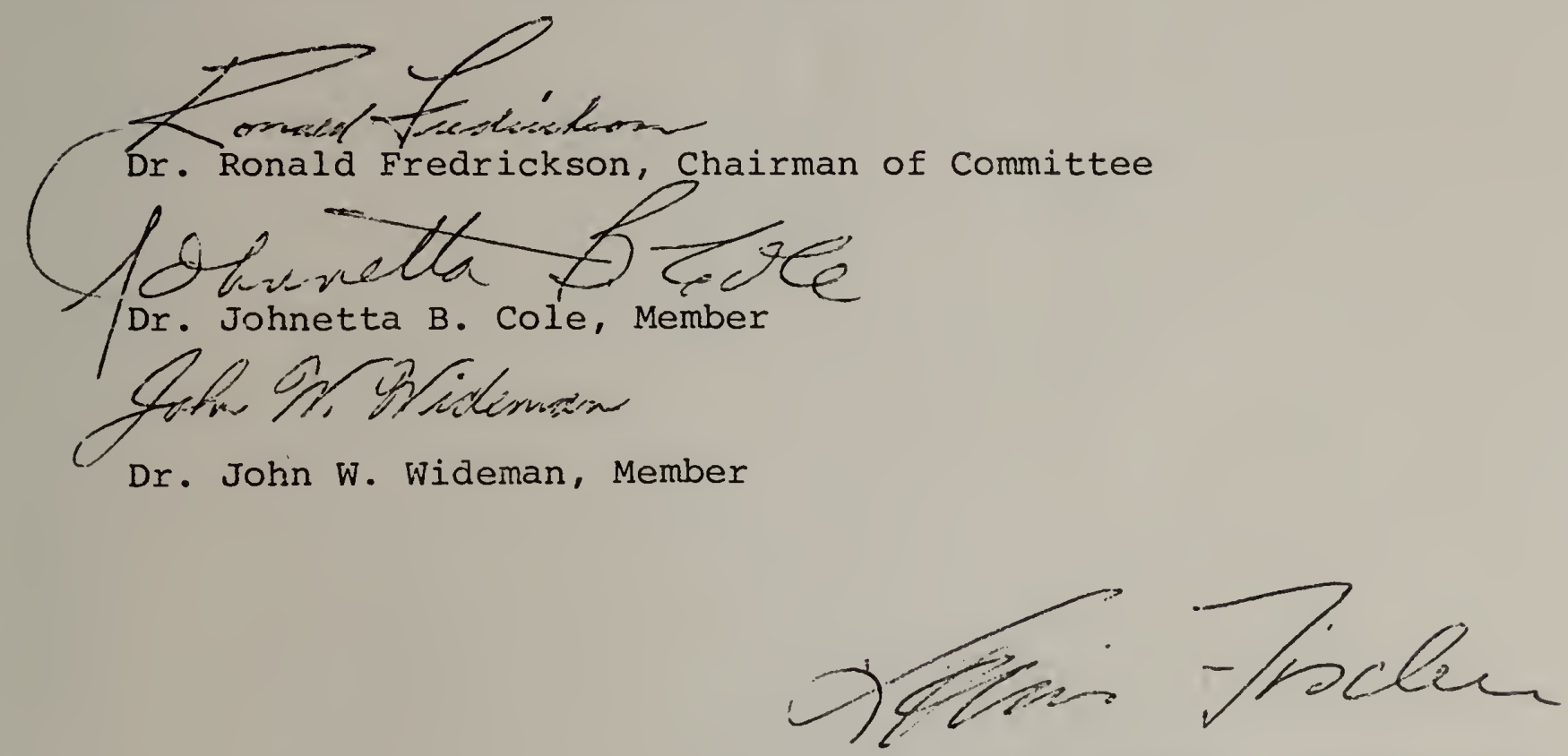

Dr. Louis Fischer, Acting Dean

School of Eãucation

April $\quad 1975$ 


\section{ACKNOWLEDGEMENTS}

The successful completion of this dissertation has been due to the immense contribution of many deserving individuals.

Dr. Ronald Fredrickson, my major supervisor and chairman of my dissertation committee merits a special mention. Through my doctoral program, I found his untiring readiness to listen and help, most astonishing and very rewarding indeed. The quality and shape of this dissertation owes much to his constant encouragement, his enthusing confidence and faith in my ability, as well as to his timely and constructive feedback. To this admirable advisor, I extend my most sincere gratitude.

To Dr. John Wideman, goes my appreciation for his sensibility to my need for reinforcement at this critical period.

To Dr. Johnetta Cole, an admired and trusted friend, who activates others with warmth and energy, I extend my most profound gratitude for her support, both moral and academic, which buoyed me up through this experience.

I thank Dr. George Urch for his time and interest in the investigation and Dr. D. Passmore for his help in interpreting the data. 
To. Dr. Haase go my most sincere thanks for his immense help with the methodological and statistical section of this investigation.

Several individuals were of invaluable help in providing some vital data used in this study. To all of them I now extend my appreciation. I'm especially indebted to Mr. John Ibeziakor, Chief Secretary to the Government of the East Central State of Nigeria, Mr. I. T. J. Ordor, General Manager, Nigerian Petroleum Refineries, Mr. Sam Nwoye, Librarian, University of Nigeria, and Mr. Cyprian Ekwensi, without whose cooperation this study, (carried on so far from Nigeria) would not have come to fruition.

My sincere thanks also go to Dr. Helen Vaznaian for giving me release time to complete this dissertation. I'm very grateful to Terry Boyle for her excellent and professional typing of this dissertation and for her understanding.

I'm particularly touched by, and thankful to my children, Chinelo, Ike, Chidi and Nwando for the quiet time they allowed me so "mummy can study her statistics."

To my sister Elizabeth and my brother Samuel for their encouragement.

My last and perhaps most important indebtedness goes to my husband Chinua Achebe. His quiet encouragement, understanding, love and undoubted faith in my ability to accomplish 
this work creditably, made the many hours of frustrations pass by less painfully. For this resource, I'm forever indebted. 
Assessing the Vocational Maturity of Students in the East Central State of Nigeria (April 1975)

Christie Chinwe Achebe, B.A. (Hons) London

$$
\begin{gathered}
\text { P.G.C.E. London } \\
\text { M.ed. Nigeria }
\end{gathered}
$$

Directed by: Dr. Ronald H. Fredrickson

This investigation surveyed the vocational developmental patter of students in the East Central state of Nigeria to determine the applicability of the vocational maturity theory (super) that in adolescence, career maturity progresses systematically with increasing age and grade.

The Attitude Scale and both the occupational Information and planning subtests of the Competence Test of the Career Maturity Inventory (CMI), modified because of terminology, were administered to 400 classes $1-4$ (grades 7-10) boys and girls, randomly chosen from four urban and rural schools.

Five null hypotheses were tested to ascertain the effect of class, sex, urban/rural school locations and age on the CMI scores as well as for significant interactions between pairs of the first three main effect variables. Threehundred and ninety-six 11-22 year olds were categorized into eight age groups for statistical analysis. A 1 X 8 Anova design exanined the effect of age on the dependent variables. 
The relationship between class, sex and urban/rural schools and scores on the CMI subtests was analyzed using a $4 \times 2 \times 2 \times 2$ Ancva design. The minimum level of significance was set at .05 level of confidence. The results indicated significant differences among classes for all three subtests, at the .001 level of confidence.

The hypothesis of no significart difference due to sex was rejected at the .001 level for the Attitude Scale and the Occupaticnal Information subtest but not for the Flanning subtest. Boys scored higher than girls in their attitude to work and job knowledge.

Similarly, urban students scored higher than rural students in work attitude, job knowledge and planning competence. The hypothesis of no significant difference by urban/ rural school location was rejected at the .001 level of confidence.

Significant differences occurred by age on all three subtests at the .05 level.

Significant interactions also occurred between each pair of main effect variables and all the dependent variables. The hypothesis of no significant interactions was rejected at the .001 level of confidence for all the subtests. The class by sex interaction indicated that the statement regarding the overall effect of class on the students' vocational 
maturity is now modified by the effect of sex. For girls, according to the CMI, appear more mature than boys in classes 2 and 3 (grades 8 and 9 ) but less so in 1 and 4 . Similarly, the sex by urban/rural interaction indicates that the higher vocational maturity of boys is true only in the rural areas for urban girls score higher than the urban boys as well as their rural sisters.

Urban students scored higher than rural students. However, the class by urban/rural interaction indicates an exception to this trend in class one where rural students score higher than their urban class one counterparts.

Based on these findings, certain conclusions and recommendations were made:

1. The overall vocational maturity of the Nigerian sample shows a prototypic pattern of progressive increase by age and especially by grade. The developmental theory of vucational maturity seems therefore to have cross cultural application.

2. The overall effects of class, sex and urban/rural school location must be qualified by the interactive effects of the pairs of main effect variables for any meaningful prediction of a ivigerian student's scores on the CMI.

3. The Competence Test is recommended for exploration by the ECS guidance program since the scores of the ECS sample and Crites' standardization group were only two points apart. 
4. The ECS is urged to intensify its guidance program for girls in rural areas.

5. The broader implications of the results of this study for test development and use in the emerging Nigerian guidance program were further explored. 
TABLE OF CONTEN'S

Chapter

I. INTRODUCTION

Statement of the Problem . . . . . . . . . 4

Trait-Factor and Developmental
Approach to Vocational

The Purpose of the Stuciy

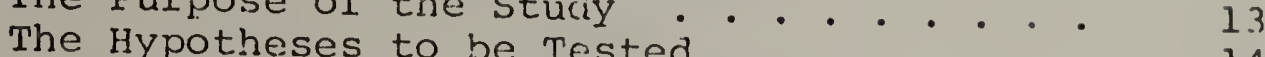

The Concept of Vocational Maturity . . . . 1.4

Significance of the study

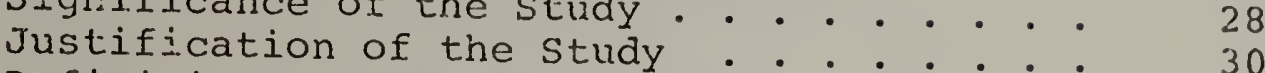

Definition of Terms

Scope and Limitation of $\dot{0} \cdot \cdot \cdot \cdot \cdot \cdot \cdot 45$

Organization of the study $4 . \cdot \cdot \cdot \cdot 4$

II. REVIEW OF THE LITERATURE . . . . . . . . 49

The Career Pattern Study . . . . . . . . 49

Career Developrnent Study (Gribbons
and Lohnes (1964)

The Vocational Development

Project (Crites, J. O.) . . . . . . . . 62

Some Limitations of the Career
Maturity Inventory . . . . . . . . 75

Research Studies with the Attitude Scale: 79

III. METHODOLOGY . . . . . . . . . . . . 88

Area studied . . . . . . . . . . . 88

Instrument . . . . . . . . . . . . . . 91

Procedure and Data Collection . . . . . 98

Summary . . . . . . . . . . . . 100

IV. PRESENTATION OF THE RESULTS . . . . . . . 101

Section I--Hypotheses of the class,

Sex, Geographic Location Main Eifects. . . 104

Section II--Hypothesis of the

Age Variable . . . . . . . . . . . . 120

Section III--Hypothesis of Interactions. . 130

Summary of the Results for the

Hypothesis of No Interactions . . . . . . 147

Sumary of the Findings......... 149 
V. DISCUSSION, CONCLUSION, IMPLICATION . . . . 153

Discussion

Conclusion $\cdot \cdot \cdot \cdot \cdot \cdot \cdot \cdot \cdot \cdot \cdot \cdot \cdot \cdot \cdot 155$

Implications $\cdot \cdot \cdot \cdot \cdot \cdot \cdot \cdot \cdot \cdot \cdot 173$

APPENDICES • • • • • • • • • • • • • • • • • • . . . 183

BIBLIOGRAPHY • • • • • • • • • • • • • • • • . . 206

xii. 
LIST OF TABLES

Table

Page

1. Vocational Life Stages . . . . . . . . . 20

2. Outline of Vocational Developmental

Tasks in Chronological Order. . . . . . .

3. Super's Dimensions of Vocational Behavior . . .

4. Intercorrelation Between Adequate and Marginal Measures of Vocational Maturity . . . . . .

5. Measurement of Vocational Maturity

A Model of Career Maturity in Adolescence . .

6. Breakdown of Population Used in the Study . . .

7. Breakdown by Age Group . . . . . . . . . .

8. Means, Standard Deviations and Standard

Errors obtained on the Attitude Scale,

Part II (Knowing about Jobs) and Part IV

(Planning) of the Competence Test of the CMI, by Class

9. Means, Standard Deviations and Standard

Errors Obtained on the Attitude Scale,

Part II (Knowing about Jobs) and IV

Planning) of the competence Test of the

CMI, by Sex

10. Means, Standard Deviations and Standard

Errors Obtained on the Attitude Scale,

Part II (Knowing about Jobs) and IV

(Planning) of the Competence Test of

the CMI, by Geographic Location of

Schools (Urban/Rural) . . . . . . . . .

11. Summary Table of $4 \times 2 \times 2$ Analysis of

Variance of the Attitude scale scores

of 400 East Central state students

Classified According to Class, Sex and

the Geographic Location of Schools

(Urban/Rural) 
12. Summary Table of $4 \times 2 \times 2$ Analysis of Variance of the Part II (Knowing about Jobs) Scores of 400 East Central State Students Classified According to Class, Sex and the Geographic Location of Schools (Urban/Rural)

13. Summary Table of $4 \times 2 \times 2$ Analysis of Variance of the Part IV (Planning) Scores of 400 East Central State Students Classified According to Class, Sex and the Geographic Location of Schools (Urban/Rural)

14. Means, Standard Deviations and Standard Errors Obtained on the Attitude Scale, Part II (Knowing About Jobs) and IV (Planning) of the Competence Test of the CMI, by Age Group . . . . . . . . . .

15. Summary Table of a 1 X 8 Analysis of Variance of the Attitude Test Scores of 396 East Central State Students Classified According to Age Group . . . . . . . . . . . . .

16. Sumnary Table of a 1 X 8 Analysis of Variance of the Part II (Knowing about Jobs) Scores of 396 East Central State Students Classified According to Age Group ...... . . . . .

17. Summary Table of a 1 X 8 Analysis of Variance of the Part IV (Planning) Scores of 396

East Central state Students Classified According to Age Group . . . . . . . . . 
LIST OF ILLUSTRATIONS

Figure

Page

1. Illustrating the Means Obtained on the

Attitude Scale, Part II (Knowing about

Jobs) and IV (Planning) subtests of the

Competence Test of the CMI, by Class... . .

2. Illustrating the Means Obtained on the Istitude scale, part II (Knowing about Jobs) and IV (Planning) subtests of the Competence Test of the CMI by Sex

3. Illustrating the Means obtained on the Attitude Scale, part II (Knowing about Jobs) and IV (Planning) Subtests of the Competence Test of the CMI by the Geographical Location of Schools . . . . . .

4. Illustrating the Means obtained on the Attitude Scale of the CMI by Age Group . . .

5. Illustrating the Means Obtained on Part II (Knowing about Jobs) Subtest of the Competence Test of the CMI by Age Group . .

6. Illustrating the Means obtained on Part IV

(Planning) Subtest of the Competence Test of the CMI by Age Group . . . . . . . . .

7. Illustrating the Interaction Between Class and sex on the Attitude scale of the CMI . . .

8. Illustrating the Interaction Between Class ard sex on part II (Knowing about Jobs) of the Competence Test of the CMI . . . . .

9. Illustrating the Interaction Between Class and sex on Part IV (Planning) Subtest of the Competence Test of the CMI . . . . . .

10. Illustrating the Interaction Between Class and Urban/Rural Schools on the ittitiude scale of the CMI . . . . . . . . . . . 
11. Illustrating the Interaction Between Class and Urban/Rural Schools on Part II (Knowing about Jobs) Subtest of the Competence Test of the CMI.................

12. Illustrating the Interaction Between Class and Urban/Rural Schools on Part IV (Planning) Subtest of the Competence Test of the CMI . . 139

13. Illustrating the Interaction Between Sex and Urban/Rural Schools on the Attitude Scale of the CMI ..............

14. Illustrating the Interaction Between Sex and Urban/Rural Schools on Part II (Knowing about Jobs) Subtest of the Competence Test of the CMI................ 143

15. Illustrating the Interaction Between Sex and Urban/Rural Schools on Part IV (Planning) Subtest of the Competence Test of the CMI . . 144 Map of the East Central State of Nigeria . . . 


\section{INTRODUCTION}

The schools of the East Central state of Nigeria

(ECS) currently have no functional or organized program of

Guidance and Counseling. However, the government which took over all schools in the state at the end of the Nigerian Civil War in 1970, is proposing, through its Ministry of Education to initiate one. The following is a policy statement and memorandum on Public Education issued by the Ministry. It is quoted extensively below, to indicate the significant guidelines and emerging focus of the new program and to identify those problems which have been unwittingly overlooked and therefore, call. for urgent attention:

The secondary school curriculum will be more broadly based in the first three years than hitherto, with emphasis on the overall deveiopment of the child. To do this, a variety of subjects will be introduced in the first three years to enable the child to discover his ability and interests before he embarks upon the work of the last two years, during which he will specialize either in the grammar, commercial or technical field. The objective is to move more steadily as funds become available towards the conversion of all secondary schools to comprehensive schools. In order to maximize the benefits derived from the comprehensive form of education, educational and vocational guidance will be introduced in secondary schools and to this end courses will be run for selected teachers on educational and vocational guiciance and counseling . . (Official 
Document No. 3 of 1971). . . . This program is designed to identify the talents of the pupils and students by means of aptitude tests, achievement tests, personality tests and interest inventories. A proper record of progress will be kept for each child indicating his areas of strengths and weaknesses: Correct information on job facilities and educational opportunities shall be made available to all the candidates. In short, the program will entail:

a) the development and use of standardized aptitude and achievement tests

b) the development and use of people's records of progress

c) the training of teachers as career masters/ mistresses

d) the development of brochures indicating training educational and occupational facilities in and outside the state

e) advice and counseling services.

With the data gathered from tests and examinations, educational and vocational guidance endeavors to discover the talents of our children in order to provide appropriate education and training for them thereby making the maximum use of our manpower, without which national progress will be retarded. The program will correct the present unhappy situation in which our children leave school without knowing what they can do and what is available for them to do. In each Zonal Inspectorate office there should be a trained Guidance officer (Educational Psychologist) who will help administer tests in the zones and distribute materials to schools. In each secondary school, there should be a career master/mistress who will be responsible for providing guidance services to the students using the tests and other materials distributed from the headquarters (Ministry of Education Draft Memo $1974)$.

Four points emerge on closer inspection of this memorandum. It is clear that the envisaged comprehensive school 
system will expect a student after the first three years, to make obvious directional type decisions, requiring him to choose a definite line of specialization from either a grammar, cormmerical or technical field, a choice which could limit prematurely his chances of exploring other areas. Such choices it is recognized would be more effectively made within the framework of a Guidance and Counseling program. Since none currently exists, one is being proposed.

By its very nature however, a system of Guidance and Counseling calls for the services and therefore training of professional counselors, a goal which largely depends for its fulfillment on the availability of funding. But as this obviously is in short supply, the program proposes to select and train potential counselors from the existing pool of teachers. These counselors will be cailed career masters/ mistresses, a designation which seems to recognize the complex and prevocational nature of the decisions that the students will be called upon to make and thus suggests a heavy career counseling orientation to the program.

An evidently important focus will be placed on standardized test development and use. This is clear from the program goal to,

discover the talents of our chilaren with the data gathered from tests and examinations in order to provide appropriate education and training for them, thereby making the maximum use of our manpower, without which national progress will be retarded. 
Indicative also of the importance attached to this consideration, is the specific mention of the function of the career masters/mistresses in each secondary school. They are expected to "administer and use the tests from headquarters." However, the type of tests specifically proposed for development and use are aptitude and achievement tests, interest and personality inventories.

One last point is worth noting. With the results of these tests, advice giving and information on jobs, the program hopes "to correct the present unhappy situation in which our children leave school without knowing what they can do, and what is available for them to do." This claim, recalls a similar optimism engendered before the 1950's in America, by the simplistic trait and factor approach to vocational counseling. It assumed that an individual can always be happily matched with a job most appropriate for him, once his traits (interests and abilities) have been determined. However, developments in the field have found it inadequate for examining the ongoing nature of career choice even though it has made great contributions to vocational counseling.

\section{Statement of the Problem}

The fundamental problem which emerges from this guideline is that the guidance program, with a career orientation, 
seems to place its emphasis entirely on the development and use of trait factor or cross sectional measures, i.e., on ability, interest and personality instruments. It thus excludes other types of measures which explore in addition the developmental nature of career decision making over time. In other words, the proposed ECS program focuses entirely on assisting students to make choices at only one decision point. It excludes from consideration the fact that individuals make not one, but an organic series of decisions in their life time and would thus need to be helped with appraisal instruments which take this developmental factor into account. Because it focuses only on trait descriptions, the approach excludes from consideration a number of motivational factors which might exercise an important influence on the kind of decision the person makes. In addition, the trait measures do not concern themselves wi.th the readiness of the students to make the kind of decisions that society demands of them. All of these factors play an intergrative part in career decision making.

Besides the omission of such tests from the program, there are no known standardized tests of this nature locally constructed and sufficiently researched for use in Nigeria. The tests now being extensively used are foreign made achievement instruments like the Ravens Progressive Matrices and the Australian Council for Educational Research tests (MC and MQ 
tests) "whose validities for Nigeria have not been given detailed study" (Yoloye, 1973).

The counselor or psychologist it is true, will use a variety of appraisal instruments such as the contemplated aptitude and achievement tests, interest and personality inventories to cope with specific crisis point decisions and to know students' interests and aspirations. But individuals are constantly revising old decisions and sometimes making new ones as they grow older. Adolescents' early vocational interests and aspirations in particular, are constantly changing (Flanagar and Cooley, 1966; Strong, 1943; Crites, 1969; Schmidt and Rothney, 1955) and are apt to be unstable and therefore unreliable at this stage of their development. Stability of these interests do not emerge until the end of high school (Shaffer, 1975). Therefore, decisions about vocational choices and preferences made at this stage and entirely on the results of these tests are likely to be unwise. There is thus a definite need for the program to shift its emphasis in order to accormodate other approaches to career decision making with their accompanying appraisal instruments. Specifically, the program needs to integrate into its present plans, an approach that sees an individual's vocational developmental pattern, not just as an isolated event in life but as a continuous, always evolving, and of a long term nature. Such an instrument is Crites' Career 
Maturity Inventory (CMI) which purports to measure the changes individuals make over time in the career attitudes and competencies that are necessary for realistic career decision making.

An attempt was made earlier on, to show how misleading is the thinking that the current problem in Nigeria whereby students leave school without knowing what jobs are appropri.. ate for thein will be solved once the results of the trait factor tests are used in combination with job information. For many decades in America similar miracles were predicted, based entirely on the use of trait factor appraoches to vocational counseling. But this approach has only tonuously justified its claims and is now being integrated with new approaches which conceive career development, not as a finished event, but as an ongoing developmental process.

The current ECS program plan is thus too limited in scope in its testing emphasis. In order to complete the developmental career picture of the individual so that appropriate help can be given, the program needs to broaden its scope to include an instrument with a developmental approach.

But since no such test is currently available in Nigeria, and the construction of a new test takes years to accomplish and makes heavy expenditures in commitment of time, effort, and money, the most economical way to solve 
the problein would be to adapt and test a relevant foreign mace test for its app].icability to the Nigerian situation. Studies of foreign made tests have already been started by Yoloye $(1965,1972)$ who investigated the predictive and concurrent validities for Nigeria of the Lorge Thorndike Intelligence tests. His findings indicate that with an extension of the standard administration time, that instrument has potential for use in Nigeria. The I-D Nigerian Aptitude Tests of the American Institute for Research team (AIR), is another example of a test of ability adapted for use in a developing country (Schwarz/Krug, 1972). Both efforts notwithstanding however, studies of career development type of tests are still lacking. With the emerging ECS career oriented guidance program, the time seems particularly opportune to undertake similar investigation.

It j.s therefore the intention of this study, to begin to bridge the existing gap by studying the applicability of the Career Maturity Inventory for Nigeria. This is important, for although cross sectional measures are useful, they should only be seen as partial studies of the developmental pattern of an individual's career process. To rely exclusively on them would imply giving a very limited service to the students and inadvertentli restricting the "maximum use of our manpower without which national progress will be retarded" (Ministry of Education Draft Memo 1974). 


\section{$\frac{\text { Trait-Factor and Developmental Approaches }}{\text { to Vocational Choice }}$}

A comparison of the trait-factor and developmental approaches to vocational choice at this point should indicate how limiting the former can be if used alone and the reed to broaden the scope of the test orientation to include the developmental perspective.

\section{Trait-Factor Approach}

The trait-factor approach to occupational choice started by Parson (1909) and continued through the 1950's, assumes that there comes a specific point in an individual's life when he has to choose an occupation. What determines the quality of his choice are certain predetermined traits or characteristics which each of us has in varying degrees. These traits in-turn impinge upon the individual to influence the specific choice he makes. What is more, there is only one job that any particular individual is best suited to do; a multiplicity of available jobs notwithstanding. Since this is so, guidance and counseling given at the critical decision point, is necessary to help an individual find that one best job. To provide this help, the characteristic traits are determined through appraisal instruments like interest, ability, and personality measures. Thereafter, the traits are perfectly "matched" with a job requiring these traits. If appropriate guidance is given, then the individual. ends 
up with the "correct" job. Otherwise, he might make the wrong choice and end up being unhappy and a loss to society.

Relating this approach to the emerging ECS program, the critical chaice point comes at the end of the first three years when the student has to decide which of the following three "slots," grammar, commercial or technical fields is the correct one for him. At this crisis point, his traits are determined. Appropriate guidance with job information given at this point, guarantees he will leave school, happy and contented, knowing what he can do and what is appropriate for him.

A number of questions arise from this. Is the student in fact ready to make this choice? Is it possible that these traits, determined so early in the life of the student remain static in spite. of the fact that he has been growing before now and continues to evolve and grow beyond this point? Besides, are individuals not in fact multipotential in the sense that there is more than one job which any one person can successfully handle? A corollary question is, isn't it therefore possible that slotting students so prematurely will inhibit their chances of exercising their multipotential quality? These questions arising from the orientation of the trait-factor approach suggest that one is almost predestined to a limited and static growth quite contrary to the dynamic and ever evolving developmental nature of the individual. 
Developmental Perspective

The developmental perspective on the other hand, evident from the $1950^{\prime}$ 's, adopts a different point of view to the career process. It assumes that an individual makes a series of vocational choices rather than one. This is so because an individual develops through stages, namely: growth (1-14), exploration (15-24), establishment (25-44), maintenance (45-64), and decline (65-). Each stage is accompanied by specific demands which in turn require related decisions. The counseling focus is thus not on a specific crisis point but on a number of points and through the various stages over time. The individual according to this view point, is capable of becoming successful in many jobs, not just one correct job. The appropriateness of an individual's vocational choice is thus not détermined by the quality of one correct choice he makes, but by the totality of the work or work related life styles or decisions, which emerge through the various life stages. Thus the counselor's service is provided all along the way as the individual develops through various periods. Relating the developmental approach to the ECS proposed program, the counselor will need to determine the life stage of the-student so that intervention strategies can be provided to help him develop the career skills and competencies necessary for realistic career decision making. For as the student progresses through the various stages of 
development, the type of decision he makes is a reflection of his potential to make subsequent ones, a process which should indicate increasingly more realistic decisions. The cumulative effect of these decisions reflects the pattern of his vocational development (Ginzberg et al., 1951). It is thus counseling as the student's' vocational development continues to emerge that is crucial. For circumstances continue to change and so the competencies that the individual needs in order to cope with new decisions as they arise in each phase of development.

The choice factor is thus not static but rather dynamic and leaves room for improvement and change. The student will need to make several more vocational decisions after the first three years, at the end of his secondary school year, as well as for many more years in his life time. Assessing his traits and advising on jobs at a particular time is only one of the exercises in the process. Choosing a particular curricular field is yet another. He may need to revise his decisions, or combine different curricular options so that "slotting" is not to his advantage. To facilitate his potential for choice making, his phase of development needs to be known and appropriate help systematically given. Thus the developmental. approach sees the individual as a multipotential person who makes several decisions through the different periods of development. 
The new ECS program thus needs to diversify the tools used to assess the student in order to view his development as an ongoing process rather than a finished event. Counseling for a student seen in the developmental context would thus take into account the variations in maturity which accompanies progressive growth. The emerging career developmental pattern of the individual would be focused on and competencies and skills relevant to realistic career decision making provided at each developmental period. The career maturity inventory (CMI) that is proposed for exploration, reflects the assumptions of the developmental approach. But since Crites' CMI was standardized and normed on a foreign population, it is essential to test out its assumption first on the Nigerian school population.

\section{The Purpose of the Study}

The purpose of this study then is to test how applicable to Nigeria are the assumptions on which the CMI is based before it can be considered for use in the ECS testing program. Specifically, this study is interested in surveying the career developmental pattern of secondary school students in the East Central state of Nigeria to see if the rationale of progressive career maturity occurring with increasing age and grade app]ies to the ECS stuaents as well. In question form, the researcher will be asking: Is there a monotonic 
function of vocational maturity scores by age and grade for secondary school students in the ECS of Nigeria? Are there sex differences in their vocational maturity scores? Does the geographical location of the schools affect their vocational maturity scores? Are there interactive effects between grade and the geographical location of these schools, i.e., whether urban or rural schools, between grade and sex, sex and urban/rural school location? In other words, this study will be interested in finding out if the vocational developmental pattern of secondary school students in ECS of Nigeria shows a progressive change as they increase in age and grade, in keeping with the developmental concept of vocational maturity.

\section{Hypotheses to be Tested}

To help provide answers to these questions, five hypotheses will be tested in the null. They are:

1. There will be no significant difference in the mean vocational maturity scores (VM) of students in classes I-IV, on the Attitude Scale and subtests II (Knowing about Jobs) and IV (Planning) of the Competence Test of the Career Maturity Inventory (CMI).

2. There will be no significant difference in the mean vocational maturity scores of classes I-IV students by age group on the Attitude Scale and subtests II and IV of the Competence test of the CMI. 
3. There will be no significant difference in the mean vocational maturity scores of classes I-IV students in urban and rural schools on the Attitude scale and subtestsII and IV of the Competence Test of the CMI.

4. There will be no significant difference in the mean vocational maturity scores of classes I-IV students by sex on the Attitude scale and subtestsII and IV of the competence Test of the CMI.

5. There will be no significant interaction effects between class/sex; class/urban or rural schools; sex/urban or rural. schools on the mean vocational maturity scores of classes I-IV students on the Attitude scale and subtests II and IV of the competence Test of CMI.

These hypotheses will help elucidate the extent to which the vocational maturity assumptions can be generalized to Nigerian students.

\section{The Concept of Vocational Maturity}

Vocational Maturity as measured by the CMI looks at an individual's career choice attitudes and career choice competencies over time to determine his degree and rate of vocational development (Crites, 1973). An individual is considered vocationally mature to the extent that he successfully copes with the developmental tasks of a life stage. It is an attempt to broaden the traditionally simplistic and 
narrow conception of the choice process as static and nondevelopmental in order to take into account the dynamic nature of the individual making the choice and the various developmental tasks which society expects him to accomplish as he grows older. The concept of vocational maturity thus grew out of the theory of vocational development and was first operationally defined by Donald Super as "the degree of vocational development, the place reached on the continuum of vocational development from exploration to decline" (Super, 1957). In arriving at this definition, super was considerably influenced by various studies and writings with heavy developmental leanings. Chief among them were Buehler (1933), Carter (1940), Strong (1943, 1955), Dysinger (1950), Ginzberg et al. (1951), Miller and Form (1951), Havighurst (1955), and Beilin (1955). Reference to the historical development of the concept is therefore necessary at this point for a clearer understanding of the meaning of vocational maturity.

Historically, then, the concept was anteceded by Carter's research (1940) on the formation of interest patterns in adolescence. He found that,

the development of vocational interests, involves interaction between growth processes, some of which are biologically controlled. Growth in this field, is a part of general maturation, of developing individuality (Carter, 1940).

In other words, vocational interest is not static but changes over time. This finding that vocational interest might change 
systematically with increasing age was also further substantiated by Strong's studies (1943, 1953). Both these historic findings challenging the static perspective, helped to influence people's thinking regarding the nature of vocational choice. Dysinger (1950) emerged with a call to reconsider the static approach to vocational decision making in order to reflect the developmental history of the individual. He argued that,

The guidance movement needs a word, parallel

to the word "socialization," in social development to express the vocational implications of maturation. The terms "vocational decision" and "vocational choice," suggest a decision, but the emphasis should be placed upon the developmental process (p. 198).

What followed, were new propositions to reflect the developmental nature of the choice process. Ginzberg et al., after a study of adolescent boys and girls concluded that,

To some degree, the way in which a young person deals with his occupational choice is indicative of his general maturity and conversely in assessing the latter, consideration must be given to the way in which he is handling his occupational choice.

Beilin (1955) reflecting on this statement, pointed out that if choice is in fact indicative of an individual's general maturity, then, "choice must be the result of the individual's past history and emerging development and should therefore be seen as part of a larger developmental scheme." In other words, if choice reflects an aspect of the individual's total development, then it should somehow be subject to the principles 
of general developmental history. Thus more and more writers were coming increasingly around to broadening their erstwhile impressions of vocational choice, as a static non-developmental event to a dynamic process which takes place over a long period of time in keeping with the dynamic nature of the individual involved in the process.

But it was on Super, who had been adding to and revising his earlier impressions about the choice process that the emerging orientation had the greatest impact. For he reasoned that there must be a means whereby the broader developmental formulations concerning the choice process can be translated into more practical application for vocational psychology. After all he observed,

The history of developmental psychology abounds with discussions of maturity, usually with an adjective. There are emotional maturity, physical maturity and social maturity, but for some reason, the alphabet stopped at the letter "s". Is vocational maturity related to these other types of maturity? Is there such a thing as maturity without an adjective or are there indeed several types of maturity? (Super, 1955)

And his conclusion was that there must be such a thing as vocational maturity, a conviction more firmly impressed on him by the work of Buehler, Havighurst, Miller and Form.

Buehler (1933) had studied the life histories of over 400 men and wornen in their old age. She emerged with a description of five life stages through which an individual normally develops. An individual, she discovered, starts 
life at the growth period, proceeds through the exploration stage, the establishment stage, maintenance stage, then to the final stage of decline. Each of these life stages, is characterized by specific problems and activities. Super then reasoned that as vocational development is an aspect of general development, it too must proceed through similar stages of development with corresponding characteristic behaviors and activities. Thus super adopted Buehler's framework for vocational development.

The industrial sociologists Miller and Form (1951) had also described the characteristics of work periods as life stages. These are the preparatory work period, the initial work period, the trial work period, the stable work period and the retirement work period. To these descriptions and categories, therefore, Super added some of Ginzberg's descriptions of behaviors most typical of life stages and the division of these stages into still sinaller units or periods. Havighurst's definition of the developmental task expected of each individual by sociaty impressed super to the extent of translating this into vocational terms. A vocational developmental task for super consists of,

A task encountered at or about a certain period in the life of an individual and deriving from the expectation that the members of a social group manifest a relatively oraerly behavioral sequence in preparing for and participating in the activity of work (Super, 1955, p. 132). 
With all these integrations and modifications, super then did for vocational psychology what had already been done for developmental psychology. The table below represents what finally emerged, a breakdown of the process of vocational development into stages with descriptions of related behaviors for each stage.

TABLE 1

VOCATIONAL LIFE STAGES

Life Stage

Characteristic Behaviour

1. Growth (birth-14)

Self-concept develops through identification with key figures in family and in school; needs and fantasy are dominant early in the stage, interest and capacity important, increasing social participation and reality testing.

(a) Fantasy $(4-10)$

(b) Interest (11-12)

(c) Capacity (13-14)
Needs dominant, role-playing in fantasy

Likes, major determinants of aspirations and activities.

Abilities given more weight, job requirements (including training) considered.
2. Exploration Stage $(15-24)$
Self examination, role try-outs, occupational exploration takes place in school, leisure activities and part-time work.

(a) Tentative (15-17)

Needs, interests, capacities, values, opportunities are al1 considered, tentative choices made and tried out in fantasy, discussion, courses, work, etc. 
TABLE 1--Continued

Life Stage

Characteristic Behavior

(b) Transition (18-21)

Reality considerations given more weight as the youth enters labor market or professional training.

(c) Trial (22-24)

A seemingly appropriate field having been located, a beginning job in it is found and tried out as a life work.

3. Establishment (25-44)

Having found an appropriate field, effort is put forth to make a permanent place in it. There may be some trial early in this stage, with consequent shifting, but establishment may begin without trial, especially in the professions.

(a) Trial (25-30)

The field of work presumed to be suitable may prove unsatisfactory, resulting in one or two changes before the life work is found or before it becomes clear that the life work will be a series of unrelated jobs.

(b) Stabilization (3l-44)

As the career pattern becomes clear, effort is put forth to stabilize, to make a secure place in the world of work. For most persons, these are the creative years.

4. Maintenance $(45-64)$

Having made a place in the world of work, the concern is now to hold it. Little new ground is broken, but there is a continuation along established lines. 
TABLE 1--Continued

Life Stage

Characteristic Behavior

5. Decline (65-)

As physical and mental powers decline, work activity changes and in due course ceases. New roles must be developed; first that of selective participant and then that of observer rather than participant.

(a) Deceleration $(65-70)$

Sometimes at the time of official retirement, sometimes late in the maintenance stage, the pace of work slackens, duties are shifted, or the nature of work is changed to suit declining capacities. Many men find part-time jobs to replace their full-time occupations.

(b) Retirement (71-)

As with all the specified age limits, there are great variations from person to person. But complete cessation of occupation comes for all in due course, to some easily and pleasantly, to others with difficulty and disappointment, and to some only with death (Super, 1957, p. 40-41).

As is reflected in the above table, vocational development is seen as a life long process consisting of a series of related decisions spanning a prolonged period of time. Clearly discernible are periods or life stages through which it procseds, beginning in the growth period through exploration, establishment, maintenance and then encing in the decline stage with corresponding substages also described in detail. 
The vocational developmental tasks required of individuals by society differ in varying degrees according to the individual's life stage. Super describes these tasks as follows :

\section{TABLE 2}

OUTLINE OF VOCATIONAL DEVELOPMENTAL TASKS IN CHRONOLOGICAL ORDER

Preschool Chi.ld

Elementary School child

High School. Adolescence

Young Adult

Mature Adult

Older Person
Increasing ability for self help, identification with likesexed parent, increasing ability for self--direction.

Ability to undertake enterprises, choice of activities suited to one's abilities. Assumption of responsibility for one's acts. Performance of chores around the house.

Further development of abilities and talents, choice of high school or work, choice of high school curriculum, development of independence.

Choice of college or work, choice of college curriculum, choice of suitable job, development of skills on the job.

Stabilization in an occupation. Providing for future security, finding appropriate avenues of advancement.

Gradual. retirement, finding suitable activities for skills to occupy time. Maintaining self-sufficiency insofar as possible (Super, 1957, p. 44). 
Viewed together therefore, the life stage and developmental task descriptions can be seen to reflect systematic changes and differentiation in the planning and decision process. For with increasing development, new behaviors are added to old ones with the result that an individual's existing behavior potential becomes modified. However, "new behaviors can only become established in the individual's behavior repetoire if those behaviors accumulated in previous periods have been sufficiently mastered" (Super, 1960). The assumption here is that if for most individuals behavior develops normally, then one is more likely to progress systematically from one stage to another as his age increases.

Super had always been concerned with the practical implications of these formulations for counseling. He reasoned that since vocational development is conceived as a continuous birth-death process with specific tasks for each life stage, counselors would benefit by a construct which could help them assess where a person stood along the vocational development continuum. Counselors will become increasingly more efficient in the help they give their students if they can assess the degree and rate of their students' vocational development with respect to career matters. For super therefore, that long searched for construct is Vocational Maturity which denotes an individual's rate and degree of maturity on a vocational development cortinuum. 
The concept of Vocational Maturity is thus better understood from a historical perspective showing those influences which prompted super to articulate the concept out of a mediey of developmental statements on the nature of the choice process. As conceptualized by developmental theorists and writers and first operationally defined by super, vocational maturity evolves on a continuum of vocational development through clearly described life stages starting from birth but presumably more specifically from exploration to decline. Each life stage is characterized by specific career developmental tasks expected of an individual by his particular society. Over time an undisturbed individual will exhibit increasing vocational competence as he grows older.

Dimensions of Vocational Maturity

To make the construct easy to assess and better understood, Super (1959) further delineated five dimensions along which an individual's behavior might mature over time and for which measures could be devised. These dimensions are presented below:

\section{TABLE 3}

SUPER'S DIMENSIONS OF VOCATIONAL BEHAVIOR

1. Orientation to Vocational Choice Defined as the individual's concern with the problem of vocational choice and the use he makes 
of resources around him in solving the problem. Measured by judge's ratings of interview protocols.

2. Information and Planning

Specificity of information about the chosen occupation, extent and specificity of planning with respect to chosen occupations. Measured by judge's ratings of interview protocols.

3. Consistency of Vocational Choice

Stability of vocational choice over time and agreement among vocational choices in field, level and family. Measured by the discrepancies between vocational choices elicited on different occasions and classified into the cells of Roe's (1956) occupational classification scheme.

4. Crystallization of 'Traits

Defined as extent to which vocationally relevant aptitudes and personal dispositions, such as mechanical comprehension and work values, have developed toward adult status. Measured by judges ratings of interview protocols and standardized tests.

5. Wisdom of Vocational Choice

Extent to which vocational choice agrees with abilities, activities, interests and socioeconomic background. Measured by the discrepancies between vocational choice and indexes of the various reality factors (Osipow, 1973).

This detailed exposition of the dimensions of vocational maturity indicates both the complexity and comprehensiveness of the construct. For indeed it includes not only the selection of an occupation but also comprehension, understanding of job requirements, planning ability, the development of 
vocational capabilities and attitude to work. Super describes it as a "multi-dimensional construct rather than one unitary variable" (Super et al., 1960).

Besides defining the construct and delineating these five dimensions along which vocational behaviors might mature, Super also proposed two flexible criteria for evaluating an individual's vocational maturity. An individual's vocational maturity can be assessed by focusing on his chronological age and corresponding developmental tasks irrespective of whether the tasks are appropriate to his age or life stage. This is vocational maturity $I$. The second method or vocational maturity II would focus on how the individual handles his developmental tasks in comparison to others handling the same tasks. In other words, the individual's vocational behavior could be compared to that of his peer group.

It is important to note what vocational maturity as defined by this theory and outlined in the five dimensions actually means for a given individual. It indicates his increasing competence in mastering in sequential stages, the vocational attitudes and competencies which his society expccts of him. Thus the nature of one's vocational maturity would be relative not only to one's peculiar life stage and socio-econorij.c background but also to the peculiar expectation of his culture for his continued growth and hence maturiry. The maturity of vocational development seems to presuppose 
an environment with a strong work ethic in which an individual is progressively exposed to and becomes involved in career related matters which are essential for his increasing competence in career decision making. It does suggest that older individuals should be more reflective and competent by virtue of both their older age and hence experience since "patterns of behavior become differentiated and integrated into repertoires of habits and skills" (Super and overstreet, 1960).

Relevant though these assumptions may be for the American culture to which the theory addresses itself, it is important to examine it to determine if it holds true for other cultures, and more specifically for students in the East Central state of Nigeria.

\section{Significance of the Study}

The results of this study to assess the vocational maturity of students in the ECS, will help determine if the theory of vocational maturity as a continuous ongoing developmental process which increases with age and grade can be generalized to boys and girls in the Nigerian secondary schools. This way, fresh data would be added to the body of research on Vocational Maturity and especially on the ability of the CMI to measure the construct in Nigeria.

With reference to the ECS guidance program develop-ment, the findings of this investigation wili help guide 
decision making. regarding test selection and use. Schwarz and Krug (1972, p. 7) have indicated that the first question that must be asked from the point of view of adapting foreign tests, is whether the test rationale is equally sound for the different cultural setting which intends to use it. This is important, for if using a particular type of test cannot be justified on rational grounds, it would clearly be wasteful to proceed with further work on it.

If the results of this study are valid for the ECS, it could minimize the expenses involved in constructing tests of a career counseling nature from scratch. If on the other hand the findings indicate that the theory has no relevance for the ECS, then it will help to eliminate the waste often inherent in using irrelevant tests of unproven merit for an unintended population. To save the ECS identifying and using the first test that sounds interesting for career counseling, the results of this study then should be of great importance.

But above all, the findings of this investigation if positive should orient the ECS program planners to the crucial need of conceiving students' career development, not as static but as a longitudinal process. Hopefully, the type of help given the student subsequently will take into consideration the existence of several decision points for which students should be prepared and equipped with competencj.es 
to help them make realistic decisions for themselves from which society will benefit.

\section{Justification of the Study}

This study to assess the vocational maturity of students in the East Central state of Nigeria can be justified on two important grounds. In the first place, the career Maturity Inventory with its developmental approach to career decision making was normed on American values. It seems only logical that its rationale and operational constructs be empirically tested for relevance to the Nigerian population before it can be considered for use. For according to Schwarz (1972) however appealing on its face value a new approach or theory may seem, it should not be blindly applied to different cultural situations unless that same theory holds true for the cultural group which intends to use it. Otherwise, the results become spurious and irrelevant. Nigeria in the past has tended to adopt foreign made tests whose validities had not, been sufficiently established on a local population.

But by studying vocational maturity, which is one of the well defined developmental constructs in the field of vocational psychology, using both male and female secondary school students, from the ages of eleven to twenty-two, in urban and rural schools of the East Central state of Nigeria, one can at least begin to provide some meaningful data to show the extent if any, to which the construct can be 
generalized to Nigeria but specifically to the ECS. There is currently no research evidence which indicates that the vocational developmental assumptions hold true for vigeria. The present study hopefully will provide this much needed data.

A second reason, and an even greater justification for undertaking this study in another culture derives from the close similarities evident in the value systems of the Americans and the Ibos from whom the sample of this study is exclusively drawn. A brief sketch of the Ibos is necessary for a clearer perspective on this issue. The map on the next page locates the East Central State within the context. of Nigeria and Africa. The area studied in this investigation is also indicated.

The Ibos with a population of eight million (1973 census) inhabit the East Central state of Nigeria, one of the twelve Nigerian states. As Levine noted, traditionally, internal decision making was not centralized among the Ibos but was carried cut by a council of elders highly responsive to the people. Age grades, title societies, individual title systems and secret societies served as political and social organs for the differential allocation of social status and as channels for the flow of influence in the community. In each village group meeting, virtually anybody had a right to speak. Other characteristics of the Ibo society, include a 


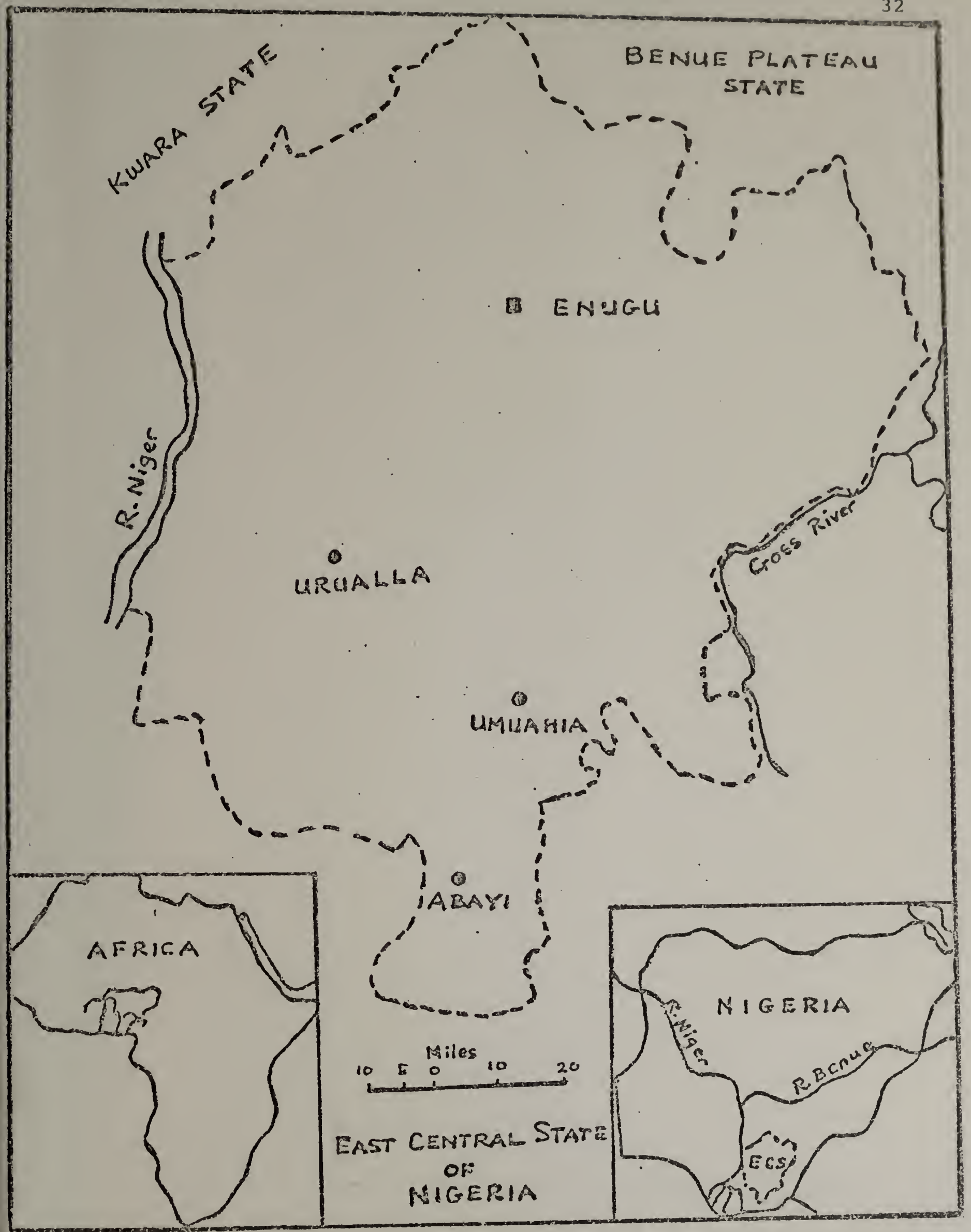


fluia status system, the most important being the title society. Membership was open to anyone of free birth, who could afford the expenses, which intentionally became increasingly prohibitive as one progressed to higher titles. The title system became a means by which one could translate his wealth into political status (Levine, p. 182). As ottenberg also observed,

The possibility of enchancing status and prestige are open to virtually all individuals except descendants of certain types of slaves, and are not restricted to members of particular lineages, cians or other social units. Ibo society is thus, in a sense, an "open" society in which positions of prestige, authority and leadership are largely achieved (1971, p. 136-137).

This emphasis on individual achievement in Ibo society is exemplified further by Levine who shows evidence that, although the wealth necessary for acquiring high status could be inherited, it could also be accumulated through a man's own effort, in either instance it needed to be accompanied by specific personal qualities (1970, p. 183).

The individual has to validate this by his own abilities and strong emphasis is placed on his ability to make his own way in life. Thus being the son of a rich man only gives the individual a "head start" over others in the community. To maintain this edge, however, depends entirely on him.

The impression which clearly emerges of Ibo society from these descriptions is that it is "open." It encourages upward mobility for virtually anybody irrespective of 
background or socio-economic level. Consequently it fosters and stresses sheer hard work as a means of both achieving and maintaining high status and excellence.

This characteristic Ibo belief in one's ability to foster his own progress closely ties with those American values outlined by Wrenn (1962). Quoting anthropologist E. Adamson Hoebel, Wrenn indicates a combination of four values which seem to dominate the American way of life. These are,

1. The notion of progress - Material and social conditions are constantly improvable.

2. A rational universe - We prefer the scientific method rather than to rely on chance or mysticism. We act as if we believed that man directs his own destinies. A nation of doers, who believe in action.

3. Equal opportunity - Each person should have the opportunity to exercise his special abilities in a manner that is personally satisfying and socially useful. Among the consequences are the ideal of universal education, a distrust of authority, a fluid status system and an intense drive to succeed. Success is often symbolized by money but the things money can buy may be valued less for themselves than for what they proclaim about a person's abilities and personal fulfillment.

4. Looking ahead - American value system is future oriented. . We count on change . . . and tend to see real improvement as still ahead (Wrenn, 1962, p. 2).

These values compare favorably with the Ibo world view especially "looking ahead," "equal opportunity," the "notion of progress" and to some extent "a rational universe." But in order to understand Ibo values fully, one has to 
start with the concept of "chi" which is at the root of their system of thought.

The Ibos believe that every individual at birth is endowed with a "chi," a personal, guiding or motivating spirit. This "chi," is unique to the individual, for no two people can have the same chi. For example, the Ibos say that "ofu nne namu, ma ofu chi adi eke." In other words, the two offspring of the same mother are not created by the same chi, which indicates that individuals are unique beings unlike any other, yet like others in some ways. Ibo attitude towards the individual seems to spin off on a comparable American note.

The Ibos further believe that a person at birth draws a contract with his "chi" specifying his life goal or anbition. The persor thus participates in the decision making process right from birth. He may for instance decide to be a medical laboratory technician. In which case, he will be endowed with the requisite abilities and characteristics to achieve the goal, and even more. But there is always a "cavaet" in the terms of agreement. The individual must be prepared to work hard to fulfill that goal. Only if he applies himself, will his "chi," who is usually very accommodating, cooperate to help him reach this goal. This contract is however also flexible. For any individual may decide when he feels ready ard competent, to modify the original 
terms, although usually it is hoped, in the direction of further progress. Here again, it is the individual who decides. He invests the hard work necessary to accomplish his new goal and his "chi" merely aids in the process. This notion is conveyed in the proverb "onye kwe chi ya ekwe" if one says "yes," his chi will affirm. It all depends on the individual who must take the initiative. Hansberry, commenting on the relationship between an individual and his "chi" amongst the Ibos, observes that "a man is permitted in a large measure to be if not the master, at all events, the architect of his own fate, the captain of his own souj." (p. 95).

Thus the individual in oux example may decide after years of accumulated experience, to advance himself through further studies to become a doctor. When this happens, his "chi" is said to be "awake," "omuanya," and will readily acquiese, helping to maximize his ability to accommodate the new shift in his goal. Thus in Ibo cosmology, nothing is ever static. No condition is permanent. There is continuous change but there is also order. There is in fact a fine balance between continuity and change. Here probably is the closest affinity with American values--flexibility and change.

However, some order is kept in the sense that for the Ibos, if one's abilities and opportunities are not reinforced 
by hard work or constantly validated, an individual's chi, who also has the interest of the larger community at heart, will intervene to reverse any prior commitment to success. In such circumstances, the individual has himself to blame for not using his talents in a inanner that is personally satisfying and socially useful. But constant application of oneself is so important to the Ibos that an individual who does not succeed in spite of hard work is urged not to give up so readily. He should continuously be seen to be striving even against odds to improve himself for after all these are merely temporary set backs. If he stubborrly persists in his quest for new achievement, "uchu," he may yet succeed in persuading his chi to think again. He can do it as expressea in the proverb "chi kesia, madu ekeghalia" after chi creates, man recreates. In other words, any individual with the will can often change his fortune.

This description of the relationship between an individual and his chi, expresses the Ibo value in continued progress, their emphasis on determination and the persistent application to achieve one's goal. It indicates too a belief that the individual is directly involved and responsible for structuring his personal goals: These values are clearly identifiable with the American view that man directs his own destiny and must validate his goals by action rather than inaction. 
The hope of continued improvement and the opportunity for upward mobility for virtually every individual is not peculiar to the Americans. The forward looking Ibos, always cptimistic that the future has better things in store for the individual, give expression to this in the name "Nkiruka" which they give their children. Perhaps the best available expression of Ibo values can be gleaned from the writings of Ibo entrepreneurs of the famous onitsha market of the East Central state of Nigeria. These young men with very little formal education, while waiting to do business, reflect generally on conditions in the society and especially on factors which make for or impede economic progress. In several phamphlets, they warn the unwary and uninitiated against laziness and the careless use of one's opportunities. The novice is enjoined to apply himself diligently and not be daunted because what one person can achieve, another can if he persists. No other popular literature documents so perceptively, the values that have meaning for the Ibos.

What a person can do, another can do it. Determination is the key to succes. When you determine to do something difficult, you will have the experience to do it. A foolish man can become a wise man tomorrow. Boys of today are the men of tomorrow and girls of today are the women of tomorrow. Everyday, new things come and old one's disappear (Obiechina, 1973, p. 89).

Thus for the Ibos, as for the Americans, things are always changing and never remain static. In such a dynamic society 
therefore, hard work is the means by which any individual can grasp the sky, if he so wills it.

The intense American drive to succeed, symbolized by how much money ane accumulated as noted by Hoebel, is just as characteristic of the Ibo value system. Since those things money can buy are eloquent signs of personal fulfillment and of the successful employment of one's abilities, Ibo popular literature stresses this relationship and spells out how this can best be achieved, i.e., through hard work.

Life is money and money is life. Every day, man works hard because of money. He leaves the land of his birth and travels to another country in search of money: He holds patience and courage under rain and sun in order to get it. Everyday he will like to gain more than any other person. He will not be happy in the night if he gained nothing during the day. He will be even happier to be busy throughout the day without resting. When a man plans for money and becomes successful, he becomes a wise man in the eyes of people, but when he fails, people will call him a foolish man (ibid., p. 86).

Thus the orainary person is aware of what it takes to succeed.

Thus the result of this awareness is that poverty, consequent on laziness is dreaded like the plague by the Ibos. For it leads to lack of self esteem and subsequently to lack of public esteem. The Ibo proverb "onye nkilika akwa bu onye nkilika okwu" sufficiently expresses this fear that a man in ragged clothes is a man of ragged words. So one is enjoined to avoid being caught in that bind. 
Poverty steels the mind of recollection from some if you have noves them useless and hopeless... Don't stay at money, you should fight for it. to work (ibid., p. 88).

Thus, however small the job is, it is still to be preferred to inaction and laziness which demean one's personality. Judged therefore by the four principles outlined by Hoebel, the Ibo value system, seems closely related to the American. For both seem to set a high premium on individual initiative and on any individual's unlimited potential to grasp the sky if he so chooses. Expressly underscoring this goal for the Ibos and implicitly for the Americans, is the emphasis on hard work and the use of one's resources to achieve one's goal.

This justification of the study of vocational maturity on ECS students cannot be complete without the analogy between the Ibo "ogbo" or age grade system, and the American perception of vocational development as occurring through progressive life stages with corresponding developmental tasks.

In traditional Ibo society, the ogbo system enables peer groups to function at their own level. Within this system which spans a whole life time, individuals learn those competencies and skills which are necessary for their efficient functioning and growth both within the particular life stage and in the larger community as well. Society imposes certain tasks on all its members but arranges that tasks are 
graded in such a way that groups of similar age span, i.e., 3-5 years, perform together. To accomplish these tasks, society established the ogbo or age grade system. The individual on his part is expected to avail himself of the oppor.tunities and challenges provided by the system to develop and fulfill himself in a way that is not only personally meaningful but socially productive for his community. Considering the lack of complexity in village life, one of the young person's first public tasks is to sweep the village "ilo" or community playground alongside his age mates. Here, he learns the norms and values of his group, acquires a positive attitude toward work and a sense of group spirit and belongingness. Keeping the "ilo" clean thus very early inculcates in the young person, the necessity and importance of work. But work takes place in a relaxed and stimulating atmosphere. For at the end of work, wrestling begins on the "ilo." The young person learns from his peers and often from an older person the skill of wrestling. In this fusion of work and play, groups of young persons are continuously pitting themselves against one another to see who will excel. The older group members supervise the area of the playground swept by the younger group. Finished tasks are rewarded with verbal reinforcement which might vary from a name that reflects thoroughness in carrying out a specific task or the name of an animal known for its bravery. The group is free 
to take on any name that they feel best describes their accomplishment. In this way, an ambience for competition and excellence is generated quite early in the young Ibo person, but what is more, the love for work.

As the group matures and successfully accomplishes the tasks of a pervious age, subsequent tasks become increasingly more difficult and complex. By the time he is fourteen the young person becomes apprenticed to a master craftsman or woman depending on the sex of the individual, a builder, a pottery maker, a farmer, a smith as the case may be. Here he begins to learn the skills necessary for professional excellence. Excellence and diligent application to detail becomes extremely important at this stage. For this is also when the young person is initiated into man or womanhood and is on his way to becoming an independent young adult. This is the stage when the individual undertakes within his group, the task of clearing the streams, replenishing his mother's "ngiga" or basket with fresh venison and when he begins to think about marriage.

A subsequent stage might impose on him the task of guarding his village against marauders, going to war, erecting public buildings and generally helping to maintain law and order in his community. Thus within this system individuals learn to use their peer groups as yardsticks to evaluate the degree to which they have succeeded in 
accomplishing the tasks of their life stage. Any serious deficiency is made up by older age group members who act as consultants by virtue of their age and experience and as excellent models for the younger ones. And so the division into age grades continues, encompassing all life stages until death, each group taking the cue from its members and at the same time utilizing the support and broader experience of the older groups.

Excellence is so fundamental within this system that ary individual, may, by virtue of an unusual feat of accomplishment over and above that expected of his group, graduate into a higher group. As the Ibo proverb puts it, "nwata kwo aka, osolu ogalanya lie nni"--if a child washes his hands, he may dine with kings or the rich. The implication being that if the young person takes the trouble to divest himself of the customary youthful dirt, and become clean, then his age should be no bar to the privileges enjoyed by people who have made it. This explains society's emphasis on hard work. The ogbo or age grade institution thus served as a vehicle through which individuals learned the tasks expected of them by their society.' These tasks varied according to the developmental stage of the group. But the system fostered a spirit of competition, of striving to excel the other person and not being satisfied until the best has been invested in any task. For in traditional Ibo society, the successful 
completion of the tasks of a particular group was accompanied by a public ceremony recognizing both this fact and the group's readiness to move into more complex tasks and life stage. Individuals as a group, were thus encouraged by societal rewards to look forward to more challenging and fuller experience as they grew older. However, an individual who failed to achieve within his age group was encouraged to use the "successes" of other members to improve his deficiencies. This is in keeping with Ibo thought:

Egbe belu ugo belu

Nke si ibe ya ebena

Nku kwa ya

In other words, a kite perches and an eagle perches, which ever denies the other the right to perch, may his wings break. Both the strong and the weak should exist, each respecting and benefiting from each other yet neither submerging the other.

This exposition of the Ibo world view, seen in action particularly through the age grade system, has been necessary to show that Ibo culture, in which the career maturity inventory is to be tested out, has very close affinities with its American counterpart. For the Ibo concept of "chi" with its emphasis on an individual's ability to direct his own destiny, with minor modifications, is analogous to the American perception of the universe in rational terms. Ibo society, with 
its "open" system, recognizing the opporutnity for social mobility for virtually any individual, compares very favorably with the American principle of equal opportunity. And both cultures place strong emphasis on excellence, on determination and application to duty. It has also been broadly demonstrated that through the age grade system, Ibo society conceives life and work as a process developing in a continuum of distinct life stages with corresponding developmental tasks comparable too to the American view point.

It then follows that there are closer cultural similarities which justify investigating the developmental assumptions of vocational maturity, premised initially on American value, on students in the East Central state of Nigeria. But no matter how close the cultural affinities between both societies, the concept of vocational maturity, as measured by Crites' Career Maturity Inventory holds little relevance for Nigeria, until its efficacy has been demonstrated by empirical research which the present study hopes to contribute.

\section{Definition of Terms}

The following terms were defined to facilitate an understanding of the terms used in this study.

Vocational Maturity as measured by the Career Maturity Inventory (CMI) and as used in this study refers to the 
individual's development on the Career Choice Attitude and Career Choice Competence dimension of vocational behavior. It assesses one's degree and rate of development on those dimensions. But the degree of the student's development is the aspect focused on in this study.

Degree of vocational maturity refers to an individual's raw score on any of the components of the CMI.

Vocational maturity score (VM) is the total score obtained by an individual on each of the CMI tests. This includes his total score on the 50 item Attitude Test, the 20 item Part II subtest (Knowing about Jobs), the 20 item Part IV subtest (Planning) of the Competence test of the CMI. Vocational Maturity score also indexes an individual's maturity on any of these tests.

Secondary school in Nigeria is a post primary institution which combines both the Junior and Senior High structure in the American school system.

Classes are similar to grades in the American school

system. There are five classes in a Nigerian secondary school. Using number of years in school as a criterion for converting "classes" into its American equivalent in grades, class I is equivalent to the 7 th grade, class II the 8 th grade, class III the 9 th grade and class IV the loth grade. However, this estimation should be considered very approximate indeed. For whereas the Nigerian student in class IV has only one more year 
to go before finishing school, his American counterpart has two more years.

\section{Scope and Limitation of Study}

This study was limited to four classes in the secondary school because class five students were busy with their school leaving examination and so were unavilable for the study. Future studies should be extended to include class five.

Only a limited number of variables namely age, class, sex, and the geographical location of schools, i.e., urban/ rural, were tested for their relation to vocational maturity. Other variables no doubt were not accounted for. Such variables as socio-economic level as indexed by father's educational level or occupation, intelligence, exposure to guidance programs, personality, achievement motivation, previous work experience, and several others could well be associated with vocational maturity but have not been explored in this study. This study focused on students in four schools in the East Central state of Nigeria. Its findings should not be generalized to the whole of the state as the sample used was not meant to be representative even though random.

The investigation is cross sectional in scope. Follow up study will be required to get a longitudinal picture of the vocational maturity of the students. 
Nigeria is full of cultural variations. Thus the Ibo society of the ECS has been described to justify the study. The results do not therefore apply to other Nigerian states.

\section{Organization of the study}

Chapter one includes an introduction to the subject of investigation, a statement of the related problem, hypothesis to be tested, significance and justification for the study, definition of terms used in the study, the scope and limitation of the study.

Chapter two contains a review of the literature in the field of Vocational Maturity including relevant research findings.

Chapter three describes the population and instruments used in the study and procedures for collecting, scosing and analyzing the data.

Chapter four is a presentation of the results of the study and the final Chapter, five, contains the summary, discussion, conclusions, recommendations and implications of the study. 


$$
\begin{array}{lllllllllllll}
C & H & A & P & T & E & R & I &
\end{array}
$$

\section{REVIEW OF THE LITERATURE}

The review of literature related to vocational maturity is divided into four sections. The first describes Super's effort through his Career Pattern Study (CPS), to validate his hypothesized dimensions of vocational maturity and the studies undertaken to further clarify his findings. The second section explores the attempts by Gribbons and Lohnes and crites to produce standard measuring instruments for the construct. Then some limitations still inherent in Crites' instrument are noted, in section three. The final section, four, analyzes the research studies using crites' instrument.

\section{The Career Pattern Study}

Having delineated five dimensions hypothesized as measures of vocational maturity, super and overstreet (1960), in the Career Pattern Study (CPS), then carried out studies to test out the validity of these dimensions. The final population of the CPS consisted of 105 ninth grade males in Middletown, New York. A longitudinal study of their vocational development over twenty years, i.e., until 1971, was also undertaken. But the major objective of the CPS was to 
test the multidimensional nature of the construct of vocational maturity. To do this, a combination of objective instruments and semi-siructured interviews was used to assess these dimensions which were broken down into several indices. Dimension I, Orientation to Choice, used ratings on students' interviews to measure the degree to which a student indicated concern for vocational problems and how effectively he made use of the available resources around him to deal with his career problems. Dimension II, Information and Planning, was assessed by asking the student about the specific information which he had accumulated about his preferred occupation, the degree of specificity of his planning for this preferred occupation and the extent to which he was involved in planning activities of a vocational nature. Here again, structured interviews were used to gather this information.

Dimension III, the Consistency of Vocational Preferences, had three indices, the consistency of vocational preferences within fields, within levels and within families (or fields and levels combined). These were based on a modified version of Roe's occupational classification scheme (1965). The procedure for assessing this dimension was as follows: The students' first two preferences were examined to see the degree to which they were in the same field and level. Then the degree of correspondence between his first 
and second choice was examined, using a combination of field and level as criterion. Here, objective scoring (Roe's) was used on data collected by semi-structured student interviews.

Crystallization of Traits, was the fourth àimension tested. This had six indices based on a combination of inventories and interview data. Two of these indices, interest maturity and patterning were derived from the results of Strong's Vocational Interest Blank (SVIB). Liking for work, concern for work rewards, vocational independence and acceptance of responsibility for educational-vocational planning were based on data from interviews. The sixth index, patterning for work values, was based on scores on the Work Study Inventory which was specifically designed by the staff of the Career Pattern Study (Osipow, 1968).

The final and fifth dimension, wisdom of Vocational Preferences, was assessed by the use of indices reflecting the agreement between ability and preferences, compared measured interests with preferences, measured interest with fantasy preferences, occupational level of measured interests with the occupational level of preferences, and the socioeconomic accessibility of the student's preference.

For Super and overstreet, acceptance of these dimensions as measures of vocational maturity should depend on a moderate but positive interrelation among them. The results 
of the study however indicated that only one dimension namely, the orientation to choice dimension, and possibly the "use of resources," proved an adequate test of vocational maturity. Thus of the twenty indices tested, only six, measuring two dimensions of vocational maturity in the ninth grade were positively interrelated to a significant degree. The table below indicates the pattern of relationship which emerged.

\section{TABLE 4}

INTERCORRELATION BETWEEN ADEQUATE AND MARGINAL MEASURES OF VOCATIONAL MATURITY

IA IVF IIA IIB IIC IB

Dimension A Orientarjon to Choice Tasks

Index IA Concern with Choice

Index IVF Acceptance of Responsibility $.56 \quad-\quad \begin{array}{llllll}.47 & .57 & .51 & .24\end{array}$

$\begin{array}{lllllllll}\text { Index IIA Specificity of Information } & .40 & .47 & - & .37 & .29 & .17\end{array}$

$\begin{array}{llllllllllll}\text { Index IIB Specificity of Planning } & .48 & .57 & .37 & - & .46 & .07\end{array}$

Index IIC Extent of Planning

$\begin{array}{llllll}.29 & .51 & .29 & .46 & -\quad .06\end{array}$

Dimension B Use of Resources

$\begin{array}{llllllll}\text { Index IB Use of Resources } & .23 & .24 & .17 & .07 & .06 & -\end{array}$

Source: Super, D. E. and Overstreet, Phoebe L. The Vocational Maturity of Ninth Grade Boys. New York: Teachers College Press, 1960, p. 60 .

The results suggested that two factors might characterize the vocational behavior of ninth grade boys. These are an "orientation to choice" and "use of resources." Thus dimension one, "Orientation to choice" seemed both well 
established and well defined. As for the other four hypotesized dimensions and fourteen indices, they were "found to fit into, or yield, virtually no clusters and in general were unrelated to each other and to the six more promising indices" (Super et al., 1960). Thus the study clearly indicated that the other four dimensions of vocational maturity have not been empirically proven as unique measures of that construct. As Super et al., noted, "the lack of relationship among the measures casts doubts on their construct validity, i.e., on their conceptual adequacy as indices of vocational maturity in the ninth grade" (ibid.). But super cautioned that the four dimensions might still be valid at some future life stage for predicting vocational development. They might prove,

Good measures of vocational maturity at some other age level: consistency, independence and wisdom as behaviorally defined here might prove to be good predictors of age of establishment in a stable career or very adequate measure of vocational maturity in the twelfth grade or at age twenty-two (Super et al., 1960).

Thus this early research ran into difficulties by not confirming four out of the five hypothesized dimensions as characteristic of vocational behavior at the ninth grade Jevel. But the pattern of intercorrelation was nonetheless positive. The problem was that it was weak and did not reach the level set by super and his colleagues. It is therefore possible that the non-objective method of assessment employed, as well as the particular population used, may have partly contributed to this inadequacy. 
Super and Overstreet however proceedẹd to study other variables that might be associated with vocational maturity. A correlation of various factors with the one adequate index of vocational maturity, the "Orientation to Choice Task" dimension, indicated the following associations:

a) Vocational maturity is related to intelligence but age was found of less significance at the ninth grade level of development. The implication being that grade placement probably offers greater homogeneity of experience for students in a school situation than age (Osipow, 1973).

b) Of the environmental variables tested, vocational maturity was positively correlated with parental occupational level, school curriculum (i.e., college preparatory vs. noncollege preparatory program); amount of cultural stimulation and family cohesiveness. It was negatively correlated with urban background and Protestantism. Rural boys seemed more vocationally mature than urban ones. As Osipow (1973) noted it seems surprising that vocational maturity should be negatively correlated with Protestantism which espows hard work.

c) Vocational aspiration was significantly correlated with vocational maturity.

d) Grades, achievement vs. underachievement, participation in school, out of school activities and independence were all positively correlated with vocational maturity. 
cluded that,

Based on these findings, super and overstreet con-

related to thonal maturity in ninth grade boys is stimulation, their lower socio-economic aspirations to higher rather than achieve reasonanomic levels and their ability to (Osipow, 1973).

Thus besides orientation to Choice, several other variables were associated with vocational maturity. Based on his findings super recommended that the school curriculum should "foster planfulness" to help students become aware of their level of occupational aspirations and also the general amount of education required to achieve that level. What was needed, he thought, was the development of the students' self knowledge by broadening their occupational perspectives. He recommended also that students should be taught to use available resources for exploration effectively.

Related Studies

The findings of Super's research on vocational maturity, generated a number of studies aimed at clarifying the theory further. Montessano and Geist (1964) reasoned that if the process of development is developmental in nature, and both "predictable and orderly," then, older boys should be more reflective in their reasons for their interests than younger bcys. In a cross sectional study of the responses and reasons for such responses, of 60 ninth and 60 twelfth 
grade boys to the Giest Picture Interest Inventory, Super's developmental theory was supported in a general way. For older boys' responses indicated more concern for vocational opportunities, more information about careers than did the responses of ninth graders.

In one of their studies, super and his colleagues had found a relationship between vocational maturity and intelligence. To further clarify this finding, Dilley (1965) hypothesized that since the dimensions for decision making ability overlap with those hypothesized for vocational maturity, there should be a positive relationship between both. Therefore, to 174 high school seniors, he administered his Decision Making Inventory and discovered a positive relationship between good vocational decision as defined by his inventory and intelligence, achievement and involvement in extra-curricular activities. Dilley then concluded that a general intelligence factor may be involved in vocational maturity. This finding thus supports Super and overstreet's (1960) conclusion that vocational maturity is more related to I.Q. than age.

In a study following the Career Pattern Study, Super and Overstreet (1961) tried to find out how consistent and stable the early vocational preferences of ninth graders were. Their findings showed a lack of close relationship between early vocational preferences and consistency. This observation 
reinforced super to question the wisdom of assigning kids early to relatively narrow programs especially if their preferences will change by the time they are through high school. However, the result of Cooley's (1967) and Astin's (1967) Project Talent study of high school students, which is inconsistent with super's findings may be because of the different classification system used. For a comparison of the educational-vorational interests and choices of ninth and twelfth grade boys indicated that the stated career plans of ninth grade boys is a relatively good prediction of twelfth grade plans. Cooley's findings thus suggest that planners can in fact develop general curricula plans oriented around broader, rather than narrow, categories of vocational events to allow students to make commitments that will remain stable (Osipow, 1973). Flanagan and Cooley (1966) however reported frequent changes in vocational choice of high school students. Astin (1967) reported a shift in vocational plans from ninth to twelfth grade usually away from science technology to business and education. But his explanation is that the students were possibly taking reality factors into account. For as students realize the slim chance of succeeding in certain job areas because social emphasis and demands for such jobs have decreased, they also shift with the mood of the times. It thus seems that Astin's findings do in fact reinforce super's vocational maturity theory. For, since 
students should be more reflective in career matters as they grow older, the observed shift by Astin indicated a greater awareness of reality factors by older individuals.

Most of the results of the above studies seem therefore to support super's theory in a general way. But none of them questioned the generalizability of the developmental concept of vocational maturity to all American males. Lo Cascio $(1964,1967)$ both in his writings and research pointed out that vocational development for some, might in fact be discontinuous or even impared. For him, the continuous process of development might hold for advantaged individuals but not for less advantaged youths. However, his research (1967) directed to test this assumption, using super's original subjects and the dimension of vocational preference implementation, rather confirmed many of Super's previous results of the Career Pattern Study. Lo Cascio had no follow up evidence to support his speculations.

On the whole, super had succeeded in validating one of his hypothesized dimensions as a measure of vocational maturity, namely, orientation to choice. The other four, planning, consistency of choice, crystalization of traits, and wisdom of choice, were not found adequate measures of that construct in the ninth grade. This may partially be due to the nature of the particular population used as well as the use of a combination of objective and non-standard 
procedures of measurement. Despite their initial setbacks, however, subsequent studies namely, those carried out by Montessano and Geist (1964), Dilley (1965) and to some extent Astin (1967) did validate in a general way super's findings. However, none of these studies included groups other than the American white male population. No one so far reviewed, extended the study to rural schools or to females. Lo Cascio came closer to extending the studies to groups other than the advantaged. However, because he used the same sample which limited super's original study, he was unable to prove his assumption that the developmental theory might be discontinuous for other groups. His theory thus remained at the level of speculation.

There is thus so far no insight as to how the construct of vocational maturity with its developmental principles might apply to groups from other cultural backgrounds. Nor has there so far emerged a standard instrument to test the theory effectively. This partially explains some of the contradictory findings, e.g., that of Cooley (1967) which emerged. Efforts were however to follow addressing themselves specifically to the refinement of procedures for measuring vocational maturity.

\section{Career Development Study (Gribbons and Lohnes (1964)}

I'he work of Gribbons and Lohnes, and John O. Crites, 
illustrate some serious attempts to standardize the measuring instrument for vocational maturity.

Gribbons and Lohnes (1964, 1965, 1968, 1969) engaged in extensive and longitudinal research studies to devise a more standard and perhaps less cumbersome instrument to measure the construct. They reasoned that such a standard technique would enable "an individual's stage of vocational maturity to be identified so that experiences can be introduced to facilitate those aspects of vocational maturity that are found deficient." Their Career Development Study (CDS) was modelled on Super's CPS, and in many respects, is a replication of the Career Pattern Study. The difference is that the longitudinal nature of their studies implied relying extensively, especially as the first limitations were recognized, on sophisticated statistical multivariate method of data analysis to establish the predictive validities for their final scale, the "Readiness for Vocational Planning" Scales (RVP) .

The CDS developed eight scales as an index of readiness for vocational planning. These consisted of the following factors:

i) Factors in Curriculum Choice

Explores abilities, interests, values, curricula and available course content. 
ii) Factors in occupational choice

Explores educational requirements, abilities,

interests, values, definite limits and scope.

iii) Verbalized strengths and weaknesses

(To educational and vocational choice.)

iv) Accuracy of self-appraisal

General scholastic abilities.

v) Evidence for self rating

vi) Interests

(Awareness and relationship to occupational choice.)

vii) Values

Awareness of values and their relationship to occupational choice.

\section{viii) Independence}

The result of Gribbons and Lohnes' study to test the hypothesis that occupational choice occurs in a sequential developmental process, showed that with eighth and tenth grade boys and girls, the mean RVP scores went up from the eighth to the tenth grade. But some eighth graders had higher RVP scores than some of the tenth graders. Most tenth graders even scored below the eighth grade mean. Based on these findings, Gribbons and Lohnes concludea that "delay in forced curriculum choice is not so much the answer as would be early identification of those with low RVP, so that intensive guidance could be given" (Gribbons and Lohnes, 1964). 
A great deal of overlap is still evident in this scale as can be seen from the many factors involved. Like Super, Gribbons and Lohnes' approach still uses extensive structured interviews which set severe limitations to the objectivity of the instrument. This device usually involves time consuming data collection and elaborate scoring procedures which make the RVP inconvenient to use. However, Gribbons and Lohnes have continued to revise and immensely improve on the instrument. The original eight scales have been collapsed into one univariate scale, the "Readiness for Career Planning," but much research is still needed with this instrument.

Both Super and Gribbons and Lohnes did have as their major objective, the goal of devising a measuring instrument, sufficiently standard and reliable to help counselors identify a person's stage of vocational maturity. But this goal continued to elude them. However, the first successful attempt to produce such an inventory focusing primarily on strict technicality of test construction was made by Crites (1961).

The Vocational Development Project (Crites, J. O.)

John O. Crites who was originally a member of the Career Pattern Study (CPS) accepted the challenge that had long eluded vocational psychologists and psychometricians, to produce an instrument that can measure a developmental variable 
such as vocational maturity. Crites has successfully devised two instruments, the Attitude scale, and the Competence Test, which, combined, measure certain aspects of Vocational Maturity.

Throughout his extensive studies $(1961 ; 1963,1965$, 1973) Crites focused primarily on rectifying the "shortcomings" which he perceived had hampered earlier attempts to measure vocational maturity and had thus succeeded in limiting their usefulness and general applicability. Crites (1965) noted that:

Satisfactory empirical meaning had not been given to the construct of vocational maturity... for either theory testing or practical application, not only because of lack of research but also because of the inherent difficulties involved in the measurement of developmental variables (Crites, 1965, p. 31).

His studies emanating from this criticism of previous efforts, had two objectives in mind, one was psychometric, to construct and standardize a measure of vocational maturity and the other methodological, to solve the problem inherent in assessing a developmental variable.

New Criteria

One problem with previous measuring efforts, had been the fluidity and inexactness of the measurement criteria used. Super's criteria for measurement included either the typical vocational behavior of the person or the developmental tasks he was coping with at the time. Crites considered this 
wasteful and suggested combining both in order to assess one's maturity "by behavior and developmental tasks rather than by one or the other separately." The implication of this combination is that it fulfills the condition for measuring a developmental variable; Underwood (1957) indicates that "the stimulus used to elicit responses should be held constant and the individuals must differ reliably in their responses to the stimulus." As Crites (1965) pointed out, the "stimulus," i.e., the developmental task, becomes the same for individuals in the same life stage so that their responses can reliably be compared for possible variations. Whereas Super's proposal suggested comparing the individual's responses, i.e., the behavior, to others "regardless of how appropriate the developmental task is to the age and expected life stage of the individual." Similarities exist between Crites' new reference point for evaluating a developmental task, that is, the age group, rather than one's age, and the method previously described, used in Ibo society for the same purpose. This further reinforces the researcher's justification to clarify the assumptions of the developmental theory in Ibo society.

\section{Scoring Key}

Having dealt with the problem of redefining the criteria for evaluating vocational maturity, Crites set to work 
on Super's measurement nodel. The model employed the age and point scales, both of which have serious shortcomings for measuring constructs which depend on age. Super had proposed that vocational maturity in adolescence should be thought of as mental age. But as crites pointed out quite rightly, even though studies had established parallels between vocational maturity and mental maturity, this comparison, also used in intelligence testing, is very limiting. This is because the age scale does not allow scores and score dispersions at different age levels to be compared. Consequently, data indicating variations in vocational behavior at various ages cannot be compared with super's model. This observation is important as super's theory indicates that there should be evidence of increasing vocational maturity with increasing age. The age scale is therefore inadequate for this task. The point scale on the other hand is limited by its low validity. To circumscribe the problems posed by both the age and point scales, crites proposed a syntheses of their best features. The new model which emerged incorporated an a priori scoring key derived from "item responses which differentiate between older and younger age groups within a given vocational life stage, and norms constructed for each age level." Association with age was an important consideration for crites who insisted that "scores may be related to other factors in addition to age, but unless 
they correlate with age, there is no support for the scoring systems as a measure of bchaviors which mature over time."

\section{Revised Definition}

What emerged from Crites' revisions was a new formulation of vocational maturity as comprising two independent variables.

The definition of vocational maturity by behavior and tasks in combination with a measuring model derived from a synthesis of age and point scales, leads to the formulation of two independent measurable variables--degree and rate of vocational development (Crites, 1961).

The "degree of vocational development" indicates the similarity between an individual's behavior and that of the oldest individuals in his vocational life stage. To measure this variable, an individual responds to an inventory of vocational behavior which differentiates older from younger age groups within a life stage. The number of behaviors endorsed in the same way as the older group, indicates the individual's raw score. Thus the higher the score, the greater his degree of vocational development. "Rate of vocational development," on the other hand, refers to the maturity of an individual's vocational behavior in comparison with that of his own age group. This is determined by interpreting the person's raw score according to the appropriate age norms to show whether he is relatively more or less vocationally mature than his peers. 
Crites' revised definition of vocational maturity seems less complex to measure. As he himself puts it, "probably more readily translated into specific measuring operations, . . and more parsimonious." However, this new definition "of degree and rate" of vocational development relies heavily on Super's original formulations, crites merely revised and in places extended them. But having redefined the construct as measuring both the degree and rate of vocational development, and having proposed a new scoring key to take the age criterion into account, crites proceeded further to revise the original dimensions proposed by Super. Here again, nothing completely new really emerged. For his new dimensions incorporated all of super's, including those empirically tested as both weak and strong. But like his previous strategy, Crites once more collapsed some of Super's dimensions and so ended up with fewer categories for his new model.

Crites' New Model

Crites indicated that behaviors which in developmental theory are expected to mature with increasing age, can be broadly grouped into "Aptitudes" and "Attitudes" (Crites, 1964). He described Aptitudes, as part intellectual and part non-intellectual. They are adjustive capacities associated with intelligence and personality and involve such cognitive 
or ego functions, as the mental activities of accumulating and organizing information, enumerating courses of action and anticipating their probable consequence, establishing future goals and relating means to ends through planning. On the other hand, "Attitudes" are "conative" dispositions involving independence in decision making, involvement in the choice process, orientation toward work and assumption of personal responsibility for the outcome of one's actions (Crites, 1964). In a later formulation however, Crites (1965) proposed that Super's dimensions of orientation to Choice, Information and Planning and certain aspects of the Crystallization of traits dimensions, can be further analyzed into several different kinds of choice competencies and attitudes so that,

together with the Consistency of vocational choice, and the wisdom of vocational choice dimensions, these competencies and attitudes can be thought of as comprising the construct of vocational maturity
(Crites, 1965).

Thus what emerged are four, rather than the original five dimensions of vocational maturity proposed by super. But all five concepts are included in the collapsed categories except that the specific names are changed. For example, Super's proposed Consistency of Choice, and wisdom of Choice remain unaltered as distinct categories. However, Orientation to Choice, Information and Planning and Crystallization of Choice, are merged and regrouped into two, rather than 
three categories namely, Choice competencies and choice Attitudes. Thus for crites, vocational maturity proceeds through four dimensions of Consistency of Vocational Choice, Wisdom of Vocational Choice, Vocational Choice Competencies and Vocational Choice Attitudes.

The resulting model, which is pictorially shown on the next page not only merged most of Super's original dimensions but also breaks the dimensions into finer and more refined units. Crites' new model, consists of a general factor-the degree of career development and four group factors each further divided into several finer indices.

The degree of career maturity in this model indicate an individual's overall progress toward vocational maturity within a given period. Crites hypothesized that this general factor should have a moderate positive relationship like .30 to .40 , to each of the group factors. The dimensions in turn, should intercorrelate moderately. Moderate association between groups and fairly high ones within groups was expected. If these correlations emerge, then, "it may eventually be possible to graph an individual's vocational maturity on a profile sheet and indicate both his degree and rate of vocational development along each dimension" (Crites, 1961).

Thus for Crites as well as for super and overstreet, Gribbons and Lohnes, the practical implication for counselors, of measuring vocational maturity has been of primary concern. 


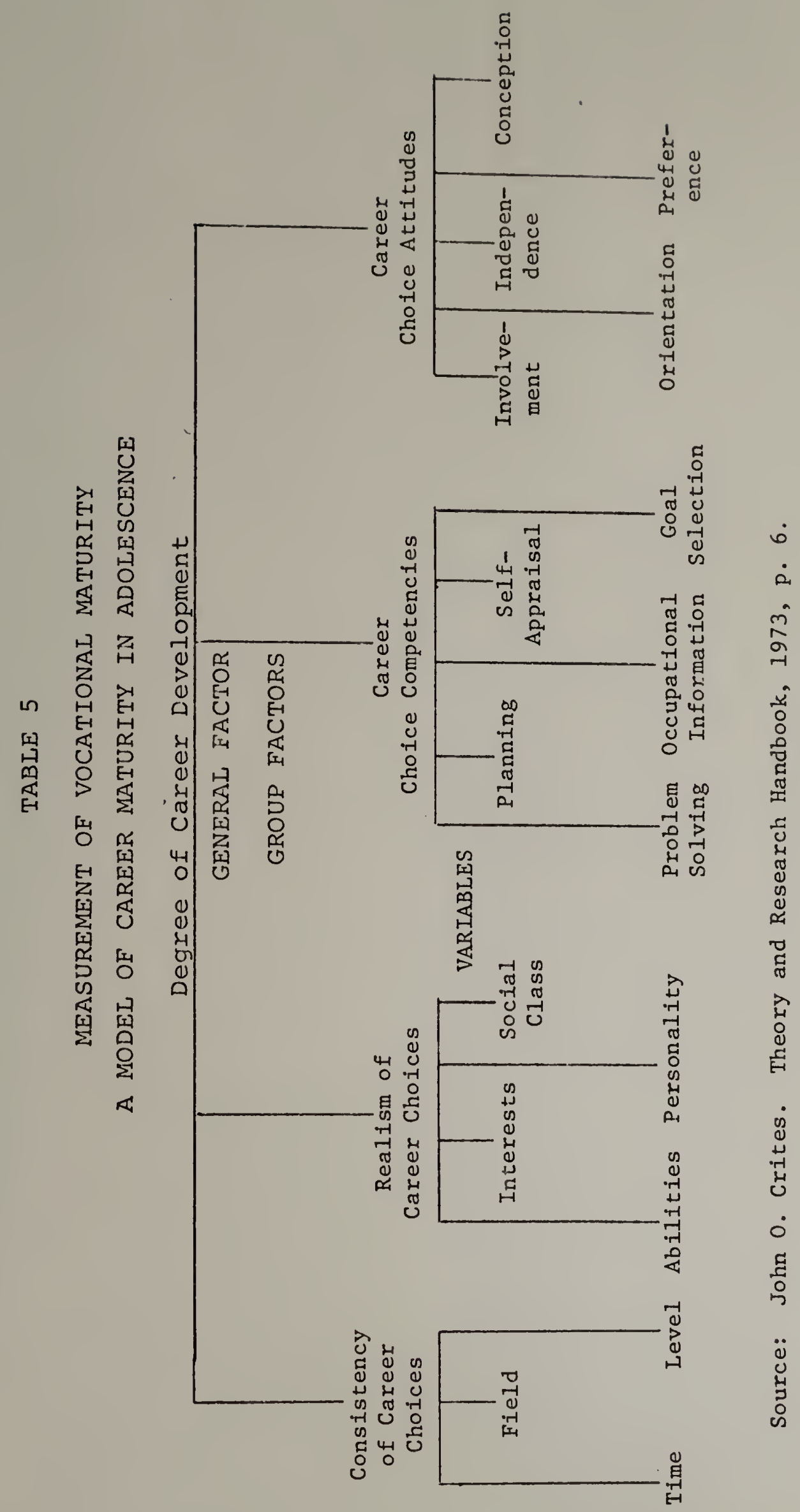


Both Super and Gribbons and Johnes had run into difficulties with this problem. Crites strenuously exerted himself to accomplish this goal. He tackled the problem through strict adherence to the conditions necessary for constructing a measuring instrument which assesses a developmental variable. The age criterion not dealt with by Super was taken into consideration in formulating a new model, which is hierarchial in nature. Furthermore, both super and overstreet, and Gribbons and Lohnes had used interview procedures in their assessment devices. This is usually neither objective nor economical especially when larger populations are involved. It was therefore to overcome these inherent limitations as well as those technical ones previously indicated, that Crites devised, tested and standardized the "Career Maturity Inventory" in two stages. Stage one saw the testing of the Attitude scale component (1961) and the second stage involved the development and research on the Competence Test component (1966). Thus crites ended up with the measurement of two out of his hypothesized four dimensions of vocational maturity.

\section{The Attitude scale}

The Career Maturity Inventory consists of two components, the Attitude Scale which is described in this section of the review of the literature on vocational maturity, and the Competence Test. The Attitude Scale, originally 
known as the Vocational Development Inventory or the VDI, is much older and has been longer researched. It consists of fifty attitudinal statements covering five attitude clusters measuring the basis for involvement in the choice process, orientation to choice, independence, preference, and conception of choice factors. These factors were, according to crites, "rationally deduced from vocational development theory." But they cover only the attitude dimensions in Crites' model. Iterns reflecting these factors were included in the Attitude scale. And the criterion variables were age and grade. Only items which were "monotonically associated with age and grade, thus reflecting passage in time," were included in the test.

Crites (1961) then carried out his research on 2,822 male and female adolescent students in grades five to twelve at Cedar Rapids, Iowa, in schools located in high and low rent districts. The result of this study showed that there was a systematic increase in means across grades with the exception of the eleventh grade which was atypical in that, though lower than the twelfth grade mean, it was equal to the tenth grade. Verbal vocational behaviors were monotonically related to both grade and age during adolescent years but were more frequently associated with the former than with the latter. Very negligible differences between sexes were observed. The correlation of vocational maturity scores with age was $x=.385$ and with grade $r=.463$. The true-false format better discriminated between the grades. The most notable trend in item response by 
age and grade was from predominantly true to false responses. The average vocational maturity of the entire sample was at approximately the eighth grade level. The relationship between vocational maturity and deviation responses which may indicate vocational maladjustment was low negative, $r=-.20$.

The purpose of Crites' investigations was specifically "to construct and standardize a measure of vocational maturity in adolescence and to develop and implement psychometric procedures appropriate for the measurement of developmental variables" (1965). The results of this study indicate that most of these objectives were accomplished. For the major principle that vocational maturity should correlate specifically with age was supportea even though the relationship proved to be higher with grade than age.

Crites' combination of both the rational and empirical approaches to test construction in the measurement of vocational maturity has circumvented some of the problems which previously arose in the assessment of developmental variables. But the results exposed an old problem which still remains unsolved. Items had been selected for the Attitude scale on the assumption that the process of rocational development is continuous and irreversible. Based on the vocational development theory, a monotonic function of scores by age and grade, was therefore adopted as criterion. However, Crites' study indicated that certain items (ten of them) on this instrument reflected vocational maladjustment or a regression in vocational 
development. The implication which thus suggests itself is that vocational development might in fact sometimes be discontinuous, "characterized by slips backward as well as steps forward" (Crites, 1965). The atypical result of the eleventh graders is a case in point. It seems to reinforce therefore La Coscio's (1967) untested speculation that for some, vocational development could be discontinuous.

\section{The Competence Test}

The other component of the Career Maturity Inventory is the competence Test. This is still very new (Crites, 1973). The measure was designed to test the choice competence dimension of Crites' model and consists of five subtests. These include Knowing Yourself or (Self-Appraisal); Occupational Information (Knowing about Jobs); Goal selection or Choosing a Job; Planning or Looking Ahead and Problem Solving or What Should They Do? Twenty item stems for each of the five subtests describe hypothetical people engaged in one or another of the several aspects of career development subsumed by Career choice competencies.

Options are given from which the relevant response to the problem posed is to be chosen. The same combination of rational-empirical test methodology was used in constructing the competence Test in order to measure variables which change systematically between grades.

Crites tried out the competence Test on 2,000 male and female students in the Santa Ana, California school 
system, in grades six through twelve. Crites indicates that his population included various ethnic and racial groups although the specific breakdown was not shown in the research handbook. The result of the test indicated a monotonic increase of scores on each subtest by grade. The correlation of the scores with either age or grade was not reported as standardization studies are still being carried out. But subtest intercorrelations seem generally good with a range of $.25-.73$ and a mean of $r=.54$. This component of the Career Maturity Inventory is still very new and has had no outside research study reported.

In summary, Crites (1965, 1973) can be said to have produced, to some degree, a standard instrument in the field of vocational psychology whose major characteristic is the monotonic function of its scores by age and especially grade. However, judging primarily from his own research studies, certain limitations are still evident. Some of these are pointed out in the next section.

\section{Some Limitations of the Career Maturity Inventory}

Crites' statements over a period of nine years, starting from 1965 to 1974 are characterized by a lot of "inconsistencies" which leave one with the impression that his formulations about the dimensions of vocational maturity and specifically how some of them can be measured, have not 
sufficiently crystalized. Nor has his objective to construct a "complete" measure of vocational maturity been accomplished. An empirical definition of what the total construct means to Crites is still needed.

\section{Incomplete Measure}

Crites (1965) initially proposed four dimensions of vocational maturity, namely, Career Choice Attitudes, Career Choice Competency, Consistency of Career Choice and Realism of Career Choice. At that time, he indicated that the consistency of Career Choice and Realism of Career Choice Dimensions may have to be assessed by "non-psychometric methods." Crites thus seemed clearly aware from the outset, of the difficulties inherent in constructing an adequate psychometric device capable of measuring both dimensions. But soon after, he proceeded to incorporate all fcur dimensions into his measurement model thereby implying that the difficulty anticipated earlier had been, or could be overcome. But then, he just as quickly dropped the two troublesome dimensions from those tested in the present form of his Career Maturity Inventory (1973). No explanation was given for this inconsistency. Crites later modified his statement by saying that his proposed instrument measured two dimensions "more completely than previous procedures" an observation, which reflects a more accurate picture of what he has so far accomplished. 
But Crites has continued to make further statements which do not clarify the issue. For in his most recent statement (Crites, 1974), he classifies all four dimensions under two categories (a) Content, comprising the consistency of Career Choice and Realism of Career Choice, and (b) Process, consisting of the Career Choice Attitudes and Career Choice Competencies dimensions. According to Crites, the relationship between the content and Process aspect of vocational maturity is that, "the more mature the Process aspect is, the more consistent and realistic an individual's career choice and over all degree of career development" (1974).

The question that arises from this statement is this: Since both the Attitude Scale and the Competence Test components of his present CMI which fall into the Process aspect of vocational maturity can be assessed through a standardized measure, should we then assume without further proof that the Realism and Consistency dimensions are simultaneously assessed? The problem with this however is that Crites still makes out that his model which measures a general factor, (consequently a key proble!n with the Career Maturity Inventory) and only two dimensions, now by very subtle implication not empirically demonstrated, also measures the other two as well. The researcher's interpretations have been extrapolated exclusively from Crites' statements and therefore are subjective. Most of his test users, will read varied meanings into his 
statements. Therefore, because of the confusion this is likely to create for counselors using the result of the CMI, Crites needs to clarify the situation as soon as possible. The present status of the CMI therefore is that it has scores for only two dimensions--Career Choice Attitude and career choice competence. The other hypothesized dimensions, Realism and Consistency of choice have not yet been addressed. Therefore crites has still not overcome the difficulties encountered by previous attempts to measure all the dimensions of vocational maturity. Stronger validity of the model as a complete measure of vocational maturity is therefore needed for further useful activity with the instrument.

No Separate Scores for Attitude Scale

Apart from the omission of these two dimensions, Realism and Consistency of Choice from CMI, its Attitude Scale component does not provide separate scores for each of the variables subsumed under it. As it stands, the test yields only one score. The pattern of interrelationship between variables is thus not known. Nor can the counselor then give his student effective help as he has no way of telling, which clusters of the Attitude Scale gives the student more or less problem. If the task of "graphing students' vocational maturity on a profile" is to be 
meaningfully accomplished, this data will be needed.

Westbrook and Cunningham (1972) have launched a rather ambitious scheme to deal with these limitations. However, until all their objectives are fulfilled crites' instrument, despite its limitations, remains a useful standardized instrument to measure certain aspects of vocational development.

The present study, to assess the vocational maturity of students in the East Central state of Nigeria is being undertaken with the inherent limitations in mind. It thus recognizes that the resulting pattern of vocational maturity noted, will be interpreted with particular reference to the Attitude and competence Test dimensions of vocational maturity. Having said this, however, the CMI as it stands provides empirical evidence of its monotonic function and so can reasonably be used to test this important developmental assumption. How applicable this is to Nigeria is the major thrust of the present study.

\section{Research Studies with the Attitude Scale}

This section of the review concentrates on studies carried out to verify Crites' findings with his Attitude Scale. No such research besides crites, has been reported for the Competence Test which is still very new (1973). 
Crites, working with semler (1967) reported the results of several years of longitudinal investigations to find the interrelationship between adjustment, educational achievement and vocational maturity. Their findings indicated that adjustment was significantly related to buth educational achievement and vocational maturity throughout the several years of the study. Particularly was vocational maturity related to these variables in the senior years of high school.

\section{Studies with Culturally Different Groups}

Most of the studies using the Attitude Scale or VDI as it was then called seemed to have focused on the relevance of the developmental assumptions for culturally different groups in America. First in the list is the study by wilstach (1967). He used super's manual and Crites' VDI on 104 ninth grade Mexican-American boys with average achievement test scores in two agricultural schools in California. One school was metropolitan, the other rural. His findings indicated that the urban and rural interview scores were on the average lower than those found by super. But the rural mean scores were higher by 3.26 points than the urban scores. Wilstach attributed the higher mean score for the rural boys to the fact that about 87.2 percent of these boys had been employed for pay as against 3.26 of metropolitan boys who had had 
similar experience. On the VDI, the Mexican-Anerican group, scored significantly lower than Crites' original group but the mean score for both groups was comparable.

Bartlett (1968) used the VDI and the Adjective Check List ( $A C L$ ) to clarify the relationship between vocational maturity and personality variables. His sample included 89 females and 65 males between 16 and 21 years, engaged in a Manpower Development and Training program. Subjects were divided into high (40), middle (30-40) and lower (30) groups, based on their VM scores. The results indicated that the groups differed significantly on six out of the twenty-four personality variables of the ACL. Four of these variables were directly related to vocational maturity. An association was indicated between higher vocational scores and higher personality variable scores on self-confidence, achievement, dominance and autonomy. From this result Bartlett concluded that vocational maturity is analogous to the development of mature personality characteristics.

The possibility that the developmental theory might not be addressing its assumptions to culturally different subjects was the focus of another study by schmieding and Jensen (1968). These authors studied the effect of an occupational unit of twenty-two fifty-minute sessions on the vocational maturity and vocational tenacity of AmericanIndian high school students. Seventy-eight American-Indian 
high school students in the eleventh and twelfth grades were divided into an experimental (39) and control group (39). Another group of white students (39) was used for comparison. Only the American-Indian experimental group attended the group guidance sessions on occupations. Finally, all subjects were administered the VDI and Vocational Tenacity Test. The results on the VDI showed that the white comparison group scored significantly higher than the Indian group with the Indian students on the occupational class scoring second.

Another study by Asbury (1968) used the VDI with rural disadvantaged eight grade boys. A group of 63 low income Kentucky Appalachian students selected randomly from four rural schools, were compared to 601 Iowa students on the VDI. The results indicated that the Appalachian boys had significantly lower scores on the VDI than the Iowa students.

The studies so far reported, have questioned the advisability of applying the developmental principle to culturally different groups since the white groups continue to outscore other groups on the VDI. Ansell (1970) was skeptical of the assumption that the vocational development of nonwhite students is comparable to that of middle class Caucasian students. To test this, he administered both the VDI and Gribbons and Lohnes' RVP to 375 eighth to twelfth graders. These were divided into three groups comprising Lower Class Caucasian (LCC), Middle Class Caucasion (MCC) and Lower Class 
Negroes (LCN). The specific purpose of the study was to determine if the VM scores of the three groups increased with age and grade at similar rates. Using a multivariate analysis of covariance to determine the effect of socio-economic groups and grade level on VM score, he found that the MCC had higher VM scores followed by LCC and finally LCN when assessed by both the RVP and VDI. And, the rate of increase was found to be approximately two years slower than the rate for the MCC.

Maynard (1970) on the other hand focused his own study on the relevance of the VDI for black inner city boys. His sample comprised 450 eighth grade boys divided into 90 blacks in segregated schools, 90 whites in segregated schools, 90 blacks in an integrated school and 90 whites in a suburban school. A comparison of their mean vocationa]. scores on the VDI showed that blacks consistently scored lower than other groups. Based on this finding, Maynard decided that the VDI is not adàressing itself to blacks in America and further that the developmental theory of vocational maturity is inconsistent with black vocational development.

Practically all the studies on culturally different groups and especially Maynard's concluded that the VDI not only does not give an accurate picture of the vocational development of these groups but that the theory doesn't address itself to non-whites. This conclusion was based on 
the finding that both the culturally different groups and the white population consistently score at unequal levels or rates on the VDI. These were all cross sectional studies with no longitudinal follow up for support. At least the results so far reported, indicate that even with the culturally different groups, the VDI fulfills its monotonic function by grade. That the non-Caucasion groups failed to score at the same level as the original sample, does not invalidate the theory for them. Rather, it points to the fact that presumably, these groups might be lacking in effective and meaningful headstart and cultural stimulation comparable to those enjoyed by the white groups. There is thus need for more research studies of a longitudinal nature to test the effects of these variables on the vocational maturity of these socially disadvantaged groups. Since the VDI was meant to be used only incidentally for "between group" comparisons, its usefulness might be more evident in "within group" studies. There is also a need to control for socio-economic level in future studies.

Sex, Urban/Rural Differences

Other areas of interest that have attracted researchers, are sex and urban/rural effects on students vocational maturity. Smith (1971) using a large sample of 2,020 eighth and tenth grade boys and girls, sought to determine sex and grade 
differences in mean scores on the VDI. With a two way analysis of variance design, his results indicated that at both grade levels, girls possessed more mature vocational attitudes than did boys. The grade level difference indicated a three point mean difference in favor of girls. He therefore concluded that females possessed more mature attitudes toward work and career planning than males in the eighth and tenth grades of the Altoona, Pennsylvania school system. This study is of interest as it contradicts Crites' standarization finding of inconsequential differences on the VDI by sex.

Davis on the other hand, set out among other objectives, to investigate the VM of white and black male and female tenth graders in urban and rural schools using the VDI. Her findings indicate that whites, both male and female, consistently scored higher on the VDI than blacks. She found no sex differences but observed that urban tenth graders scored significantly higher than rural tenth graders. White students scored higher than blacks. Urban tenth grade males scored higher than rural tenth grade males. Rural white males scorea higher than rural black males. Rural white females scored higher than rural black females. Urban white males had higher VM scores than urban black males. Urban white females also scored higher than urban black females. Concluding from these findings, Davis called for an intensification of efforts to step up vocational guidance in rural schools. 
$\underline{\text { Summary }}$

This review of studies carried out by Crites and Semler, Wilstach, Bartlett, Schmieding and Jensen, Asbury, Ansel, Maynard, Smith and Davis, all indicate that the monotonic function of scores by grade especially, has strong support. The rate of score increase for non-white and lower class students seems lower than for the white middle class students. White males consistently scored higher than black male students on this scale and white females scored higher than black females except for one study. The findings on the urban/rural relationship is not consistent, although in some, urban students scored higher than rural students. Contradictory findings emerged on the effect of intervention strategies on vocational maturity. More research is thus required in this area. Inconsistent findings are reported for the effect of sex.

None of these studies however used samples other than American. Furthermore, none provides an insight as to the applicability of the CMI to developing nations who are in the habit of adopting tests from western countries. There is therefore a great need to test it out in a developing nation such as Nigeria and especially in its East Central State, to determine how global the theory is for the career development of other cultures. The present study tested the monotonic theory of the CMI on adolescents in the East Central State of 
Nigeria. Male and female students in classes one to four, (grades 7-10) in urban and rural locations were included in the sample. Considering the inconsistencies in some of the results of the American studies, the effect of the following variables sex, class, urban/rural schools, and age, on the vocational maturity scores of the students was investigated to provide evidence on the extent to which the CMI can be applied to Nigeria, and specifically to its East Central state. 


$$
\begin{array}{llllllllllllllllll}
C & H & A & P & T & E & R & \text { I } & \text { I } & \text { I }
\end{array}
$$

\section{METHODOLOGY}

The primary focus of the present investigation was to determine the extent, if any, to which the monotonic theory of vocational maturity, as measured by the career Maturity Inventory holds true for secondary school students in the East Central state of Nigeria (ECS) in both urban and rural schools. The population included males and females, ranging from eleven years of age to twenty-two who are in classes one through four (grades 7-10). The present chapter describes the population used in the study, the instruments administered, data collection and analysis. A random sampling procedure to be described, was used in the selections.

\section{Area Studied}

The ECS of Nigeria, for reasons stated in the justification of this study was found to reflect most closely, the value system of the American culture on which the developmental theory of vocational maturity, was based. Predominantly agricultural, the ECS is peopled exclusively by the Ibos who number over eight million (1973 National Census). Urban areas included in the study were Umuahia and Enugu, and the rural, Urualla and Abayi (see map on page 32). 
$\underline{\text { Schools }}$

There are 209 secondary schools in the ECS (Ed. Statistics 1971). Thirty-five are located in urban areas. of this number, 19 are for boys, 13 for girls and 3 are mixed. In the rural areas, there are 174 schools. Ninty-one of these are boys' schools, 54 are girls' and 29 are mixed. Mixed schools were not included in the study. Each of the 19 urban male schools was assigned a number ranging from 01 to 19 written on a piece of paper. The same procedure was adopted for the 13 urban female schools (01-13), the 91 rural boys' schools (01-91), and the 54 rural girls' schools (01-54). Since only a few schools were involved the slips of paper were shuffled in four separate baskets and a number drawn from each basket. By this stratified simple random process, 4 schools were selected: 2 girls' and 2 boys' schools, in urban and rural areas.

\section{Classes}

Four classes namely 1-4 (grades 7-10), were selected from each of the 4 schools. It was originally pianned to include all the classes in the school, i.e., 1-5. However, class five which is the terminal class was involved in the West African School Certificate Examination when the field study was undertaken in June, 1974. Class five was therefore excluded from the study. 
$\underline{\text { Subjects }}$

Each class had approximately 90 students. Selection procedure for students consisted of assigning the 90 names in each class consecutive numbers. A selection index was then obtained from a table of random numbers (Popham, p. 369). Corresponding numbers were then taken until the desired 30 were selected from each class. There were therefore an initial number of 120 students from each school and a total of 480 boys and girls. However, after eliminating subjects with pertinent data missing from their answer sheets, 25 subjects were retainea in each class. The final total used for the study was 400 students: 200 girls, and 200 boys. These were further divided into eight age groups, ranging from eleven to twenty-two. Four students were dropped because pertinent age data were incomplete. The age grouping thus involved only 396 students. The pattern of the final breakdown is presented below in Tables 6 and 7 .

TABLE 6

BREAKDOWN OF POPULATION USED IN THE STUDY

\begin{tabular}{|c|c|c|c|c|c|c|c|c|}
\hline \multirow{2}{*}{ Sex } & \multirow{2}{*}{$\begin{array}{l}\text { Urban/U } \\
\text { Rural/R }\end{array}$} & \multirow{2}{*}{ Schools } & \multicolumn{4}{|c|}{ Class } & & \multirow{2}{*}{ Total } \\
\hline & & & 1 & 2 & 3 & 4 & & \\
\hline Boys & U & Fisher High School & 25 & 25 & 25 & 25 & 100) & \\
\hline Boys & $\mathbf{R}$ & Ngwa High School & 25 & 25 & 25 & 25 & 100) & 200 \\
\hline Girls & $\mathrm{U}$ & Queen's High School & 25 & 25 & 25 & 25 & 100) & \\
\hline \multirow[t]{2}{*}{ Girls } & $\mathrm{R}$ & $\begin{array}{l}\text { Urualla Girls High } \\
\text { School }\end{array}$ & 25 & 25 & 25 & 25 & 100) & 200 \\
\hline & & & 100 & 100 & 100 & 100 & 400 & \\
\hline
\end{tabular}


TABLE 7

BREAKDOWN BY AGE GROUP

$\begin{array}{lrrrrrrrrr}\text { Age } & 11-12 & 13 & 14 & 15 & 16 & 17 & 18 & 19-22 & \text { Total } \\ \text { Treatment groups } & 1 & 2 & 3 & 4 & 5 & 6 & 7 & 8 & \\ \text { Sample size } & 18 & 28 & 64 & 100 & 72 & 53 & 35 & 26 & 396\end{array}$

\section{Instrument}

The instrument used in this study was the Career Maturity Inventory constructed and standardized by John 0 . Crites (1973). This was slightly modified by the researcher (Appendix A, B, and $C$ ). The instrument has two components, namely the Attitude Scale and the Competence Test. The Attitude Scale and Parts II and IV of the Competence Test were used in the study. Each of the subtests fulfills the monotonic function. Therefore any of them can be used without bias to test the theory.

\section{The Attitude Scale}

The Attitude Scale is made up of 50 attitudinal items measuring five attitude clusters. These reflect involvement in the choice process, orientation toward work, independence in decision making, preference for career choice factors and conception of the choice process (Crites, 1973). Orientation toward work, for example, is defined as "the extent to which an individual is task- or pleasure-oriented in his attitudes 
toward work and the values he places upon work." A sample item reflecting this dimension in the scale would be "work is dull and unpleusant," and "work is worthwhile mainly because it lets "you buy the things you want" (Crites, 1973). These attitudinal statements according to Crites, are derived from contemporary theories of vocational development. They are then empirically keyed to differentiate the responses of fifth through twelfth grade students. The items were standardized to ensure that the mean responses are monotonic function of age and grade. The scale yields a total score of 50. The score correlates $r=.385$ with age and .463 with grade. Ten of the items on the scale: $1,2,3,9,17,22$, $35,44,46,47$, yeild a deviation response score which is hypothesized to measure vocational maladjustment. Sex differences in item responses are "negligible" and so Crites recommends the scale to be used for both male and females. Reliability studies indicate an internal consistency estimate (KR Formula 20) in the .60's and .80's with an average coefficient of .74 . The test-retest stability over a period of one year is .71. The criterion related validity indicate a relation of $r=.39(p<.01)$ with the Occupational Aspiration Scale (Bathory, 1967) which is a measure of realism of aspiration, and an $r=.38(p<.01)$ with Gribbons and Lohnes' Readiness for Vocational planning (Crites, 1973, p. 16). 
The Competence Test

The other component of the CMI used in this study was the competence Test which consists of five subtests namely, I Self Appraisal, II Occupational Information, III Choosing a Job, IV Planning and V Problem Solving. However, only Part II (Knowing about Jobs or Occupational Information) and Part IV (Looking Ahead or Planning) were used. Two considerations influenced the choice of both parts. One was the cost involved in administrating all five subtests to 400 students at the researcher's limited buaget. More importantly, was the reliability report for the two subtests. Part II and IV of the test indicate the highest internal consistency coefficients (KR 20) across grades. A range of $r=.81-.88$ was reported for Part II and an $r=.82-.90$ for Part IV (Crites, 1973). Each of the five subtests fulfills the monotonic function.

All the items in the competence Test describe hypothetical people in a hypothetical situation who are engaged in one or another of the several aspects of career development subsumed in the career choice competencies. Part II seems to fulfill the need for a standardized measure of occupational information which hitherto has been unavailable (Buros, 1961). This part focuses on job duties and tasks in the world of work rather than on all aspects of Occupational 
Information. The subtest consists of twenty items with vignettes of a worker at a job constituting each stem. Options are given from which to choose the relevant response. For example:

Melinda smiled and handed Mr. Whetstone two packages of quarters, five of dimes, and ten of nickles. She said "Have a nice day," as he gathered up the coins and left. There was no one else at her window, so she took the time to check how much change she had left in her coin drawer and filled some notes she would need to balance her cash at the end of the
day.

What is her occupation? a) accountant, b) bank teller, c) buyer, d) postal
clerk, e) don't know.

Part IV, Looking Ahead or Planning, also consists of twenty items. "The stem gives the career goal of a hypothetical individual and a set of unordered steps necessary to attain it" (Crites, 1973). The individual is expected to reorder the steps in the correct sequence. For example:

Elazabeth has chosen to be a lawyer. Three steps she can take to become one are:

1. pass bar exams

2. go to law school

3. major in history in college

What is the correct order of these steps?

$$
\begin{array}{lllll}
\mathrm{F} & 1 & 3 & 2 & \\
\mathrm{G} & 2 & 3 & 1 & \\
\mathrm{H} & 3 & 1 & 2 & \\
\mathrm{~J} & 3 & 2 & 1 & \\
\mathrm{~K} & \text { don } & & t & \text { know }
\end{array}
$$


The only reliability study reported using the Kuder Richardson Formula 20 (KR 20) indicate an internal consistency coefficient across grades in the range of $.72-.90$ with Parts II, III and IV indicating the highest intercorrelation. Construct validity report shows a product moment intercorrelation among subtests ranging from $r .25-.73$ with a mean of .54 which Crites reports is the approximate theoretical expectation (Crites, 1973, p. 34). Crites is still further analyzing data on the Competence Test and has not reported further findings.

Test Modification

The researcher made minor stylistic modifications on the scale prior to administering it to Nigerian students. The strictly stylistic modifications involved nos. 84 and 89 in the Attitude Test, where phrases that were likely to be conFusing were rephrased to reflect typical Nigerian usage making sure, however, that the original meaning of the text was retainea. For example item 84 (See Appendix C) in the original reads, "I guess everybody has to go to work, sooner or later but I don't look forward to it." This was modified to read, "I suppose everybody has to go to work someday, but I don't look forward to it." In item 89, "the greatest appeal of a job to me.. ." was rephrased to read, "the greatest attraction of a job to me. . . " 
Further modifications occurred in no. 101 of the Attitude scale and in Parts II and IV of the competence Test. In the Attitude scale no. 101 reads, "By the time you are 15, you should have your mind pretty well made up about the occupation you intend to enter." The age 15, was changed to "half way through school." The assumption behind the change is that in America where compulsory education is the rule, the child who starts school at the age of six will normally be half way through school by the time he is fifteen. But in Nigeria where compulsory education does not operate, there would be a wider age differentiation at any one stage. The researcher reasoned that a generalization, rather than a concrete age, would more meaningfully apply in the Nigerian situation.

For Part II of the Competence Test, the general principles followed in the modification reflect those sug-gested by Schwarz and his team (1972). Basically, Nigerian names were substituted for American rames in some of the items and the details of job duties which did not totally duplicate sirnilar conditions in Nigeria, were modified. An example of such changes occurs in no. 5 of Part II (Knowing about Jobs). The "bank teller," in Crites' sample, hanailes "packages of quarters, fives of dimes and tens of nickles." His Nigerian counterpart uses "two bags of kobo and naira notes" even though the task remains the same. 
Part IV of the test presents the career goal of a hypothetical person and a set of unordered steps necessary to attain it. The task is then to structure a correct response order for these steps. Four answer alternatives are presented, with a "don't know" option. The correct order usually involves a sequence of a) obtaining the relevant training b) gaining employment in the occupation and c) taking advanced examinations or certification in the field where required (Crites, 1973). These guidelines used by Crites were strictly adhered to in substituting steps which would be followed in Nigeria. An example is given below:

Ngozi wants to be a secondary school teacher. Three steps she can take to become one are,

1. find a job as a teacher

2. pass a professional teachers' exam

3. at.tend a University or teacher training college

What is the correct order of these steps?

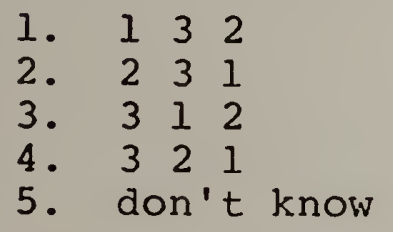

The correct option is (4).

An important consideration in the test adaptation was that the jobs included should be readily available in the country. Informational materials on them should also be reflected in the National Standard Classification of Occupations (1966). With this in mind, the "forester" using a 
helicopter in Crites' inventory was changed to "forest officer," who would be doing the same job but without the helicopter (see Part IV, No. 45 in Appendix B). The tests can be examined in Appendix $B$ and $C$. No substantial changes were made on the test to affect its ability to measure what it purports to measure.

\section{Procedure and Data Collection}

In January 1974, the Principals of those schools selected for study were contacted for permission (which was readily given) to administer the tests in their schools. Then in June, the researcher travelled to Nigeria. With the help of the principals, students were selected using a random number table (Popham, 1967). A teacher and sometimes a school prefect helped supervise the test administration. Test instructions seemed fairly understood so that the main task of the teachers was to help students fill in biographical data. The test instruction provided in the test manual was adhered to as well as the time limit of 25 minutes stipulated for each test. The researcher found no need to extend the time for any of the classes. The researcher supervised the overall operation and clarified questions as they arose.

\section{Data Scoring and Analysis}

Standardized optical scan answer sheets were used. This made it easier to score the data by machine in the 
University of Massachusetts Computer Center. An analysis of variance (ANOVA) was used to test the hypotheses of no mean score difference by class, sex, age, urban/rural schools on the Attitude Scale and Parts II and IV of the Competence Test of the CMI. A three way analyses of variance was used to test the hypotheses of no mean difference by class, sex and urban/rural schools and a separate one way analysis of variance was used to statistically compare the mean score by age group. The ANOVA was chosen as a statistical devise to cope with the problem under study, because it is a convenient method for the simultaneous comparison of many means in order to decide if some statistical relation exists between the dependent and independent variable (Hays, p. 356). Four factors were examined, age, class, sex, urban/rural school location with eight, four, two and two levels respectively. The ANOVA enabled a decision to be made regarding any statistical relation between the dependent variable (VM score) and the independent variables (class, sex, geographic location and age).

The computer program used in the University of Massachusetts Competer Center, is the BMDOIV Analysis of Variance for one way design--Version of May 4, 1965, of the Health Sciences Computing Facility, UCLA, and the BMDO8V Analysis of Variance, version of September 1, 1965 of the Health Sciences 
Computing Facility, UCLA. A hypothesis was considered rejected if the probability associated with the null hypothesis was .05 or less.

\section{$\underline{\text { Summary }}$}

A total of 400 students, selected on a random sampling basis, from classes one to four, both male and female, ranging from age eleven to twenty-two, who are in urban and rural schools, were used in the study. The Attitude Scale and Parts II and IV of the Competence Test of Crites' Career Maturity Inventory were modified because of terminology before being administered to students in groups of thirty. The data was analyzed using an analysis of variance test. 


\section{C $\begin{array}{lllllllllllll} & \text { A } & \text { P } & \text { T } & E & R & \text { I } & \end{array}$}

\section{PRESENTATION OF THE RESULTS}

The results of the data obtained in this investigation of the vocational maturity of students in the East Central state of Nigeria, are presented in this chapter. The purpose of the investigation was to test out on students in the East Central state of Nigeria, the developmental assumption of vocational maturity, on which crites' Career Maturity Inventory (CMI) is based. The assumption is that since vocational maturity increases as an individual grows older, scores on the CMI must be a monotonic function of age and especially grade. In other words, scores must increase or decrease systematically by age and grade in particular. The study also tested if sex and the geographic location of a school, i.e., whether urban or rural location had any effect on the CMI scores. It was also the interest of the researcher to find out if there were significant interactions among the three independent variables: class, sex, and the geographic location of schools and the CMI scores. The dependent variables in this study are a student's score (VM), on the Attitude Scale, on Part II (Knowing about Jobs) and also Part IV (Planning) of the Competence Test of the CMI. The independent variables are class, sex urban/rural 
schools and age. The Attitude Scale yields a total VM score of 50, Part II, a total score of 20 and Part IV a total score of 20. The number of students involved in the study is 400 . The four classes used are classes 1, 2, 3, and 4, with 100 subjects in each class. Sex is represented by two categories with 200 boys and 200 girls included. The geographic location of schools, i.e., urban/rural, has 200 students in each group. Three-hundred and ninty-six students are divided into eight age groups with the sample size for each group indicated in the following brackets. For example, 11-12 year olds are (18), 13 year olds $(28,14$ year olds (64), 15 year olds $(100), 16$ year olds (72), 17 year olds (53), 18 year olds (35) and the 19-22 year group (26).

A three-way analysis of variance with fixed effects (Edwards, p. 301) was used to test the possible relationship between the VM scores on each of the subtests of the CMI studied, and the three independent variables: class, sex, urban/rural schools, as well as for significant interactions. Then a separate one-way analysis of variance was used to test the relationship between VM scores on the Attitude Scale, Part II and IV of the Competence Test of the CMI, and age. Five hypotheses were tested in the null form:

$\mathrm{Ho}_{1}$ There will be no significant difference in the mean vocational maturity scores (VM) of students in Classes 1-4 on the Attitude Scale, Part II (Knowing about Jobs) and IV 
(Planning) of the Competence Test of the Career Maturity Inventory (CMI).

$\mathrm{Ho}_{2}$ There will be no significant difference in the mean vocational maturity scores of students by sex, on the Attitude Scale, Part II and IV of the Competence Test of the CMI.

$\mathrm{Ho}_{3}$ There will be no significant difference in the mean vocational maturity scores (VM) of students in urban and rural schools, on the Attitude Scale, Part II and IV of the Competence Test of the CMI.

$\mathrm{Ho}_{4}$ There will be no significant difference in the mean vocational maturity scores (VM) of students by age group, on the Attitude scale, Part II and IV of the Competence Test of the CMI.

$\mathrm{Ho}_{5}$ There will be no significant interactions between class and sex, class and urban/rural schools, sex and urban/ rural schools, on the Attitude Scale, Part II and IV of the Competence Test of the CMI.

The chapter is divided into three sections. Section I presents the results of the three null hypotheses for the three main effects: class, sex and geographic location of schools, on the Attitude Scale, Parts II and IV of the Competence Test of CMI. The descriptive data and their graphic illustrations, as well as the complete three-way analysis of variance results for each of the CMI subtests are presented consecutively, for maximum clarity and convenience in explaining 
the data. These are followed by a discussion of the results for each of the three hypotheses.

Section II follows a similar pattern, but this time presents the findings for the null hypothesis concerning the effect of age on the three subtests of the CMI.

Finally, section III contains the data and figures representing the results of the null hypothesis regarding the interactions between class and sex, class and geographic lcoation of schools and sex and geographic location of schools.

All $F$ values are tested at the .05 level of confidence. A summary of the findings is presented at the end of each section, then at the end of the chapter the general findings are summarized.

\section{Section I--Hypotheses of the Class, Sex, Geographic Location Main Effects}

Immediately following in section $I$, are a series of six tables and three figures representing the descriptive results for the effect of the three main effects: class, sex, and the geogrpahic location of schools on the Attitude Scale, Part II and IV of the competence Test of the CMI. Tables 8,9 and 10 present the means, the standard deviations and standard errors obtained by class, sex and the geographic Jocation of schools (urban/rural) on the Attitude scale, Part II (Knowing about Jobs) and IV (Planning) of the Competence Test of the CMI. Figures 1,2 and 3 contain graphic representations of the data, and Tables 11,12 and 13 show a 


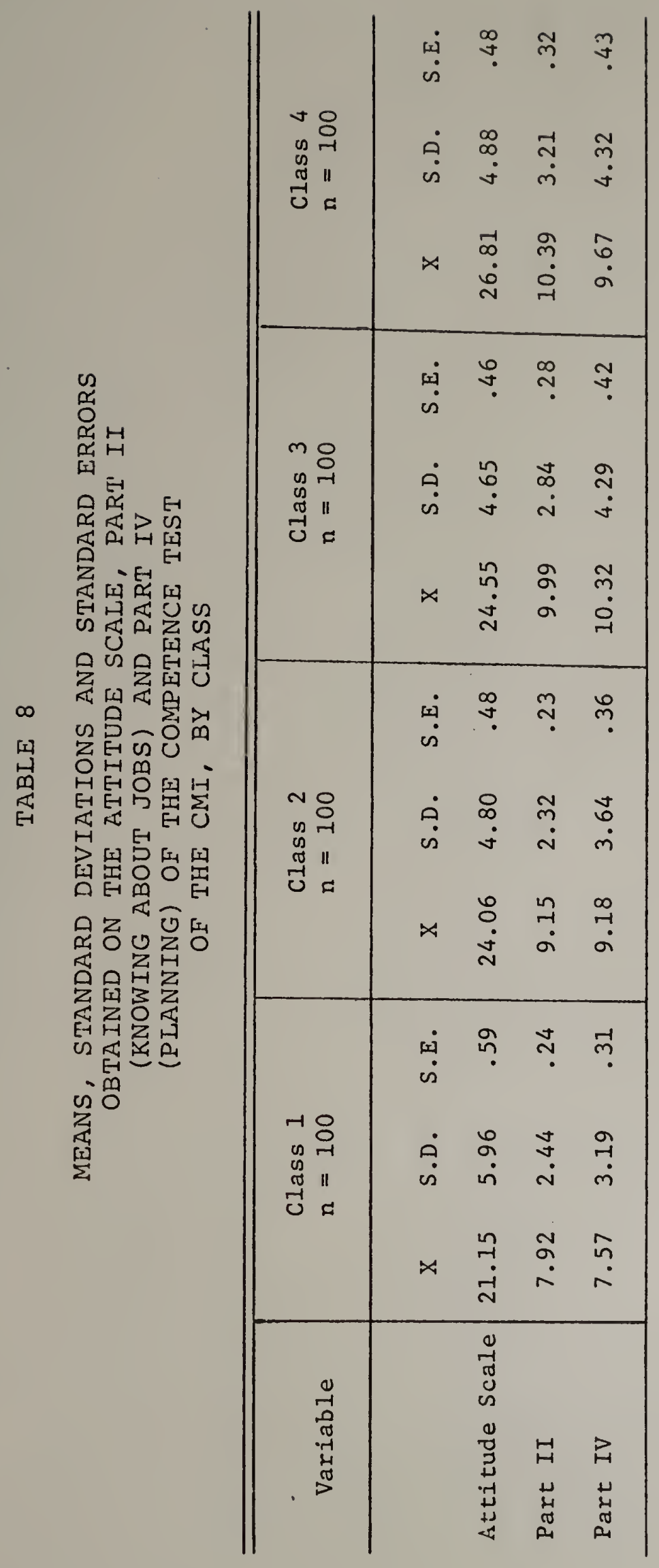


TABLE 9

MEANS, STANDARD DEVIATIONS AND STANDARD ERRORS

OBTAINED ON THE ATTITUDE SCALE, PART II

(KNOWING ABOUT JOBS) AND IV (PLANNING)

OF THE COMPETENCE TEST OF THE CMI, BY SEX

\begin{tabular}{l|rrr|rrr}
\hline \multicolumn{1}{c|}{ Variable } & \multicolumn{3}{|c|}{$\begin{array}{c}\text { Male } \\
\mathrm{n}=200\end{array}$} & \multicolumn{3}{|c}{$\begin{array}{c}\text { Female } \\
\mathrm{n}=200\end{array}$} \\
\hline & $\mathrm{X}$ & S.D. & S.E. & $\mathrm{X}$ & S.D. & S.E. \\
Attitude Scale & 24.89 & 4.77 & .34 & 23.40 & 6. & .42 \\
Part II & 9.82 & 2.73 & .19 & 8.91 & 2.95 & .21 \\
Part IV & 9.20 & 3.74 & .26 & 9.17 & 4.26 & .30 \\
\hline
\end{tabular}


TABLE 10

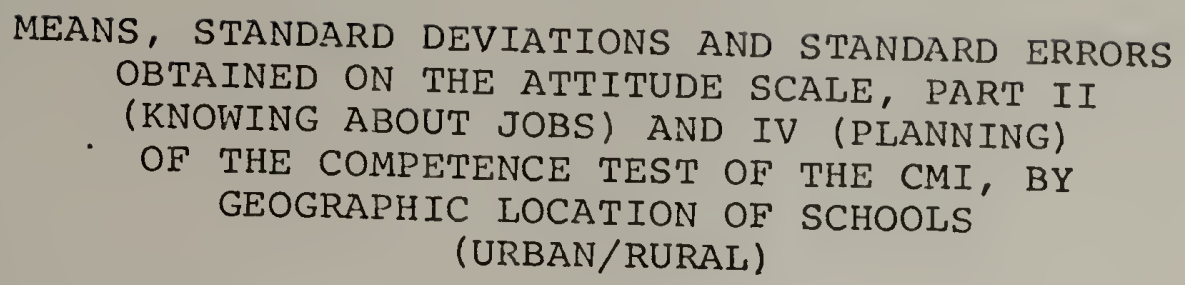

\begin{tabular}{l|rrr|rrr}
\hline \multicolumn{1}{c|}{ Variable } & \multicolumn{3}{|c|}{$\begin{array}{c}\text { Urban } \\
\mathrm{n}=200\end{array}$} & $\mathrm{X}$ & S.D. & \multicolumn{3}{c}{$\begin{array}{c}\text { Rural } \\
\mathrm{n}=200\end{array}$} \\
\hline & 25.14 & 5.55 & .39 & 23.15 & 5.20 & .37 \\
Attitude Scale & 25.99 & 2.89 & .20 & 8.74 & 2.73 & .19 \\
Part II & 10.31 & 4.19 & .29 & 8.07 & 3.49 & .24 \\
Part IV & & & & & & \\
\hline
\end{tabular}


TABLE 11

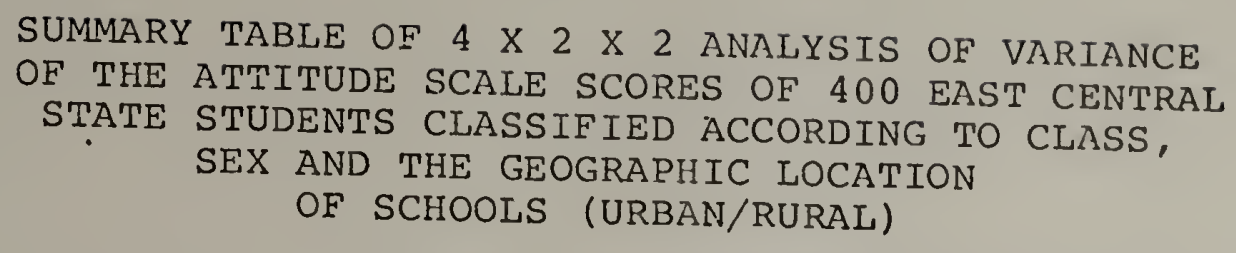

\begin{tabular}{l|r|r|r|c}
\hline \multicolumn{1}{c|}{ Source of Variation } & SS & df & MS & $F$ \\
\hline Class & 1624.35 & 3 & 541.45 & $23.77 * * *$ \\
Sex & 394.02 & 1 & 384.02 & $17.30 * * *$ \\
Geographic Location & 223.50 & 1 & 223.50 & $9.81 * *$ \\
Class X Sex & 213.65 & 3 & 71.22 & $3.13 *$ \\
Class X Geographic & 293.65 & 3 & 97.88 & $4.30 * *$ \\
Location & 340.40 & 1 & 340.40 & $14.94 * *$ \\
Sex X Geographic & 83.31 & 3 & 27.77 & 1.22 \\
Location & 8746.00 & 384 & 22.78 & - \\
Class X Sex X & & & & \\
Within Error Term & & & & \\
\hline
\end{tabular}

$$
\begin{gathered}
{ }^{*} \mathrm{p}<.05 \\
* * \mathrm{p}<.01 \\
* * * \mathrm{p}<.001
\end{gathered}
$$


TABLE 12

SUMMARY TABLE OF $4 \cdot \mathrm{X} 2 \times 2$ ANALYSIS OF VARIANCE

OF THE PART II (KNOWING ABOUT JOBS) SCORES

OF 400 EAST CENTRAL STATE STUDENTS

CLASSIFIED ACCORDING TO CLASS, SEX

AND THE GEOGRAPHIC LOCATION OF

SCHOOLS (URBAN/RURAL)

\begin{tabular}{l|r|r|r|r}
\hline \multicolumn{1}{c|}{ Source of Variation } & \multicolumn{1}{c|}{ SS } & df & \multicolumn{1}{c|}{ MS } & \multicolumn{1}{c}{ F } \\
\hline Class & 357.55 & 3 & 119.18 & $34.64 * * *$ \\
Sex & 155.00 & 1 & 155.00 & $26.96 * * *$ \\
Geographic Location & 89.30 & 1 & 89.30 & $15.53 * * *$ \\
Class X Sex & 118.128 & 3 & 39.38 & $6.85 * * *$ \\
$\begin{array}{l}\text { Class X Geographic } \\
\text { Location }\end{array}$ & 221.99 & 3 & 74.00 & $12.87 * * *$ \\
$\begin{array}{l}\text { Sex X Geographic } \\
\text { Location } \\
\text { Class X Sex X Geo- }\end{array}$ & 128.82 & 1 & 128.82 & $22.40 * * *$ \\
graphic Location & 21.81 & 3 & 7.27 & 1.26 \\
Within Error Term & 2207.84 & 384 & 5.75 & - \\
\hline
\end{tabular}

$$
\begin{gathered}
* p<.05 \\
* * p<.01 \\
* * * p<.001
\end{gathered}
$$


TABLE 13

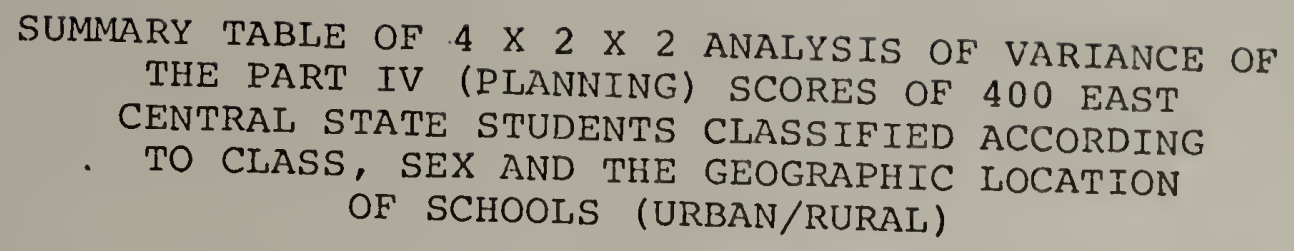

\begin{tabular}{l|r|r|r|r}
\hline \multicolumn{1}{c|}{ Source of Variation } & SS & df & MS & F \\
\hline Class & 413.17 & 3 & 137.72 & $12.35 * * *$ \\
Sex & .2500 & 1 & .2500 & .002 \\
Geographic Location & 501.76 & 1 & 501.76 & $45.00 * * *$ \\
Class X Sex & 204.29 & 3 & 68.10 & $6.11 * * *$ \\
$\begin{array}{l}\text { Class X Geographic } \\
\text { Location }\end{array}$ & 295.94 & 3 & 98.65 & $8.35 * * *$ \\
$\begin{array}{l}\text { Sex X Geographic } \\
\text { Location }\end{array}$ & 645.16 & 1 & 645.16 & $57.86 * * *$ \\
$\begin{array}{l}\text { Class X Sex X Geo- } \\
\text { graphic Location } \\
\text { Within Error Term }\end{array}$ & 65.10 & 3 & 21.70 & 1.95 \\
\hline
\end{tabular}

$$
\begin{gathered}
* p<.05 \\
* * p<.01 \\
* * * p<.001
\end{gathered}
$$




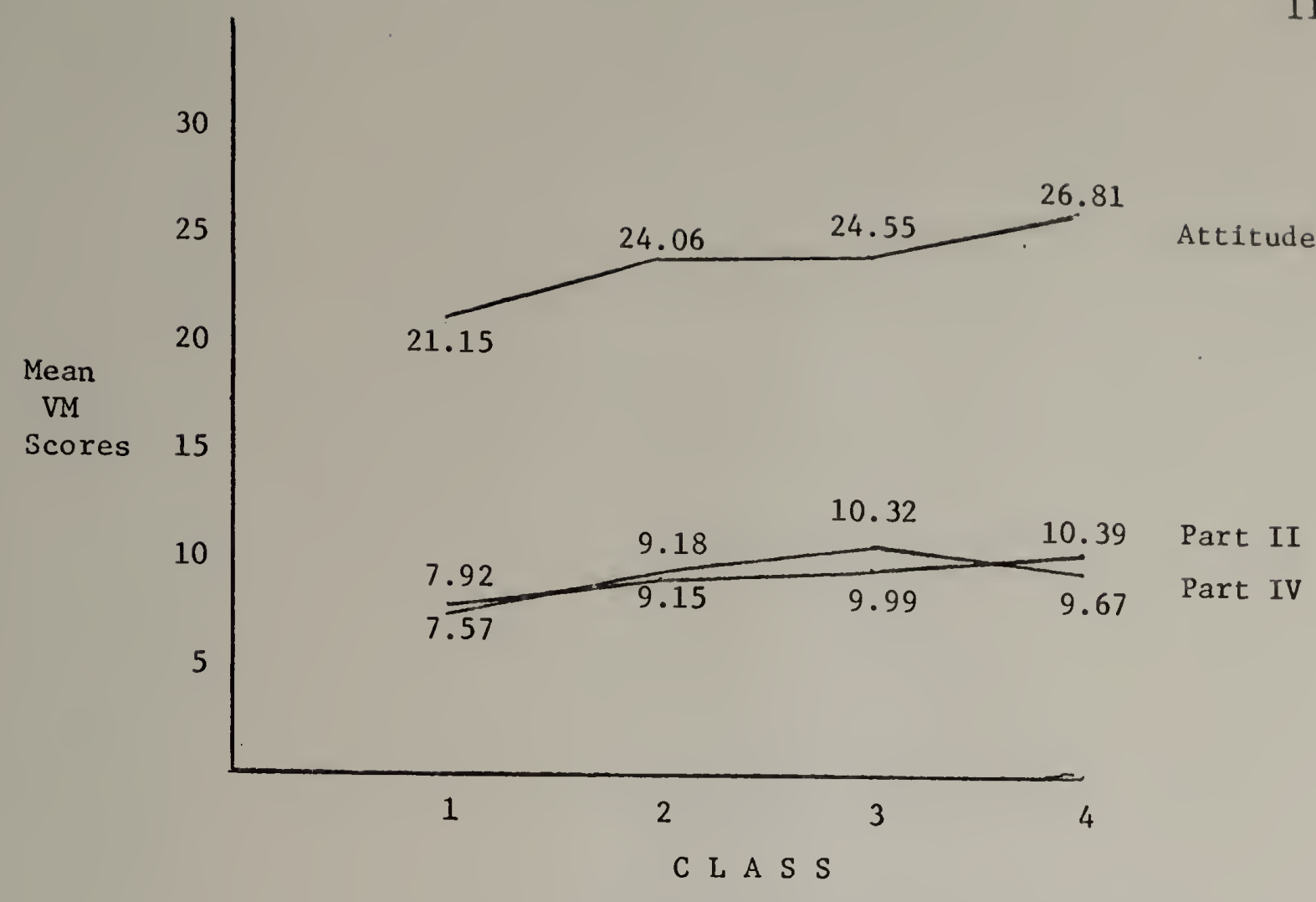

Fig. 1.--Illustrating the means obtained on the Attitude Scale, Part II (Knowing about Jobs) and IV (Planning) subtest of the Competence Test of the CMI, by Class

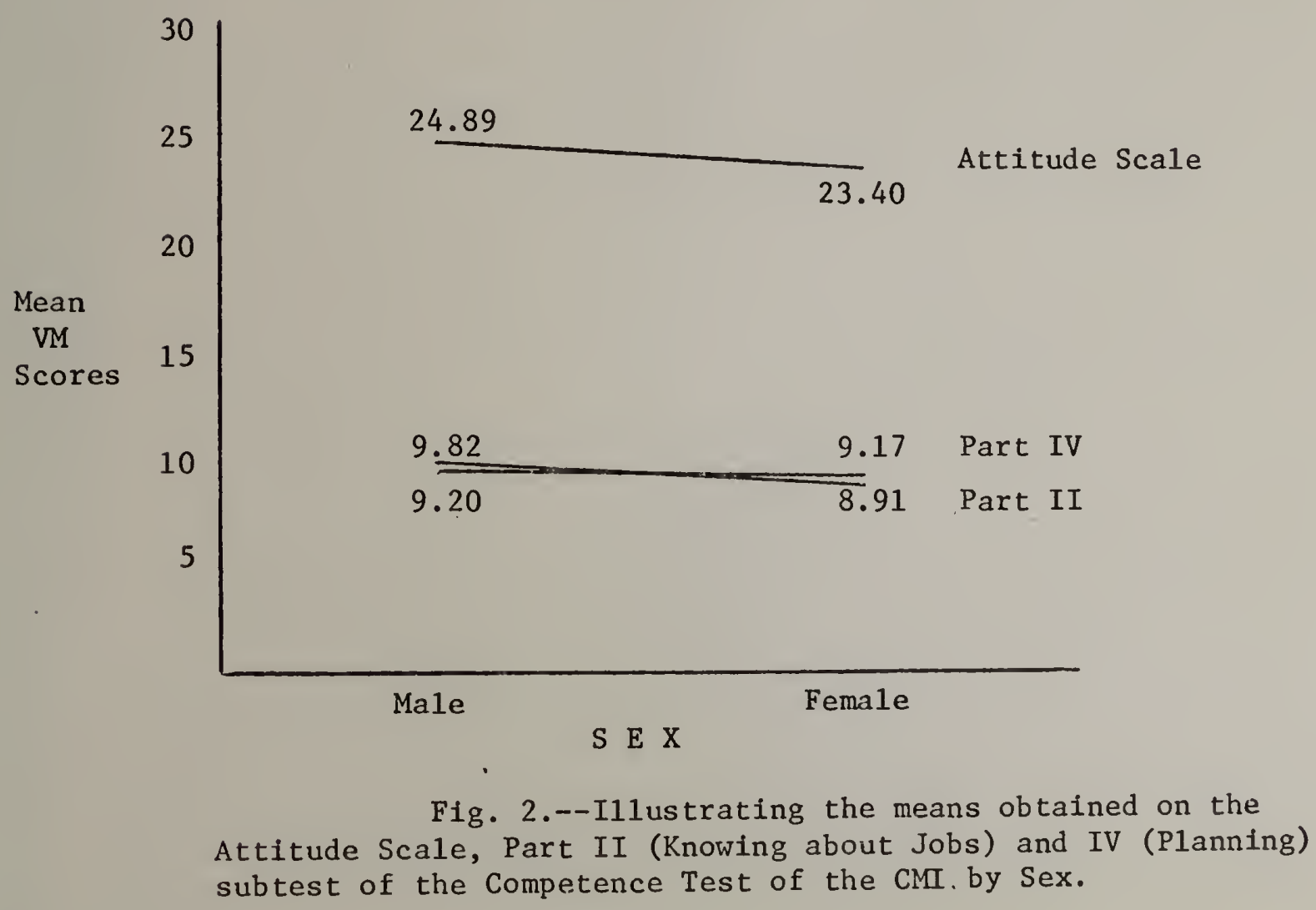




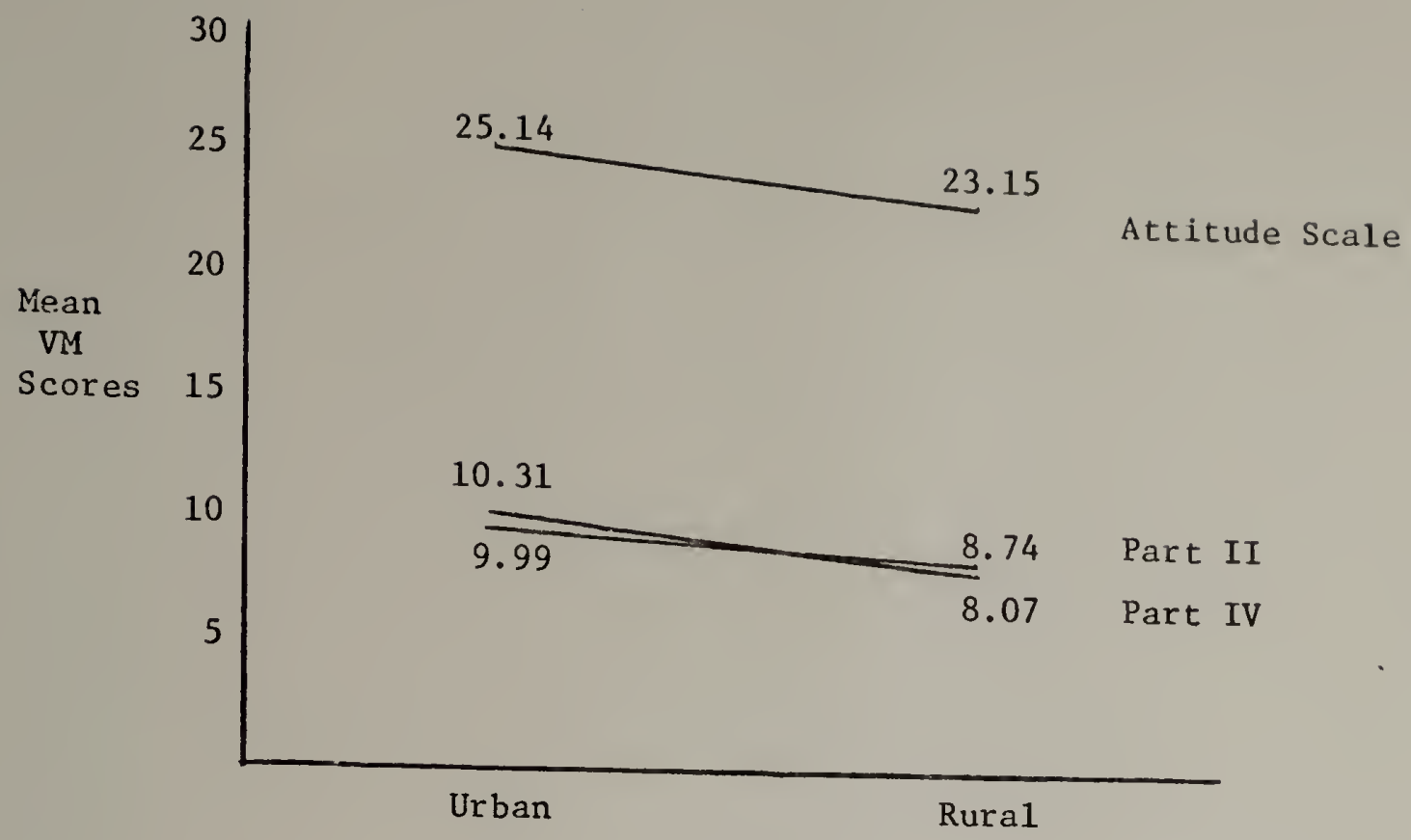

Fig. 3.--Illustrating the means obtained on the Attitude Scale, Part II (Knowing about Jobs) and IV (Planning) subtests of the Competence Test of the CMI by the geographic
location of schools. 
$4 \times 2 \times 2$ complete analysis of variance results for the scores on the Attitude Scale, Part II and IV of the competence Test, of the CMI, in that order.

Analysis of Research Hypotheses 1, 2, 3

In his standardization study of the Attitude scale, Crites found significant differences in scores across grades (classes) but negligible difference between the sexes and schools. On the competence Test, he observed that its demographic descriptors are largely those of a middle class suburban school system. But crites recommends that his CMI can be generalized across schools and sexes. It was necessary to test this conclusion with the ECS students.

Hypothesis 1: The first hypothesis of no difference was for the class variable.

${ }_{1}$ There will be no significant difference in the mean vocational maturity scores (VM) of students in Classes 1-4, on the Attitude Scale, Part II, (Knowing about Jobs) and IV (Planning) of the Competence Test of the CMI.

An examination of Table 8 indicates that the mean VM scores of students increased systematicaily by class (grade) when assessed by the Attitude Scale, and Part II of the Competence Test. The same pattern is almost true of Part IV of the Competence Test, except that a regression was noticed for Class 4 students. Crites noted that the score for his eleventh 
graders was atypical on the Attitude Scale, in the sense that the eleventh grade score was equal to the tenth grade. The atypical behavior of scores was in the present study, noted for Part IV.

Although systematic differences in mean scores by class was noted on all three subtests, the ECS students scored 9 points lower than their American counterparts on the Attitude scale. For example, Class 1 students scored 21.15 S.D. 5.96 while in Crites' study 7 th graders scored 29.21 S.D. 5.55. Class 2 scored 24.06 S.D. 4.80, (8th graders 32.84 S.D. 5.09) Class 3 scored 24.55 S.D. 4.65 and (9th graders, 34.29 S.D. 5.09) Class 4 scored 26.81 S.D. 4.88 and 10 th graders scored 35.31 S.D. 5.28).

The obtained $F$. ratio found in Table 11 , shows a significant difference across classes. For 3 and 200 degrees of freedom, an $F$ of 2.65 is required for significance at the .05 level. With 3 and 400 degrees of freedom an $F$ of 2.62 is needed. Therefore, with 3 and 334 degrees of freedom, the ANOVA test indicates an F. of 23.77 which far exceeds the critical ratio needed for significance. F was significant at the .001 level. Therefore, with $F=23.77(p<.001)$ the hypothesis of no difference by class was rejected for the Attitude Scale.

Systernatic score differences were also observed by class on Part II of the Competence Test of the CMI. An 
inspection of Table 8 indicates that Class 1 students scored 7.92 S.D. 2.44 (7th graders 10.23 S.D. 4.44), Class 2 scored 9.15 S.D. 2.32 (8th graders 11.59 S.D. 4.60), Class 3 scored 9.99 S.D. 2.84 (9th graders 11.35 S.D. 4.32) and Class 4 sccred 10.39 S.D. 3.21 (10th graders 12.23 S.D. 5.04 ). It is interesting to note that the difference between scores for the Nigerian and American samples on Part II of the Competence Test, is only 2 points. Table 12 shows the ANOVA result for Part II. An F of $34.64(\mathrm{p}<.001)$ was obtained. The F value was in excess of that required for significance at the .05 level. Therefore, with 3 and 384 degrees of freedom, an $F=$ $34.64(p<.001)$ means that the hypothesis of no difference on Part II of the competence Test, by class, had to be rejected.

Differences in mean VM scores were also noticed (Table 8) for Part IV of the competence Test of the CMI, by class. Scores increased progressively from classes 1-3, then a regression is noticed in Class Class 1 students scored 7.57 S.D. 3.19 (7th graders 8.73 S.D. 4.74). Class 2 scored 9.18 S.D. 3.64 (8th graders 8.99 S.D. 5.07). Class 3 scored 10.32 S.D. 4.29 (9th graders 8.45 S.D. 5.33) and Class 4 scored 9.67 S.D. 4.32 (10th graders 9.86 S.D. 5.60).

In observing the scores closer, it can be seen that the ECS students in Classes 2 and 3 scored higher than their American counterparts by .19 and 1.76 points respectively. In 
Classes 1 and 4, Crites' sample scored higher by 1.16 and .19 points respectively. Table 13 shows that on Part IV of the Competence Test, the ANOVA result indicates an $\mathrm{F}$ of 12.35 with 3 and 384 degrees of freedom, which was significant at the .001 level. Thus, the hypothesis of no difference by class on Part IV was also rejected.

Thus, for the Attitude Scale, Part II and Part IV of the Competence Test of the CMI, the first hypothesis of no difference in mean vocational maturity scores by class was rejected at the .001 level.

Hypothesis 2: The second hypothesis tested the assumption that there are no differences on the CMI by sex.

$\mathrm{Ho}_{2}$ There will be no significant difference in the mean VM scores of students on the Attitude Scale, Parts II (Knowing about Jobs) and IV (Planning) of the Competence Test of the CMI, by sex.

In an earlier study of the vocational aspirations of secondary school students in the ECS, Achebe (1972) discovered sex differences in job aspirations. For even though girls aspired to high level jobs, they tended to aspire to more middle level jobs than did the boys. The proportion of responses for the middle level category for girls was 8.1 percent as against 2.1 percent for the boys. It was then necessary to check if the CMI, inspite of Crites' finding shows any sex difference. 
A visual inspection of Table 9 shows that on all three tests, but especially marked in the Attitude Scale and Part II of the Competence Test, there were differences between the mean VM scores of boys and girls, in favor of boys. On the Attitude Scale, boys obtained 24.89 S.D. 4.77 as against 23.40 S.D. 6, for girls. On Part II, as well, the boys scored higher with 9.82 S.D. 2.73, while girls scored 8.91 S.D. 2.95. Again, on Part IV, the boys still scored higher, recording 9.20 points S.D. 3.74 as opposed to 9.17 S.D. 4.26 for girls. Figure 2 shows the trend more clearly. The very small difference of .03 between the sexes on Part IV is also obvious from Figure 2.

The ANOVA test indicates an $F$ of $17.30(p<.001)$ on the Attitude Scale, $F=26.96(p<.001)$ for Part II and $F=$ .002 , which was not significant, for Part IV. Since the obtained $F$ values for the Attitude Scale and Part II of the Competence Test were significant beyond the .05 level, the hypothesis was rejected for both subtests. In other words, there is sufficient evidence that differences do exist between the sexes on both tests. However, for $I$ and $384 \mathrm{df}$, the $\mathrm{F}$ of .002 obtained for Part IV did not reach the required level for significance. Thus, the hypothesis of no difference by sex wasn't rejected for Part IV of the Competence Test of the CMI. 
The second hypothesis of no difference by sex on the Attitude Scale, Part II and IV of the Competence Test of the CMI was rejected for the first two subtests and not rejected for Part IV.

Hypothesis 3: Crites indicated that the CMI can be used irrespective of school types or location, a conclusion emphasized especially for the Attitude scale which has been longer used. This assumption was tested with the Nigerian sample.

$\mathrm{HO}_{3}$ There will be no difference in the mean vocational maturity scores of students in urban and rural schools on the Attitude Scale, Part II and IV of the Competence Test of the CMI.

The data in Table 10 shows differences in mean VM scores for students in urban and rural schools on all three subtests of the CMI. On the Attitude Scale, urban students scored higher than their rural counterparts, the former scoring 25.14 S.D. 5.55 while the latter scored 23.15 S.D. 5.20. Figure 3 indicates this differentiation. On Part II (Knowing about Jobs) urban students again scored higher (9.99 S.D. 2.89) than the rural students who scored 8.74 S.D. 2.73. Similar results are evident for Part IV where the urban students still scored higher than the rural students with 10.31 S.D. 4.19 as against 8.07 S.D. 3.49 for rural students. The ANOVA tests 
for the three subtests of the CMI (Tables 11,12 and 13) indicate significant $\mathrm{F}$ ratios for all three. On the Attitude Scale, with 1 and 384 degrees of freedom, the obtained $F$ of 9.81 was significant at the .01 level.

Inspection of Table 12 indicates for Part II an $F=$ 15.53 which, with 1 and 384 degrees of freedom was significant at the .001 level. Table 13 also shows for Part IV an F ratio of 45.00 with 1 and 384 degrees of freedom which was significant at the .001 level. Thus the hypothesis of no mean vocational maturity score differences on the Attitude Scale, parts II and IV of the competence Test of the CMI, by geographic location of schools had to be rejected. This means that significant differences do exist between urban and rural schools on all three subtests of the CMI. Figure 3 shows the slope of the mean scores plotted for each subtest.

\section{Summary of the Three Research Hypotheses Regarding}

Class, Sex and the Geographic Location of Schools: The results of three null hypotheses were presented in section I of this chapter. It was hypothesized that there will be no sifnigicant difference in the mean VM scores on the Attitude Scale, Part II and IV of the Competence Test of the CMI by class, sex and the geographic location of schools. In Tables 11,12 and 13, it can be observed that significant $F$ ratios were obtained on all the three subtests and for nearly all the three independent 
variables except sex, which was found not to have any effect on scores for the Part IV of the CMI.

Therefore, all the three hypotheses were rejected except for the hypotheses of no difference by sex on Part IV of the Competence Test of the CMI, which was not rejected.

\section{Section II--Hypothesi"s of the Age Variable}

Result of the Null Hypothesis for the Attitude Scale, Part II and IV of the Competence Test of the CMI, by Age

This second section of the result chapter presents the results of the fourth hypothesis of no difference by age group, on the Attitude scale, Part II and IV of the competence Test of the CMI.

In his standardization study, Crites found that on the Attitude scale, verbal vocational behaviors were monotonically related to both grade and age during adolescence, but were more frequently associated with the former than with the latter. Moreoever, grade had a higher correlation with VM scores, i.e., $r=.463$; than age which was $r=.385$. He thus decided that since grade was found to yield greater differentiation than age the former "was consequently chosen as the index of time in all subsequent analyses" (Crites, 1973).

Hypothesis 4: It was the interest of the researcher to test if VM score was a monotonic function of age, as well. The hypothesis tested was: 
${ }_{4}{ }_{4}$ There will be no significant difference in the mean vocational maturity scores of students by age group, on the Attitude Scale, Part II (Knowing about Jobs) and IV (Planning) of the Competence Test of the CMI.

All the descriptive data are first presented, followed by a discussion of the results. Table 14 presents the VM scores, the standard deviations and standard errors obtained on the Attitude Scale, Part II and IV of the Competence Test of the CMI. Tables 15, 16 and 17 present the separate one way analysis of variance results for each of the subtests and Figures 4,5 and 6 give graphic representations of the relevant data. The descriptive data follows, starting with Table 14.

Analysis of the Result of the Hypothesis of No Difference on the Attitude Scale Part II and IV of the Competence Test, By Age Group

An examination of Table 14 indicates differences in scores on all three subtests, by age group. However, no consistent pattern is evident. Rather what emerges is evidence of "slips backwards and steps forwards."

For example, on the Attitude Scale, the 11-12 year group starts with a mean VM score of 23 followed by a VM score of 26.6 for the 13 year olds, i.e., a difference of 3.6 in an upward direction for the latter. The 14 year olds, however, then register a lower mean (23.9) than the 13 year 


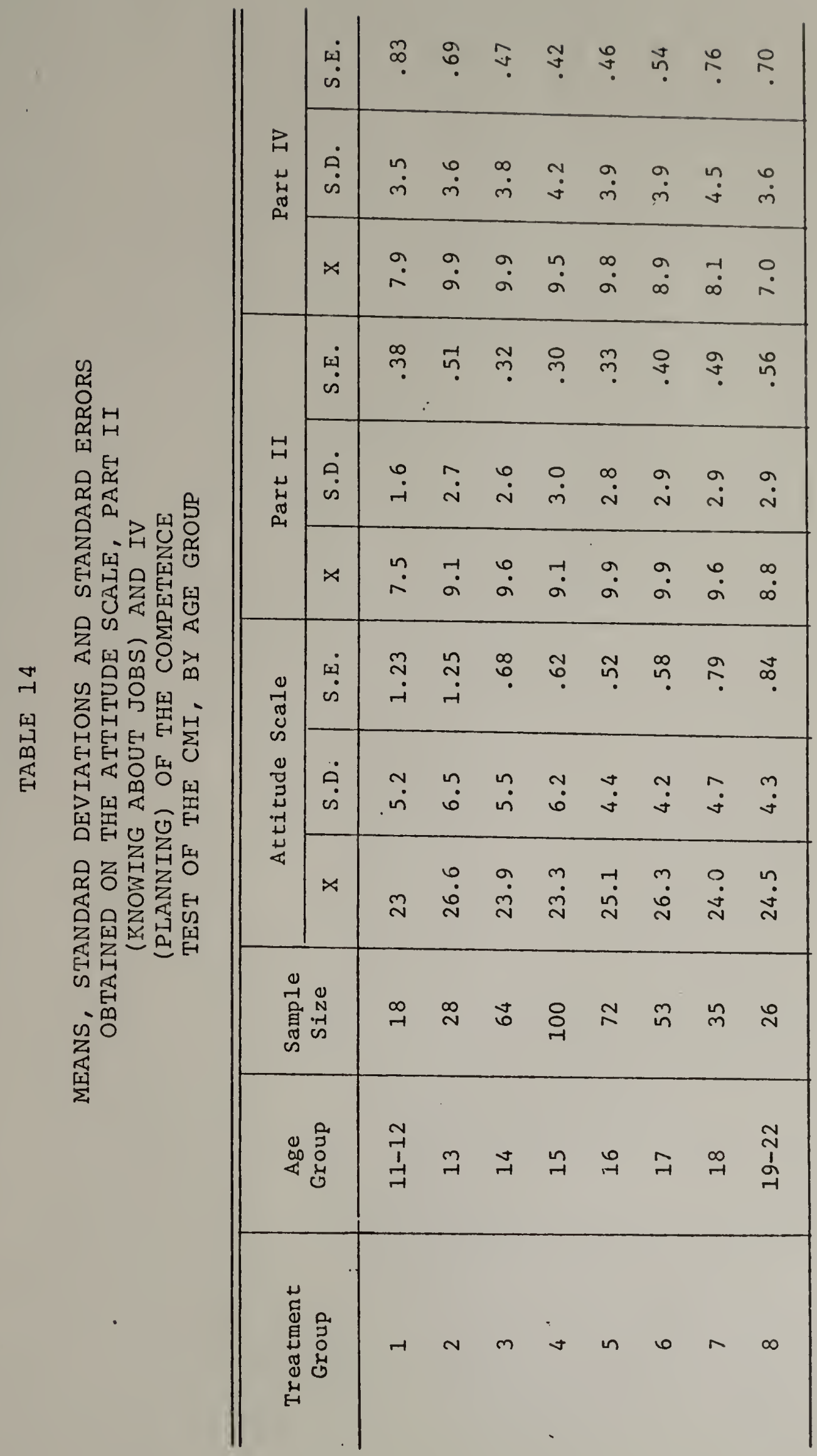


TABLE 15

SUMMARY TABLE OF A 1 X 8 ANALYSIS OF VARIANCE

OF THE ATTITUDE TEST SCORES OF 396

EAST CENTRAL STUDENTS CLASSIFIED ACCORDING TO AGE GROUP

\begin{tabular}{l|r|r|r|r}
\hline Source of Variation & \multicolumn{1}{|c|}{ SS } & df & MS & F \\
\hline Between Groups & 458.4897 & 7 & 65.4985 & $2.3254 *$ \\
Within Groups & 10928.5078 & 388 & 28.1663 & \\
Total & 11386.9975 & & & \\
\hline
\end{tabular}

${ }^{*} \mathrm{p}<.05$ 
TABLE 16
SUMMARY TABLE OF A 1 X 8 ANALYSIS OF VARIANCE
OF THE PART II (KNOWING ABOUT JOBS) SCORES OF 396 EAST CENTRAL STATE STUDENTS
CLASSIFIED ACCORDING TO AGE GROUP

\begin{tabular}{l|r|r|r|c}
\hline Source of Variation & SS & df & MS & F \\
\hline Between Groups & 116.6515 & 7 & 16.6645 & $2.0549 *$ \\
Within Groups & 3146.5303 & 388 & 8.1096 & \\
Total & 3263.1818 & & & \\
\hline$* \mathrm{P}<.05$ & & & &
\end{tabular}


TA.BLE 17

SUMMARY TABLE OF A 1 X 3 ANALYSIS OF VARIANCE

OF THE PART IV (PLANNING) SCORES OF 396

EAST CENTRAL STATE STUDENTS CLASSIFIED ACCORDING TO AGE GROUP

\begin{tabular}{l|r|r|r|r}
\hline Source of Variation & SS & df & MS & F \\
\hline Between Groups & 270.2967 & 7 & 38.6138 & $2.4665^{*}$ \\
Within Groups & 6074.3397 & 388 & 15.6555 & \\
Total & 6344.6364 & & & \\
\hline
\end{tabular}

${ }^{*} p<.05$ 


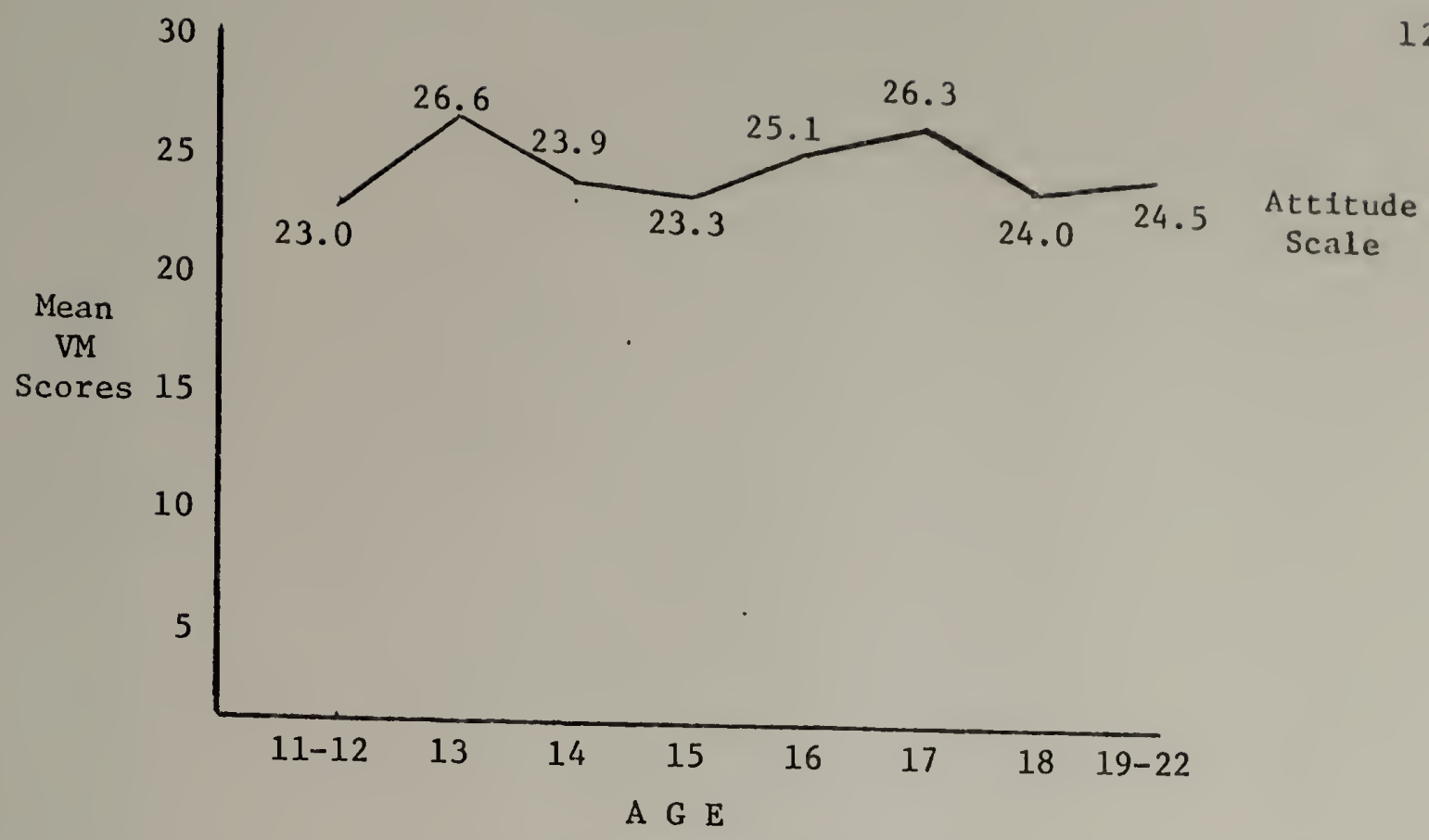

Fig. 4.--Illustrating the means obtained on the Attitude scale of the CMI by age group.

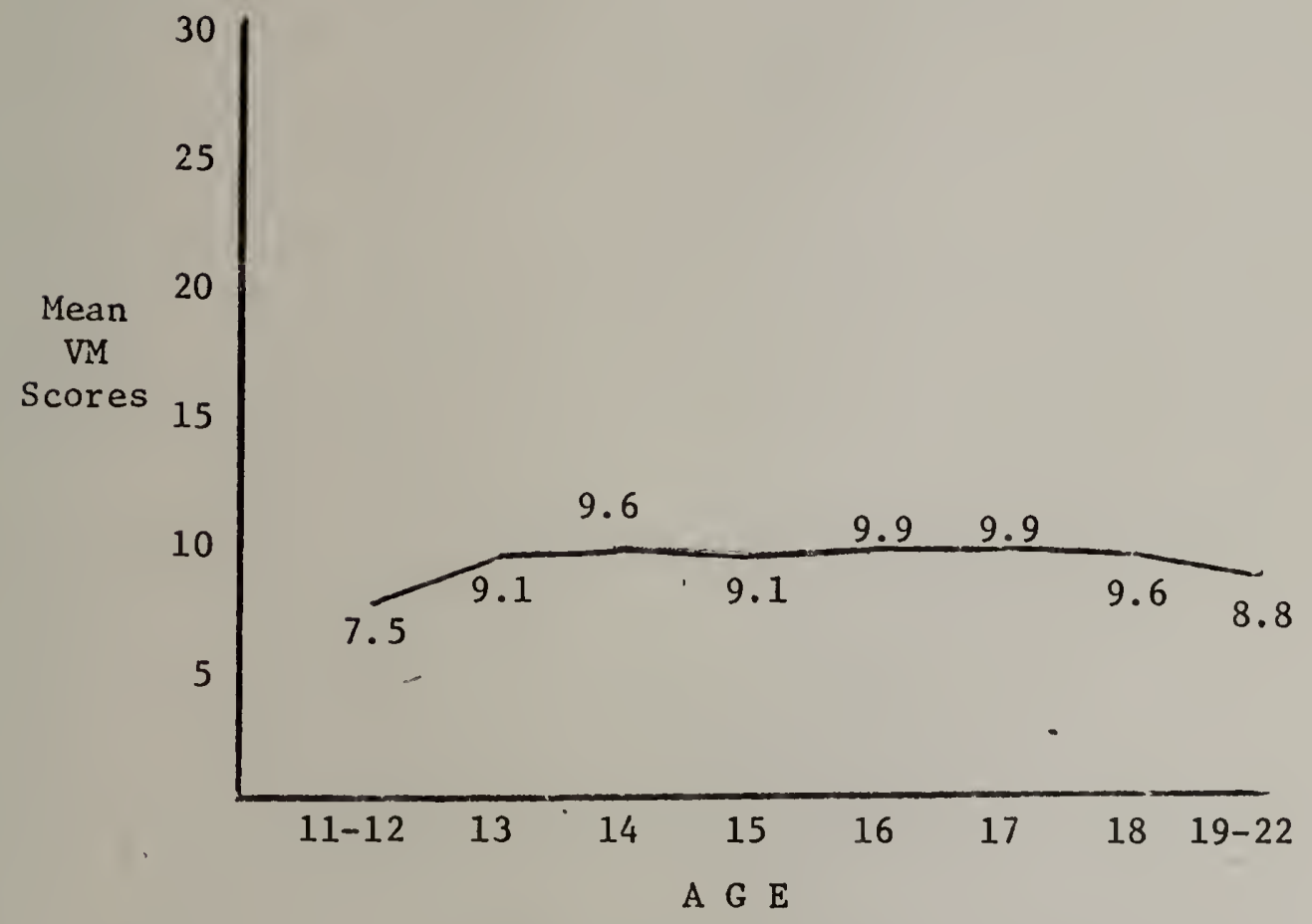

Fig. 5--Illustrating the means obtained on Part II (Knowing about Jobs) subtest of the Competence Test of the CMI by age group. 


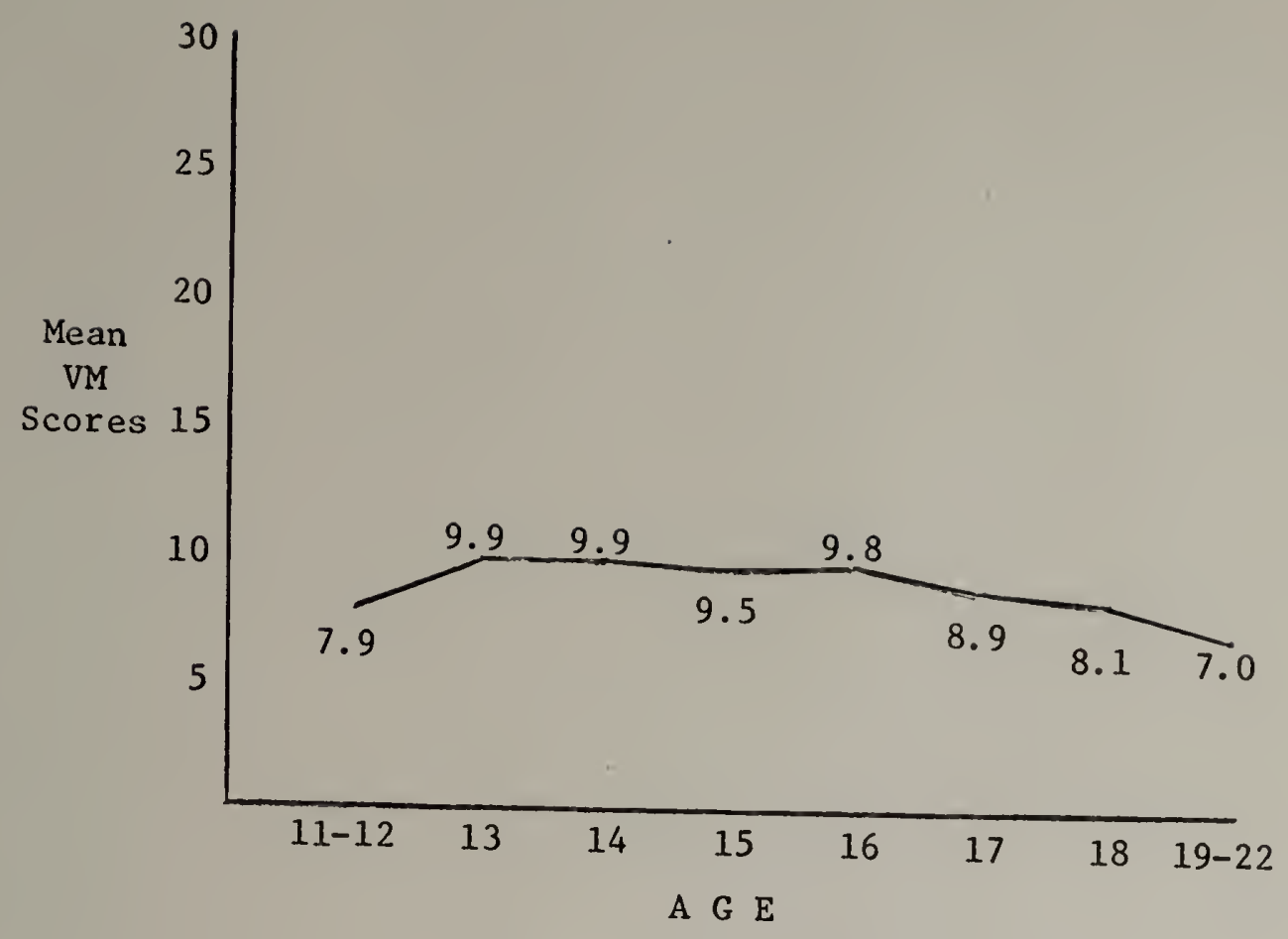

Fig. 6.--Illustrating the means obtained on Part IV (Planning) subtest, of the Competence Test of the CMI by
age group. 
olds and the 15 year olds also score lower (23.3) than the 14 year old group. Rather than a continuing "slip backwards" which was beginning to emerge, the scores once more begin to rise gradually from 25.1 for the 16 year olds to 26.3 for the 17 year olds. At this point, another regression is noticed for the 18 year olds who score $24.0,2.3$ points lower, than the 17 year group and then a slight rise (24.5) for the 19-22 age bracket occurs.

The same irregular pattern can be observed for Part II of the Competence Test. In this case, the mean begins by rising from 7.5 for the $11-12$ year group to 9.1 and then to 9.6 for the 13 and 14 year olds respectively. Then a drop to 9.1 occurs for the 15 year olds, followed by a rise to 9.9 for the 16 year group. This remains constant for the 17 year group (9.9). However, scores begin to drop again to 9.6 for the 18 year olds and further still to 8.8 for the 19-22 year group.

Though there were differentiations on Part IV (Planning) of the Competence Test, the results are equally erratic. Mean scores start with 7.9 for the 11-12 year olds, then increase to 9.9, remaining at that level for both the 13 and 14 year olds, then drop to 9.5 for the 15 year group and then rise once more to 9.8 for the 16 year group. Then a consistent decrease in scores begins to be noticed, starting with 8.9 for the 17 year olds; to 8.1 for the 18 year group and then 
7.0 for the 19-22 year bracket. Figures 4, 5 and 6 plot the irregular differentiation observed on the three subtests.

An inspection of Tables 15,16 and 17 show that with

7 and 388 degrees of freedom, $F$ values of $2.3254,2.0549$ and 2.4665 were significant at the .05 level, for the Attitude Scale, Part II and IV of the Competence Test of the CMI, in that order. With 7 and 200 degrees of freedom an F of 2.05 is required for rejection at the .05 level. For 7 and 400 degrees of freedom, an $F$ of 2.03 is needed. Therefore, for 7 and 388 degrees of freedom, the F's of $2.3254,2.0549$ and 2.4665 obtained on the Attitude Scale, Part II and IV of the Competence Test respectively, are significant at only the .05 level, indicating a border line effect. However all F's were significant at the .05 level and so the hypothesis of no difference in mean VM score by age group, on the Attitude scale, Part II and IV of the Competence Test of the CMI, was rejected. In other words, there is some indication of significant differentiation by age on the CMI score even though the differentiation appears less marked by age than grade.

Summary: The fourth fypothesis of no difference in mean VM scores by age on the Attitude Scale, Part II and IV of the Competence Test of the CMI was rejected. $F^{\prime} \mathrm{S}$ of 2.3254 , 2.0549 and 2.4665 obtained on the Attitude Scale, Part II and IV of the Competence Test in that order, were barely significant at the .05 level of confidence. 


\section{Section III--Hypothesis of Interactions}

Analysis of Research Hypothesis Regarding Interactions among the Subtests of CMI

This section examines the results of the fifth null hypothesis regarding the interaction between the three main effects, class, sex and the geographic location of schools. It was necessary to find out if there was any functional relationship among the dependent variables, i.e., scores on the Attitude Scale, Part II and IV of the Competence Test, and the combined interaction of the three independent variables. The hypothesis was tested in the null.

Hypothesis 5 :

$\mathrm{Ho}_{5}$ There will be no significant interaction between class sex, class and the geographic location of schools, sex and the geographic location of schools on the Attitude scale, Part II (Knowing about Jobs) and IV (Planning) of the Competence Test of the CMI.

For better clarity and understanding of the interactions, this section will be further subdivided into four smaller sections. Each subdivision will deal with the result of the interaction between each combination of factors and each independent variable. Three first order interactions (Popham, p. 197-200) were tested, i.e., interactions between Class X Sex, Class X Geographic location of schools, Sex X Geographic 
location of schools. Then a fourth second order interaction is examined, i.e., interaction among the three main effects; class, sex and the geographic location of schools.

The results are presented in the following order. First appears the result for the interaction between class $\mathrm{x}$ Sex. This is followed by the results for the interaction between Class $x$ Geographic Location of Schools, and then, that for the third interaction between Sex $x$ Geographic Location of Schools. Finally, the result for the second order interaction between Class $\mathrm{X}$ Sex X Geographic Location of Schools is presented.

Interaction Between Class $x$ Sex on the Attitude Scale, Part II (Knowing about Jobs) and Part IV (Planning) of the Competence Test of the CMI: The results of the first order interaction between Class $\mathrm{x}$ Sex on the Attituade Scale, Part II and IV of the Competence Test of the CMI follows. The $\mathrm{F}$ ratios obtained for the class $\mathrm{X}$ Sex interaction on the Attitude Scale can be found in Table 11. Table 12 contains the analysis of variance $F$ ratio for Part II and the F ratio for Part IV is in Table 13. The graphic representations of the means reflecting the presence of an interaction follows immediately, in Figures 7,8 and 9.

An examination of the three Figures 7,8 and 9 show evidence of marked crossing of lines as opposed to paraliel lines. An absence of parallel lines is a clear evidence of 


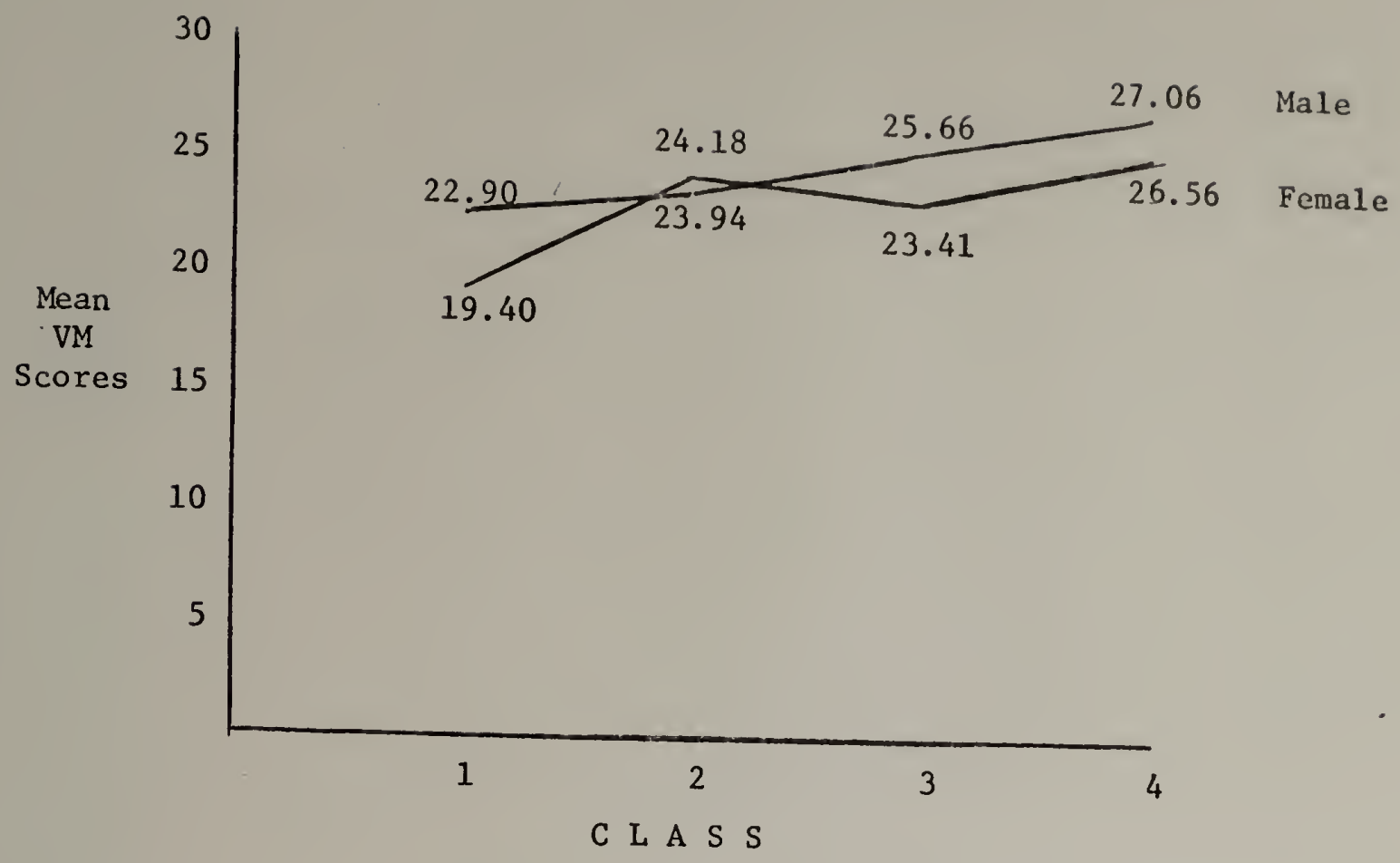

Fig. 7.--Illustrating the interaction between Class and Sex on the Attitude Scale of the CMI.

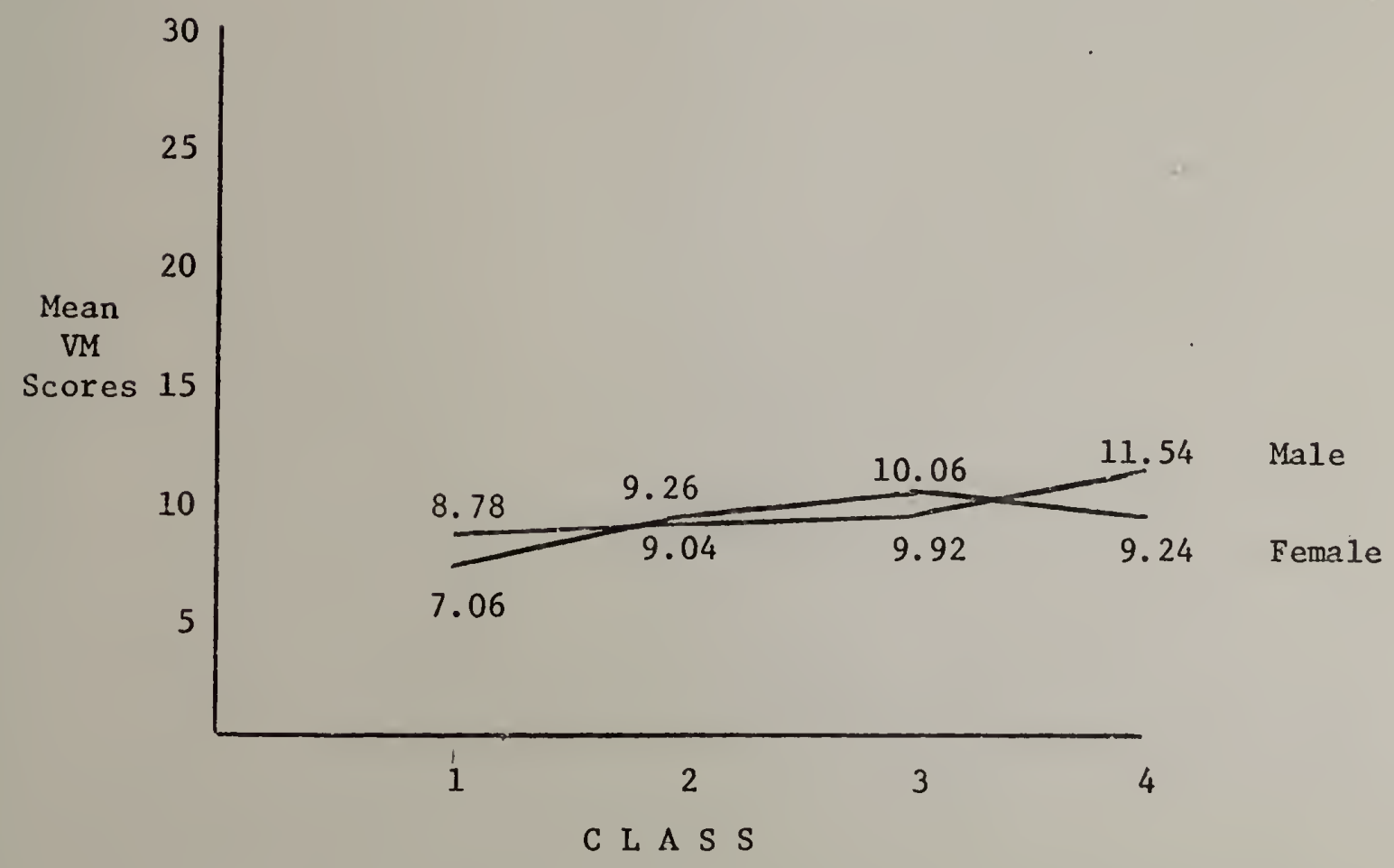

Fig. 8.--Illustrating the interaction between Class and Sex on Part II (Knowing about Jobs) of the Competence Test of the CMI. 


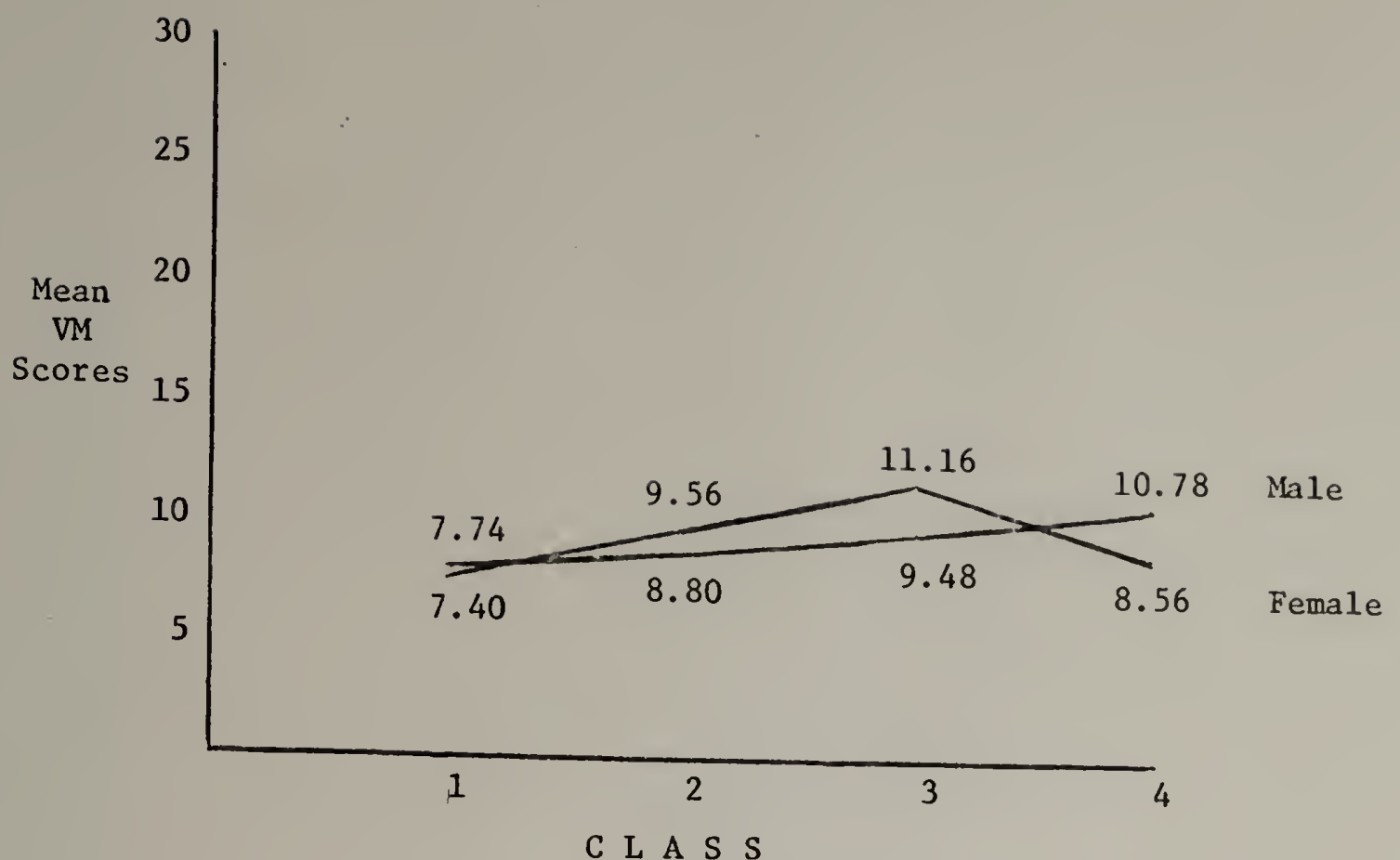

Fig. 9.--Illustrating the interaction between Class and Sex on Part IV (Planning) subtest of the Competence Test of the CMI. 
the presence of interaction effects (Edwards, p. 186).

Figure 7 shows that on the Attitude Scale, in Class 1. girls score lower (19.40) than boys (22.90). In Class 2 however, the VM scores of girls, exceed (24.18) that for boys (23.94). Then in class 3, the girls drop to 23.41 while boys score 25.66, thus overtaking the girls. The boys continue to maintain their lead in Class 4 (27.06) while the girls still lag behind boys (26.56). In short, the pattern of scores for boys and girls is not parallel when their classes are considered.

For there to be a functional relationship between scores on the Attitude scale and the combined interaction between class and sex, a critical ratio approximating 2.63 is required for rejection of the null hypothesis at the .05 level. The obtained $F$ ratio of 3.13 with 3 and 384 degrees of freedom noticed in Table 11 for the interaction between class by Sex is significant at the .05 level. The hypothesis of no interaction between the effect of class and sex on the Attitude scale of the CMI was therefore rejected. In other words, there is a relationship between a student's performance on the Attitude Scale and his class and sex.

An inspection of Table 12 indicates an $F$ of 6.85 with 3 and 384 degrees of freedom which was significant at the .001 level for the interaction between class and sex on Part II (Knowing about Jobs) of the CMI. This value also exceeds 
that required for significance at the set level of .05. For Part II therefore, the hypothesis of no interaction was rejected. Evidence thus exists of a relationship between scores on Part II of the competence Test and the combination of Class X Sex.

The nature of this interaction can be explored in Figure 8 which shows a marked crossing of lines for the males and females at each class level. Class 1 girls score lower (7.06) than their male counter parts (8.78). But in Class 2, the score for girls (9.26) exceeds that for boys (9.04). Girls continue to lead in Class 3 with 10.06 as opposed to 9.92 for boys. However, in class 4, girls suddenly drop to 9.24 to be outstripped by boys (11.54). Here again the lack of parallel lines clearly indicates the presence of an interaction.

As indicated on examination of Figure 9, the lack of parallel lines once more suggests the presence of an interaction. On Part IV of the Competence Test, Class 1 girls again begin by scoring lower (7.40) than the boys (7.74). However, in Classes 2 and 3 , the girls pick up, scoring much higher than the boys. Girls register in Class 2, a mean VM score of 9.56 as opposed to 8.80 for boys. In Class 4 however, the score for girls (8.56) characteristically drops much below that for boys (10.78). 
Table 13 further shows a significant $F$ value on the ANOVA test. With 3 and 384 degrees of freedom, the obtained F of 6.11 was significant at the .001 level. Therefore the hypothesis of no difference was rejected. There is evidently an appreciable relationship between Class $X$ Sex on performance on Part IV (Planning) subtest of the competence Test.

Summary for the class $x$ Sex Interaction: The results from Tables 11,12 and 13 as well as from Figures 7,8 and 9 indicate the presence of an interaction effect between class $X$ Sex on the Attitude Scale, Part II and IV of the Competence Test of the CMI. All obtained $F$ ratios of 3.13, 6.85 and 6.11 with 3 and 384 degrees of freedom were significant. The F ratio of 3.13 obtained on the Attitude Scale was significant at the .05 level. For Part II of the Competence Test, the $F$ of 6.85 was significant at the .001 level so also was the $F$ of 6.11 obtained on Part IV of the competence Test. Since all F's were significant, and there was an absence of parallel lines in the graphic representation of the data, the hypothesis of no interaction between class $x$ Sex on the Attitude Scale, Part II and IV of the Competence Test was rejected.

Interaction Between Class X Geographic Location of Schools (Urban/Rural on the Attitude Scale, Part II (Knowing about Jobs) and IV (Planning) of the competence Test of the CMI: The result of another first order interaction, this 
time between Class and the Geographic Location of Schools on the three subtests, is presented in this section. F ratios resulting from the ANOVA for this interaction can be seen in Tables 11, 12 and 13 and Figures 10, 11 and 12, which follow immediately, show the trend for the obtained means.

Figure 10 and Table 11 contain the data for the interaction between Class $x$ Urban/Rural students on the Attitude scale. The pattern of means observed in Figure 10 indicates that Class 1 urban students start off by scoring lower (20.72) than rural students (21.58). However, from Class 2 urban students pick up with 25.24 against the mean of 22.88 scored by rural students. Urban students maintain this lead in Class 3 (25.92 against 23.18 for rural students) through to Class 4 where they score 28.66 while their rural counterparts score 24.96. Once again, the lines are not parallel which suggests the presence of interaction effect. The obtained F of 4.30 with 3 and 384 degrees of freedom observed in Table 11 is sigrificant at the .0l level of confidence. Thus the hypothesis of no interaction between Class and Urban/Rural Schools on the Attitude scale of the CMI is rejected.

Figure 11 and Table 12 contain the results of the interaction between Class and Urban/Rural Schools on Part II of the Competence Test of the CMI. The pattern of interaction is almost similar to that observed for the Attitude Scale. Urban students in Class 1 start off again by scoring 


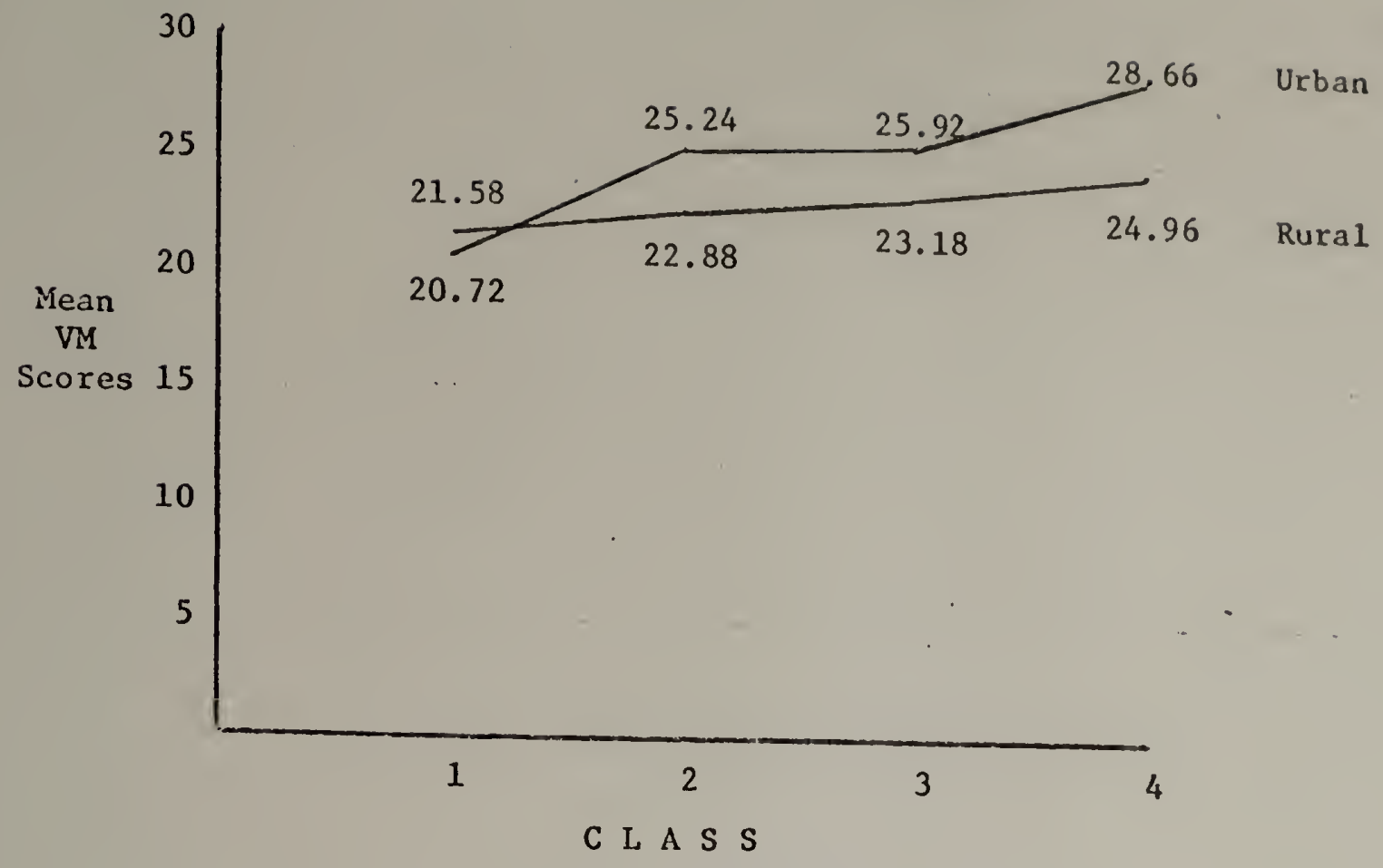

Fig. 10.--Illustrating the interaction between Class and Urban/Rural Schools on the Attitude Scale of the CMI.

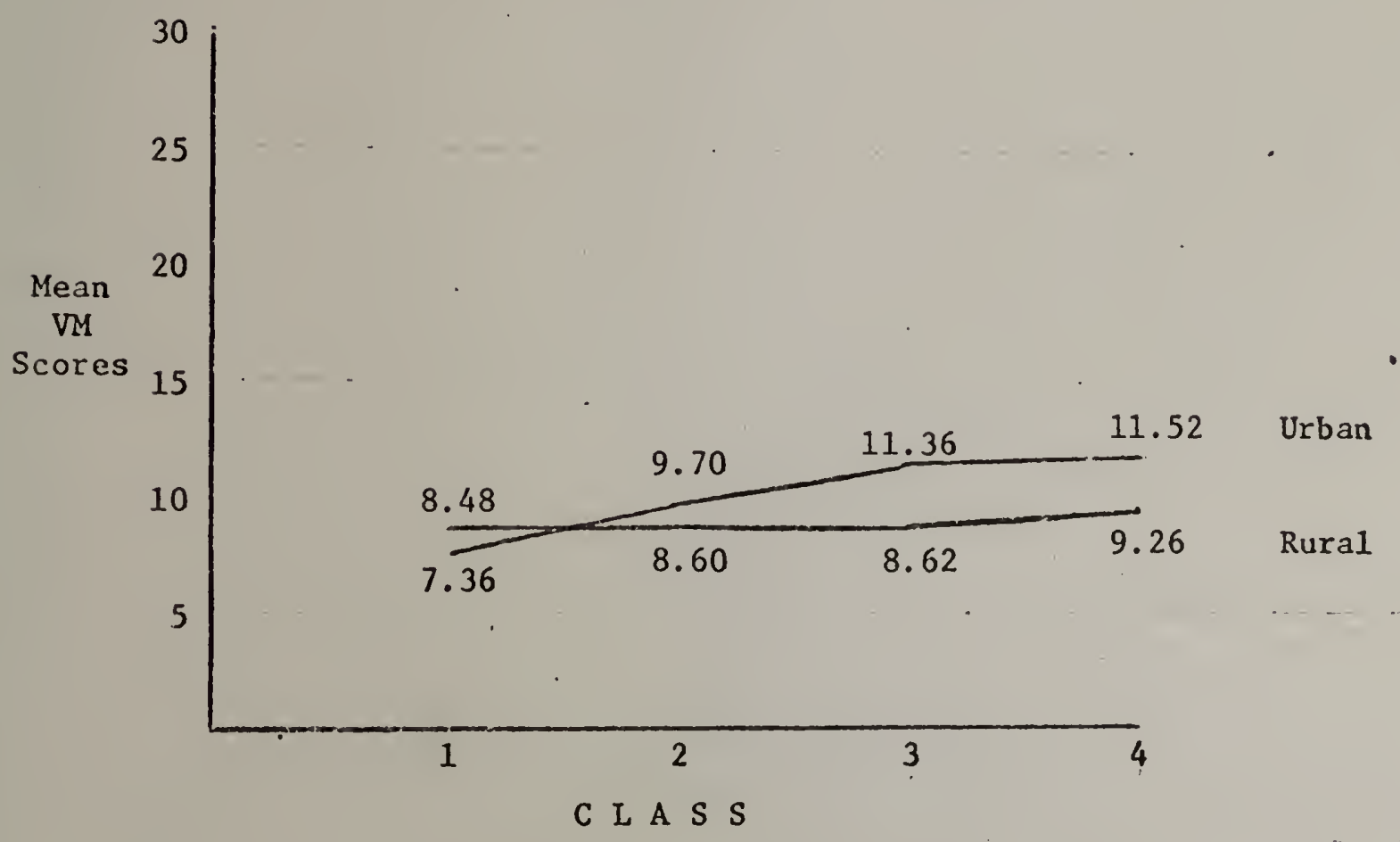

Fig. 11.--Illustrating the interaction between Class and Urban/Kural Schools on Part II (Knowing about Jobs) subtest of the Competence Test of the CMI. 


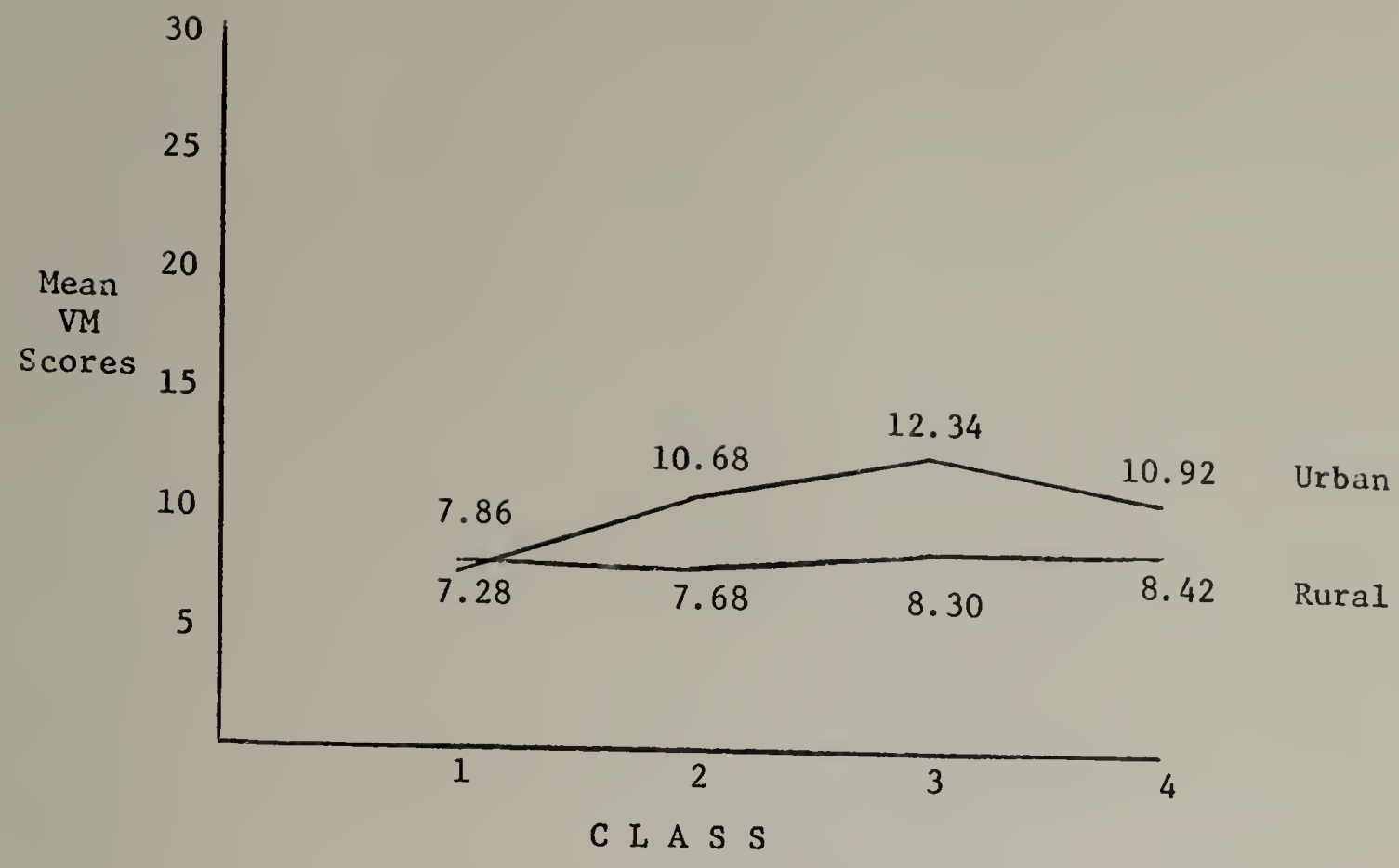

Fig. 12.--Illustrating the interaction between Class and Urban/Rural Schools on Part IV (Planning) subtest of the Competence Test of the CMI. 
lower (7.36) than their rural counterparts (8.48). But in Class 2 urban students score higher (9.70) than rural students (8.60). This increase is maintained through Class 4, where urban students score 11.52 and rural students 9.26. Here again the lines are not parallel, thus suggesting an interaction effect.

the ANOVA test (Table 12) indicates that an $F$ of 12.87 with 3 and 384 degrees of freedom was obtained. This is in excess of the value of 2.65 needed for rejection at the .05 level of confidence. Therefore, the hypothesis of no interaction between Class and Urban/Rural Schools on Part II of the Competence Test of the CMI had to be rejected. Graphically, too, we see that a significant interaction shows the failure of the two lines in Figure 11 to be parallel within the limits of random sampling.

Figure 12 and Table 13 contain the ANOVA result for the interaction between Class and Urban/Rural Schools on Part IV of the Competence Test of the CMI. Table 13 indicates an obtained $F$ of 8.85 with 3 , and 384 degrees of freedom. With 3 and 200 degrees of freedom, F's of 2.65 and 3.88 are needed for significance at the .05 and .01 levels respectively. And for 3 and 400 degrees of freedom, F's of 2.62 and 3.83 are required for significance at the .05 and .01 levels in that order. Thus the obtained $F$ of 8.85 with 3 and 384 degrees of freedom far exceeds the expected value for rejecting the 
the null hypothesis. So the hypothesis of no interaction between Class and Urban/Rural Schools is rejected at the .001 level, for Part IV of the $\mathrm{C}$ ompetence Test.

Examining Figure 12, we observe further that the pattern of the lines are not parallel. Urban Class 1 students start off as usual with a lower VM score (7.28) than rural students $(7.86)$. But by Class 2 , urban students had overtaken (10.68) their rural counterparts (7.68). In Class 3, urban students' VM scores continue to accelerate (12.34) while the rural students continue to score lower (8.30). In Class 4, urban students still score higher (10.92) than their rural counterparts (8.42) although the urban class 4 score is now lower than the scores for the urban Class 3 students.

The hypothesis of no interaction between Class and the Geographic Location of Schools on the Attitude scale, Part II and IV of the Competence Test of the CMI was rejected. On the Attitude Scale, the obtained $F$ ratio of 4.30 with 3 and 384 degrees of freedom was significant at the .01 level. For Part II, the F of 12.87 with 3 and 384 degrees of freedom was also significant this time at the .001 level. The same was true of Part IV where the obtained $F$ of 8.85 was significant at the .001 level. On all the three subtests of the CMI therefore, there appears a clear evidence of a functional relationship between Class and the Geographic Location of Schools and performance on the Attitude Scale, Part II and IV of the Competence Test of the CMI. 
Interaction Between Sex $x$ Geographic Jocation of Schools on the Attitude Scale, Part II and IV of the Competence Test of the CMI: The results for the third, first order interaction, i.e, between sex and the geographic location of schools on the Attitude Scale, Part II and IV of the competence Test of the CMI are presented in Tables 11,12 and 13 and also in Figures 13, 14 and 15. Table 11 and Figure 13 show the results for the Attitude Scale. Table 12 and Figure 14 indicate the findings for Part II of the Competence Test while Table 13 and Figure 15 contain the results for Part IV of the Competence Test.

The three Figures 13, 14 and 15 are presented sequentially, and the results for each of the subtests follow, beginning first with the Attitude Scale, then Part II and Part IV. Figures 13, 14 and 15 follow.

The result for the interaction between sex and Geographic Location of Schools on the Attitude scale is now as follows. Data is from Table 11 and Figure 13. Figure 13 indicates that in urban schools, girls score higher (25.39) than boys (24.88). However, in rural schools, the reverse is the case with boys scoring 24.82 as opposed to 21.48 for girls. Urban females seem to score higher than both the urban and rural males, as well as their rural sisters, and rural females score lower than boys in both urban and rural schools. 


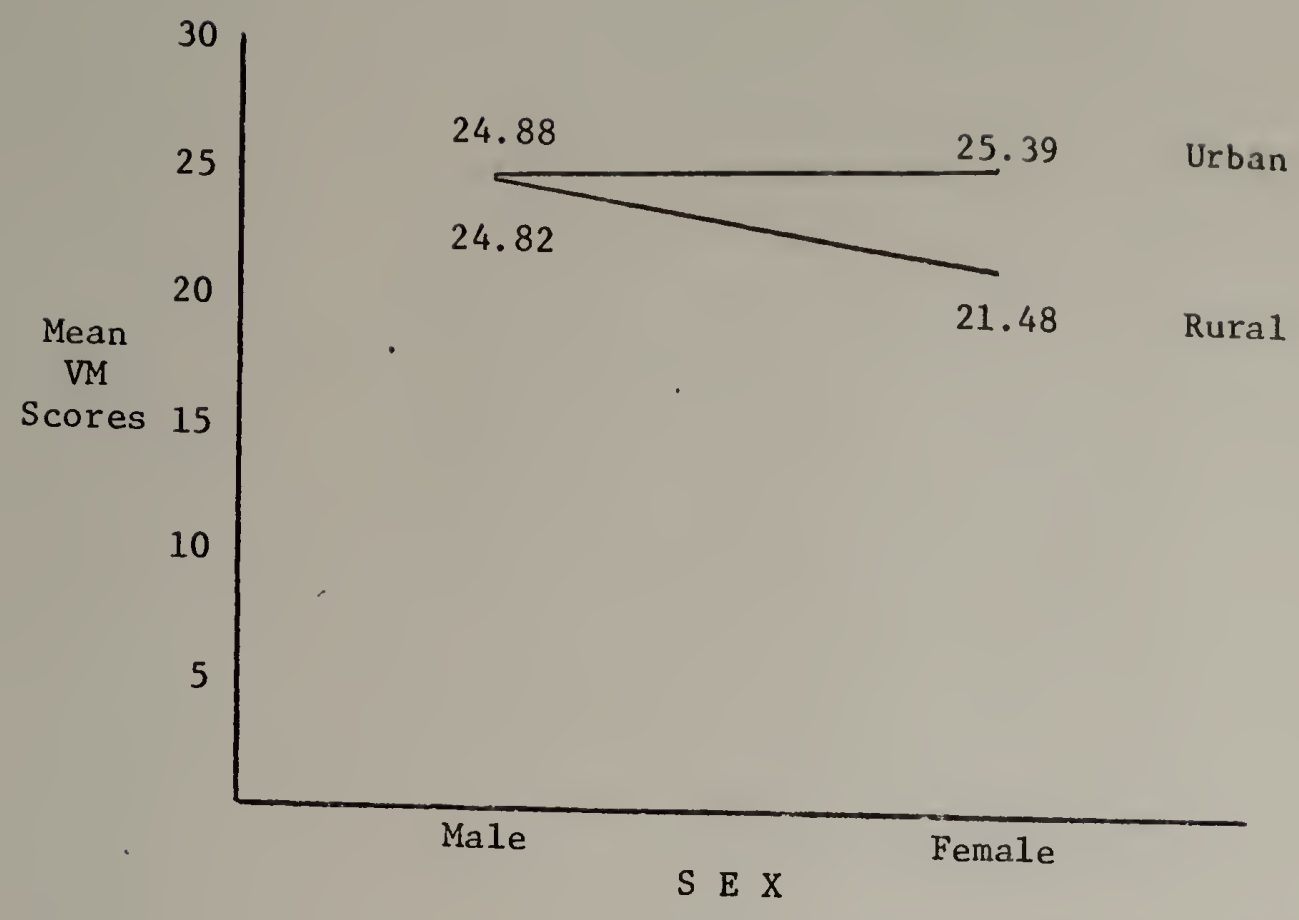

Fig. 13.--Illustrating the interaction between Sex and Urban/Rural Schools on the Attitude Scale of the CMI.

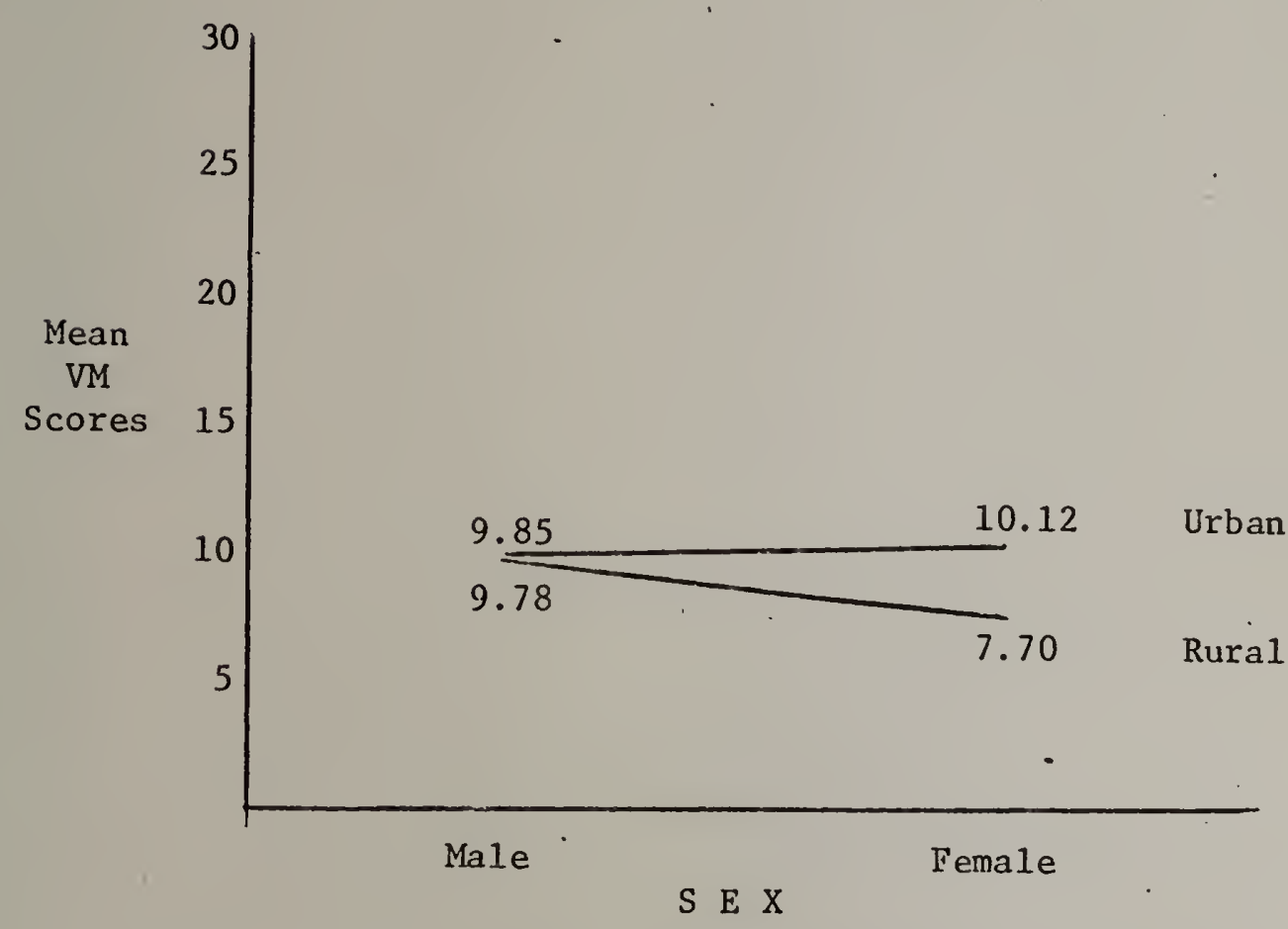

Fig. 14.--Illustrating the interaction between Sex and Urban/Rural Schools on Part II (Knowing about Jobs) subtest of the Competence Test of the CMI. 


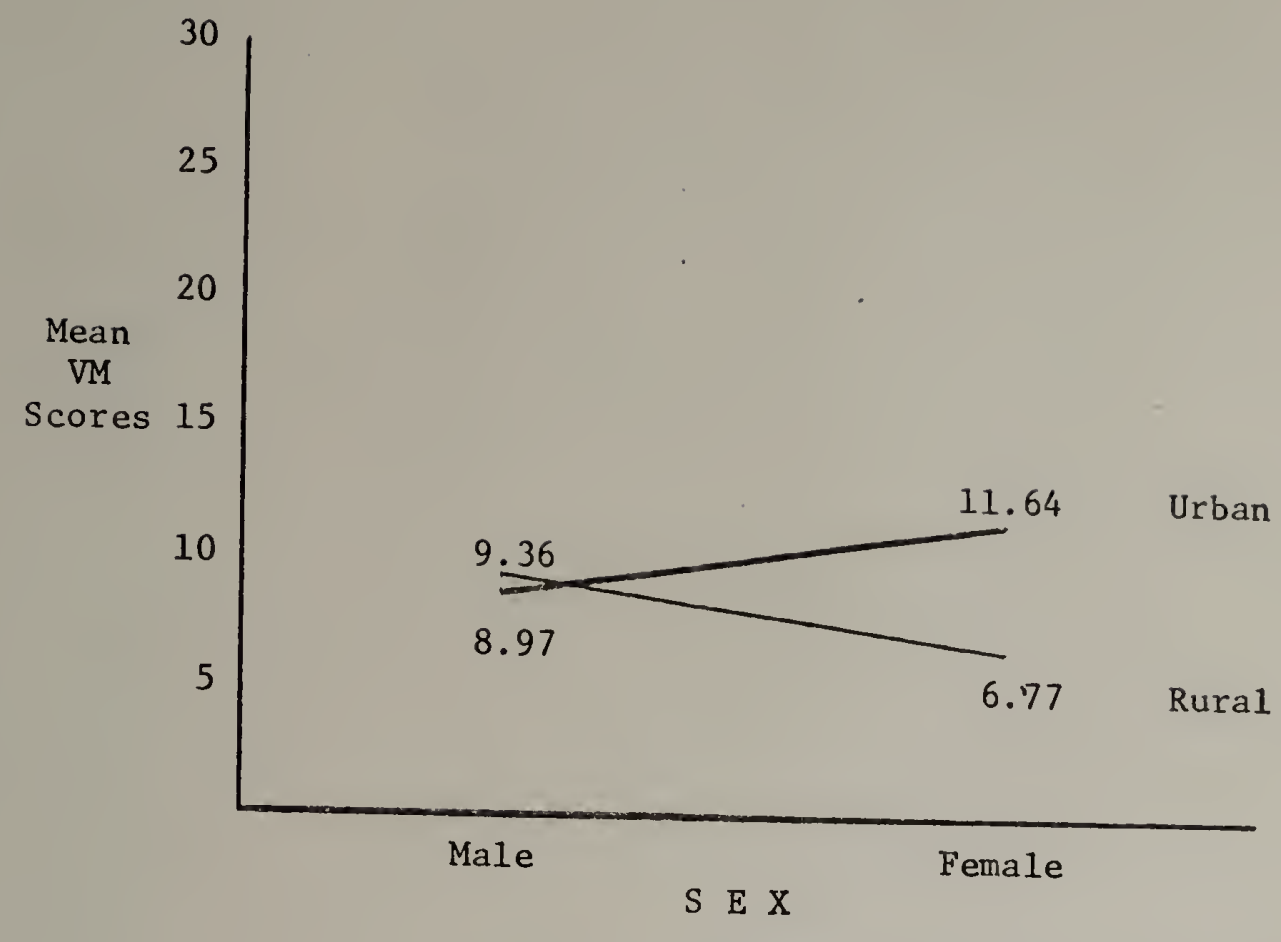

Fig. 15.--Illustrating the interaction between Sex and Urban/Rural Schools on Part IV (Planning) subtest of the Competence Test of the CMI. 
The corresponding mean plot for the sex and geographic location interaction, (Figure 13) shows that the lines are far from being parallel, thus suggesting the presence of significant interaction. Table 11 shows too, that for 1 and 384 degrees of freedom, the obtained $F$ of 14.94 is significant $(p<.001)$. Thus for the Attitude Scale, the hypothesis of no interaction between sex and the geographic location of schools is rejected.

Table 12 and Figure 14 contain the results for Part II of the Competence Test. Figure 14, shows that in urban schools, males score lower. (9.85) than females (10.12) while in rural schools the reverse is noticed and the males score higher (9.78) than females (7.70). Urban girls once more appear to have scored higher than the males in urban and rural schools and also higher than their sisters in the rural schools. Again, the graph shows no evidence of parallel lines, which goes to suggest the presence of an interaction. The ANOVA test indicates an F of 22.40 with 1 and 384 degrees of freedom, which is significant at the .001 level. Thus, the hypothesis of no interaction between sex and urban/rural schools on Part II of the Competence Test is rejected. Figure 15 and Table 13 contain the results for Part IV of the Competence Test of the CMI. Once again, the absence of parallel lines in Figure 15, indicates a significant 
interaction. Urban males again score lower (8.97) than urban females ( 11.64 ) but rural males score higher (9.36) than rural females (6.77). Similarly, urban females score higher than urban and rural males, as well as their rural sisters. The significant interaction suggested by the absence of parallel lines, is further confirmed in Table 13 by the significant $F$ ratio obtained in the ANOVA test. For the null hypothesis to be rejected at the .05 level, an F of approximately 3.89 is needed with 1 and 200 degrees of freedom, and an $F$ of 3.86 with $I$ and 400 degrees of freedom. This being so, the $F$ of 57.86 obtained with $I$ and 384 degrees of freedom grossly exceeds the required value. Thus, the hypothesis of no interaction between sex and urban/rural schools on Part IV of the Competence Test of the CMI, was also rejected at the .00I level.

Summary: Figures 13, 14 and 15 show no evidence of a parallel relationship between the lines thus suggesting the presence of significant interactions. This is confirmed by the obtained ratios from the ANOVA tests (Tables 11,12 and 13) which indicate that with 1 and 384 degrees of freedom, the obtained F's of $14.94,22.40$ and 57.86 were all significant at the .001 level. This means that the hypothesis of no interaction between sex and the geographic location of schools, on the Attitude Scale, Part II (Knowing about Jobs) and Part IV (Planning) had to be rejected. 
Interaction Between Class $x$ Sex $x$ Geographic Location of Schools on the Attitude Scale, Part II and IV of the Competence Test of the CMI: The second order interaction among the three main effects, class, sex and the geographic location of schools was not significant (Tables 11,12 and 13). There was no need to graph the results.

\section{$\frac{\text { Summary of the Results for the }}{\text { Hypothesis of No Interactions }}$}

The fifth hypothesis tested, was that of no interaction between class and sex, class and the geographic location of schools, and sex and the geographic location of schools, and scores on the Attitude Scale, Part II and IV of the competence Test of the CMI. Three first order interactions and one second order interaction were tested. The three first order interactions were: Class X Sex, Class X Geographic Location of Schools, Sex and the Geographic Location of Schools. The second order interaction was Class X Sex X Geographic Location of Schools.

The results indicated in Figures 7-15 show no evidence of a parallel relationship between the lines, thus suggesting the presence of significant interaction effects between the variables tested. Tables 11,12 and 13 show that all F's were significant beyond the .05 level.

On the Attitude Scale, the interaction between class and sex was significant $F=3.13(p<.05)$. On Part II an $F$ 
of $6.85(p<.001)$ was obtained. And on Part IV of the CMI, the interaction was also significant with $F=6.11(p<.001)$. For 1 and 384 degrees of freedom, the significant F's of 3.13 , 6.85 and 6.11 meant that the null hypothesis of no interaction between class and sex and scores on the Attitude Test, Part II and IV of the Competence Test of the CMI, was rejected.

The interaction between Class $\mathrm{X}$ Geographic Location of Schools and scores on the Attitude Scale, Part II and IV of the Competence Test of the CMI, was also significant. The null hypothesis was therefore rejected. On the Attitude Scale (Table 11 ) an $F$ of $4.30(p<.01)$ was obtained. On Part II of the Competence Test, (Table 12) with 1 and 384 degrees of freedom, an F of $12.87(\mathrm{p}<.001)$ was obtained and for Part IV of the CMI (Table 13), F = 8.85 ( $<<.001)$ also resulted.

The interaction between Sex $x$ Geographic Location of Schools was also significant. With 1 and 384 degrees of freedom. An F of $14.94(p<.001)$ was obtained for the Attitude scale, $F=22.40(p<.001)$ for Part II of the competence Test and $F=57.86(p<.001)$ for Part IV of the Competence Test. Tables 11,12 and 13 indicate these results. The hypothesis of no interaction between sex and the geographic location of schools and scores on the Attitude Scale, Part II and IV of the Competence Test of the CMI was thus rejected. 
The second order interaction between class $x$ Sex $x$ the Geogrpahic Location of Schools was not significant.

\section{Summary of the Findings}

The results of five null hypotheses tested in this investigation were presented in this Chapter. Tables 11,12 and 13 contain the results. A summary of all the findings is now presented.

A three way analysis of variance was used to test the hypothesis of no difference by class, sex and the geographical location of schools and a separate one way analysis was used to test for the age variable. All $\mathrm{F}$ values were tested at the .05 level of probability.

The first hypothesis stated that there will be no significant difference in the mean vocational maturity scores of Class 1-4 students on the Attitude Scale, Part II and IV of the Competence Test of the CMI. The hypothesis of no difference by class was rejected for all three subtests of the CMI since significant $F$ values were obtained on all three. What this means is that the three subtests do differentiate across classes in measuring vocational maturity.

The second hypothesis tested was of no significant mean score difference by sex on all three subtests of the CMI. Statistically, significant results were obtained for the Attitude Scale and Part II of the Competence Test and the result for Part IV was not significant. 
As a result, the hypothesis of no difference was rejected for the Attitude Scale and Part II but not rejected for Part IV. In other words, both the Attitude scale and Part II of the Competence Test, do discriminate between the sexes when used to measure Attitude and level of job knowledge. However, Part IV (Planning) does not yield serious differentiation between male and females.

The third hypothesis of no significant mean score difference by geographical location of schools was also rejected. This shows that differences in scores do occur on the three subtests, depending on whether the school is located in an urban or rural area.

The fourth hypothesis was that of no significant difference by age group on all three subtests of the CMI. The F's obtained on the Attitude Scale, Part II and IV of the CMI were all significant at the .05 level of confidence. Therefore, the hypothesis of no difference was rejected. This shows that on all three subtests of the CMI, score differentiation occurred by age group.

The fifth hypothesis stated that there will be no interaction between Class X Sex, Class X Geographic Location of Schools and Sex X Geographic Location of Schools. With the class by sex interaction, significant interactions occurred on all three subtests. Therefore, the hypothesis of no 
interaction between class and sex was rejected. In other words, although class has the effect of yielding score differentiation on all three subtests, however this effect is not independent of the effect of sex on the scores. The effect of both factors in combination should be taken into account in interpreting the results.

The hypothesis of no interaction for the class by geographic location combination was also rejected. The presence of this interaction thus means that the difference found across classes on the Attitude Scale, Part II and IV of the Competence Test, depends on the effect which urban or rural school location as well, has on scores on all three subtests.

The hypothesis of no significant interaction between sex and the geographic location of schools was rejected on all three subtests. This again shows that any statement about the effect of sex on the scores obtained on the three subtests, must be qualified by statements or information on the effect of urban or rural schools on the scores. In other words, information on the effect of both is needed simultaneously, for appropriate interpretation of the scores.

On the whole, practically all hypotheses of main effects and interactions were rejected with the exception of the nypothesis of no difference by sex on Part IV of the CMI which was not rejected. Differences do occur on the three 
subtests of the CMI used in this study, when the effect of class, sex or the geographic location of schools are tested. Such differences do not occur when the effect of sex on scores of Part IV of the Competence Test is examined. However, the effect of the three variables separately cannot stand alone in any prediction. One should also take into account simultaneously, the interactive effect of the variables on one another. 


\section{H A P T E R \\ DISCUSSION, CONCLUSION, IMPLICATION}

The purpose of this investigation was to find out the vocational maturity pattern of students in the East Central State of Nigeria.

Very briefly, the developmental theory from which the construct of vocational maturity evolved, assumes that vocational development and vocational decision making is a life long process which matures with increasing age but more importantly, with increasing grade level (Super, 1957; Crites, 1973). As each individual matures vocationally, he proceeds through a series of life stages from growth, exploration, establishment, maintenance and decline. In each stage, he is faced with a number of specific vocational developmental tasks which his society expects him to accomplish. Some of these tasks according to crites (1973) include the maturity of his vocational attitude and vocational competencies. To the extent that he successfully copes with the vocational tasks of each life stage, will he also cope with subsequent ones, and his ability to cope successfully with each task, reflects his level or degree of vocational maturity.

It was shown earlier on that the ECS of Nigeria and America share rather close cultural affinites especially with 
reference to their work ethic. If vocational maturity increases with age and grade level in America, is this same pattern true for students in the ECS? This was the primary focus of this investigation. However, considering that both cultures are at very different levels of industrial and economic development, it was also the interest of the researcher to find out if sex and the geographic location of schools have significant effects on the maturation of vocational behavior for ECS students.

Crites' Career Maturity Inventory (CMI, 1973) was constructed to measure the degree of vocational maturity using age and grade level as criterion. The items reflect a monotonic function of age and grade, i.e., scores on the instrument are expected to increase by age and grade. They should not significantly reverse themselves although they need not be strictly linear.

Three subtests of the CMI, namely the Attitude Scale, Part II (Knowing about Jobs) and Part IV (Planning) of the Competence Test were used on 400 secondary school students in the ECS of Nigeria at schools in urban and rural settings. This chapter discusses the findings of the investigation, makes conclusions from them and draws implication for theory, research and practice. 


\section{$\underline{\text { Discussion }}$}

\section{Differences Between Classes}

The first hypothesis tested stated that there will be no significant difference in the mean vocational maturity scores of students in Classes $1-4$ on the Attitude scale, Part II and IV of the competence Test of the CMI. The findings yielded $F$ values which were significant at the .001 level of confidence. Thus the hypothesis of no difference on all three subtests was rejected.

This result indicated that on all three subtests of the CMI, score differences existed. Figure 1 shows that there were progressive and systematic increase of mean vocational maturity scores by class. In other words, as students progress from class to class, they mature in a corresponding manner, in their vocational attitude. The observed trend is gradual but positive with students progressing from classes 1-4 in an upward direction, although in terms of their planning competence, the class 4 students show a regression below Class 3 mean.

The construct of vocational maturity expects that in the American culture, individuals should show progressive maturity with respect to vocational matters as time passes. From the results of the ECS study, it seems clear that the pattern of vocational maturity of students in the East Central 
State of Nigera, when assessed by the Attitude Scale, Part II and IV of the Competence Test of the CMI, empirically supports the theoretical expectation of the construct and the instrument.

Admittedly, students in Class 4 were less mature than the Class 3 students in planning to achieve their career goal. However, this regression should not detract from the "prototypic" result of this study. This is because Crites hypothesized that scores across classes while showing a monotonic trend need not significantly reverse themselves although at the same time, they need also not be strictly linear. In his standardization study, Crites (1965) discovered that on the Attitude scale, the eleventh grade mean was much more like the ninth grade mean than any other grade. Thus granting that the sampling in the ECS study was not biased, the Class 4 students seem atypical. However, this may be due to the fact that students in Class 4 have a need for further planning at that stage and so were less eager to commit themselves than if they had been in an upper class. This however, will need replication to settle the problem.

It seems clear that the overall significant difference found for all three subtests go to indicate that in the ECS, students in Classes 1-4 exhibit increasing maturity in their vocational attitude in their job knowledte and in their vocational planning as they progress from the lower to the upper classes. 
This result is supported by Ansel's study (1972) of the vocational maturity of 8 th to 12 th graders which showed also significant increase in vocational maturity from the $8 \mathrm{th}$ to 12 th grade. The researcher was not surprised at the findings resulting from the ECS study. In any culture with a strong work ethic, one expects individuals to exhibit more mature vocational behavior as their experience increases and to accumulate and add to their awareness and competencies with respect to the world of work. In a general sort of way, the result of this study seems to give a more global complexion to the assumption of vocational maturity.

However, if one examined the scores obtained in this study and those recorded for Crites' standardization sample, it becomes immediately clear that the ECS students scored lower on the average, than their American counterparts, although for Part IV of the test, the reverse was the case especially for two ECS classes. No serious cross cultural comparison between sample scores is intended here since as crites (1973) stated, the reference group used for comparison shouid be relevant. Since no norms yet exist for the ECS, this comparison cannot be made.

But a cross reference to the American scores showed that on the two parts of the Competence Test used, the difference was no more than 2 points and about 9 points for the Attitude scale, in favor of the original American 
standardization sample. The close similarities of the ECS scores with Crites' sample score on the Competence Test component of the CMI, seems to point to the possibilities of this component (perhaps after subsequent studies) being used in the ECS.

Based primarily on the results of this study, one can confidently conclude that the vocational maturity of the ECS students does show a "prototypic" pattern of progressive increase by class with respect to their vocational planning competence. And regarding the effect of class on vocational maturity, this result seems to point to a possible applicability of the construct to the ECS students.

\section{Difference by Age Group}

The hypothesis of no significant difference by age group was also rejected. In order words, the Attitude scale, Parts II and IV of the Competence Test, do differentiate across age groups, so that age does have an overall effect on the vocational maturity of the different age groups used in the study.

Crites hypothesized that vocational maturity should increase with age. But in a more recent statement (Crites, 1973, p. 13) he recommended that grade rather than age should be used as.an index of the passage of time in subsequent analysis. This decision resulted from the findings of his 
standardization study that age yielded less differentiation than grade. A comparison of the score differentiation due to the effect of age and class for the ECS study, seems to support Crites' findings. For the $F$ values for the age variable were barely significant at the .05 level of confidence, where as the hypothesis of the class mean effect was rejected at the .001 level of confidence. A comparison of the score plot obtained for the age main effect (Figures 4, 5 and 6) and that for class (Figure 1) reveals a more systematic, differentiation in vocational maturity by class, usually in the direction of the upper class. The differentiation in vocational attitude, occupational information and job planning noted for the age variable is more irregular.

What can, however be concluded from the results of this study is that for the ECS students age does have an overall effect on the maturity of their vocational attitude, on their vocational information and planning competence when assessed by the three CMI subtests but that class shows a more systematic differentiation. Thus the assumption of vocational development that as one grows older he should mature in his vocational behavior seems, in a general way, to apply to the ECS of Nigeria. Although age proved to be a less potent factor than class (grade level). 


\section{Differences Between the Sexes}

The hypothesis of no difference in the mean vocational maturity scores by sex obtained on the Attitude Scale and Part II of the Competence Test of the CMI, was rejected at the .001 level but not rejected for Part IV of the CMI. In other words, it was discovered that girls and boys differ in the maturity of both their vocational attitude and job knowledge. However, when it comes to Planning to achieve their vocational goals, they show hardly any difference.

In Crites' standardization study, he found that there are "negligible" differences between the sexes on his CMI. However, the result of this study does not support his findings, especially with respect to the Attitude scale and part II subtest. Only for the Planning subtest, do the two studies agree.

This lack of correspondence with Crites' results also extends to Davis' study (1972). Davis, using a multivariate analysis of variance design to examine for differences, observed no variation in the maturity of vocational attitude between her loth grade boys and girls. However, the findings obtained by Smith and Herr (1972) showed significant difference in favour of girls.

The variation observed for the ECS boys and girls, with reference to the maturity of their vocational attitude and knowledge of jobs, might, to a large extent, be due to 
cultural factors. Most jobs as we know them today in the United states as well as in the developing countries, require some form of formal education, no matter how rudimentary. In Nigeria, formal education in the ECS is neither compulsory nor free. Since people are poor and school fees hard to come by, when it comes to choosing who to send to schools, the boy, for obvious reasons, is given priority. This is because society expects him primarily to be highly achievement oriented, to work and augment his family income and only secondarily, to marry and raise children. For girls, however, societal expectation is towards the goal of being a wife and mother at the earliest possible opportunity. With such differential role expectation, it seems only plausible that in their vocational attitudes, boys would be more readily oriented toward positive work attitudes and therefore more mature in their work perspective than girls. Boys would also be expected to involve themselves more in exploration about available jobs than girls. In a previous study, Achebe (1972) found that girls had less, knowledge of job opportunities than boys. Besides, their level of job aspiration was lower than that for boys. It seems, therefore that the result of the ECs study reported here is not surprising. Cultural pressure and expectation seem to predispose girls to be less vocationally mature than boys. 
The reason for the lack of sex differentiation with respect to planning is not easily obvious and the result is surprising.

However, it seems clear that judging from previous studies (Davis, 1972; Smith and Herr (1972); Crites, 1973) the evidence regarding the assumption that sex does not significantly affect vocational maturity, is not consistent even in America. The result of the ECS study, for Part II of the Competence Test and the Attitude Scale does not support Crites' and Davis' studies, but corresponds with smith's. This points to the need for further empirical validation of Crites' assumpiion in the American society. Further ECS studies should also clarify this problem.

But from the frame of reference of the ECS study, it seems clear that boys and girls respond significantly different on the Attitude Scale and Part II of the competence Test of the CMI. In their maturity of vocational attitude and knowledge of jobs, boys in the ECS tend to be more mature than the girls. However, when their level of planning is measured by Part IV of the Competence Test, the differences cancel out.

Difterences Between Urban and Rural Schools

It was also hypothesized that there will be no difference in the mean vocational maturity scores of students 
by geographic location of schools with respect to their scores on the Attitude Scale, Part II and IV of the competence Test of the CMI. The resulting F's were all significant at the .001 level of confidence so the hypothesis of no difference was rejected. This means that urban and rural students respond differently with reference to their vocational attitude when assessed by the Attitude scale. In urban schools students tend to be more mature in this respect than in rural environments. The same is true in the maturity of their job knowledge and in their planning competence.

These results are contrary to Crites' conclusion that the CMI can be used "irrespective of school variance." Davis (1972) found that urban tenth graders were more mature than their rural counterparts when assessed with the Attitude Scale. This finding supports the results of the ECS study. It is not surprising that urban ECS students are more mature than their rural counterparts with respect to their vocational attitude, their job knowledge, as well as their planning competence. Rural environments in the ECS of Nigeria are still predominantly agricultural and relatively undeveloped than urban areas. There are very few job opportunities available in the rural areas and the general lack of stimuli and lack of exposure to a wide variety of jobs and job experiences may have affected the vocational maturity level of these rural students on all three subtests. Urban 
areas on the other hand are much more likely to benefit from any form of expansion first and by the same token, to provide a wider variety of jobs and more favorable attitude towards career matters. The drift from rural to urban environments noted by Callaway (1960) and the concern which this problem poses for the country as recorded in the Third (Nigerian) National Development Plan (1974-78) further reinforces this lack of environmental stimulation in rural areas, which should predispose to vocational maturity. In an urban environment, students would have a broader exposure to a wider variety of jobs. They would have access to resources that broaden awareness of the work world, e.g., radio, television, newspapers, workers in different occupations, as models, etc. It is thus not surprising that rural students, even if they come in with much more mature work attitudes, are likely not to progress as fast as their urban counterparts. However, future studies should throw more light on this problem.

From the present ștudy however, it can be concluded that for the ECS students, the geographic location of schools, i.e., whether urban or rural does affect the maturation of career attitude, knowledge and planning differently. It seems in this study that urban students are more vocationally mature than their rural counterparts, and this nust be considered in interpreting the results of the CMI. 


\section{Main Effect Summary}

The results regarding the main effect variables indicate that vocational maturity, in keeping with developmental theory of vocational development, increases systematically for ECS students by class: As the classes increase from the lower to the upper, they show more mature vocational attitude, know more about jobs and can better plan towards the achievement of their career goals.

Age also affects vocational maturity, but it does not show as strong and as systematic a differentiation across groups as does class in school. The overall effect however, was in keeping with Crites' hypothesis that age does not differentiate as well as grade with respect to vocational maturity.

Sex differences appear in the maturity of their vocational attitude and job knowledge. Boys seemed more mature than girls in the two areas but as far as their job planning competence is concerned, they are comparable. This finding of sex differenciation on two of the subtests contradicts both Crites' and Davis' studies but is supported by Smith and Herr (1972). The result for the planning competence supports Crites' assertion that sex difference in vocational behavior does not exist when assessed by his CMI. More studies are required to further clarify these inconsistencies. 
Urban or rural school location does differentiate vccational maturity scores. In the maturity of vocational attitude, job knowledge and planning competence, urban school location seems to predispose students to more mature vocational behavior. Davis found that in her study, urban tenth graders were also more vocationally mature than their rural counterparts.

Possible reasons for the variations by sex and urban/ rural schools discovered in this study were offered as sex role expectation and the lack of vocationally related stimulation in rural environments.

\section{Interactions}

Interaction Between Class $\mathrm{x}$ Sex

Interactions between class and sex significant at the .001 level was noticed on all three subtests of the CMI used in this study. The hypothesis of no interaction was therefore rejected.

The presence of an interaction now modifies the statemert made about the main effects of class and sex separately. In other words, this new interactive information shows that even though for the ECS students one can say that as students progress from lower to higher classes their vocational attitude, knowledge of jobs and planning competence become increasingly more mature, yet this tatement must be qualified by the sex of the students in the classes concerned. 
For example, Figures 7-9 show that on all three subtests the boys seem in a general way to be more systematic in their career growth and development than the girls. Looking at the pattern for girls, one notices how in their attitude to work, their job knowledge and planning competence, they start off so much less mature than the boys in class 1.

However, for the next two classes, they become more mature in their planning competence and job knowledge than the boys, although this is not very pronounced. In these same classes however, their attitude towards work fluctuates between being more and less mature than the boys. It is not until class 4 that the difference becomes really pronounced. With respect to their job attitude, though the girls increase from their level in Class 3, yet they remain still less mature than the boys. In terms of their job knowledge, they now become not only seriously less mature than their male counterparts in the same class, but also less mature than both the Classes 2 and 3 boys and girls. Thus, something happens to girls as they come into the first class of a secondary school, during the middle classes and worse still when they are just about leaving school, usually around the age of 16 .

The pattern which emerges then is that after the initial lag in Class 1 , girls tend to increase and surpass boys in their vocational maturity level in Classes 2 and 3 especially in their job knowledge and planning competence. 
However, by the time they are in class 4 they reverse almost to their initial level when they came into school. Their vocational attitude also exhibits an "up and down" pattern, increasing in one class, declining in the next and then picking up again in class 4.

With this observed difference in the pattern of the development of Classes $1-4$ boys and girls, it becomes clear that no categorical statement about overall increase in maturity due to class can be effectively made without relating this to the appropriate sex of the student. It can however, be concluded that boys are more likely to exhibit a gradual and systematic career pattern than girls as they progress from Class 1-4. However, the seemingly greater maturity, of boys over girls occurs only in classes 4 from (about 16 years) and 1 , rather than in the middle years of the secondary school.

The reason for their viarations in classes by sex may be speculated. It is to the mind of the researcher, perhaps due more to cultural factors than to the failure of the test assumption per se. For in Nigeria and especially amongst the Ibos of the ECS, society expects girls to marry early and häve children. Boys on the other hand are expected to go to school, but what is more, complete school and so acquire competencies, that will fit them into the world of work. Thus the Class 1 girls who come in less vocationally mature, 
oniy fit societal expectation. But by Class 2, they seem more certain that they will stay in school so that their erstwhile ambivalence and uncertainty only gradually begins to fade giving way to an increasing level of maturity. The increasing confidence continues to grow in class 3 , by which time they seem determined to make good use of their opportunity and involve themselves in planning and job exploration. This however, does not mean that their attitude towards work has stabilized as can be seen by the fluctuations still noted in this respect. By Class 4, when they have only one more year to finish school, it seems to dawn on them that society will be expecting them to get married first and foremost, almost as soon as they are out of school. With such pressure, anxieties and expectations, they are forced to lower their maturity level with regards to vocational matters since marriage rather than work, will be the most immediate goal for most of them. Thus, even though their attitude continues to mature, yet this can no longer be translated into vocational action. Besides, it is also possible that as the available places in post-secondary institutions are severely limited, and the training long and expensive, these girls would rather set their goals elsewhere, possibly to marriage, than expend their energies in futile vocational plans and explorations. For boys on the other hand, because of the high goal society sets for them, it is a question of just taking things 
in their "customary" stride and level, starting off with assurance and confidence that they will make it. Not being unduely pressured, they progress in a more leisurely and relaxed manner in the middle classes (grades) but suddenly wake up to the realization in class 4 that much more is expected of them.

\section{Interaction Between Class $\mathrm{X}$ Geographic Location of Schools}

Significant interactions also occurred for the class and geographic location of school effect so that the hypothesis of no interaction between these two variables had to be rejected. The presence of this interaction indicate once more that the general effect of class on vocational maturity needs to be qualified with further information indicating whether the class is in an urban or rural school location. The meaning of this interaction and how it qualifies the effect of each of these variables, can be demonstrated with the graph in Figures 10, 11, and 12. In their vocational attitude, job knowledge and career planning, a difference appears for urban and rural class 1-4 students. In all three subtests, urban Class 1 students begin by being less mature than their counterparts, but by class 2 , they succeed in outstripping the rural class and consistently maintain their lead through to class 4 . In the rural areas on the other hand, students come into class 1 more mature than their urban 
counterparts but although they progress in their vocational maturity level as they move to the upper classes, they do so more gradually and consistently, class by class, even though they are still less mature than the urban classes.

Environmental influence comes to mind as probably a contributing factor to the noted variation in maturity. First of all, urban areas provide a wider variety of jobs and more stimulating and broader exposure to the world of work. The Class 1 urban students generally are not allowed the same leeway to go to town as the other classes would have. But as they progress from class to class, they have more freedom and are allowed more responsibility. In which case, they would be allowed to go to town more often and so have contact with the various influences that might seem to predispose them to greater maturity in vocational matters. In the rural areas on the other hand, though students may come in better work oriented than their urban counterparts, the lack of environmental stimuli may act as a constraining factor to minimize the rate of their development in relation to the urban classes. This being so, any statement about the overall effect of class on the vocational attitude, job knowledge and planning of students must be predicated on the geographic location of those classes. If in urban areas, these classes will tend to exhibit less mature vocational behavior in Class 1, but thereafter, accelerate through class 4. If in a rural area, 
Class 1, will be more vocationally mature than urban class 1 , but thereafter will accelerate less gradually, always lagging behind their urban counterparts till class 4. However, the overall effect would be a higher level of maturity for urban classes.

Interaction Between Sex X Geographic Location of Schools

Significant interaction between sex and the geographic location of schools occurred for all three subtests used. The hypothesis of no interaction was therefore rejected.

Since an interaction occurred, it shows that the statement about sex affecting the vocational maturity of these students in favor of boys, needs to be further qualified by a statement indicating whether the boy is in an urban or rural area. For this differentiation in favor of boys is only true in the rural areas. In urban areas the difference favors girls, although the distance between them is less pronounced. Thus boys will be expected to have a more mature vocational attitude than girls in rural areas but in urban areas, the reverse will be expected.

The same pattern is noticed with respect to their varying maturity in job knowledge. In rural areas boys are again more vocationally mature but in urban areas girls are more mature than the boys. 
With respect to their planning to achieve their career goals, boys are more mature than girls in rural areas to the same degree that girls exhibit more maturity over boys in urban locations. For boys exceeded girls by 2.59 points in rural areas while girls excelled boys by 2.67 points in the urban areas.

The explanation for this may lie in the fact that girls in rural areas are likely to be largely influenced by traditional concepts of sex roles in which their primary aspirations would focus on marriage and homemaking rather than on careers. On the other hand, girls in urban areas, enjoying the new liberating influence of modern cities and more stimulating exposure to career matters, might tend to surpass boys for whom the new opportunities do not represent such a dramatic change.

\section{Conclusion}

The findings of this study indicate that in a general way, there are differences in vocational maturity for students in the ECS of Nigeria as they grow old and progress in class (grade level). The effect of class on their vocational maturity is more systematic than the effect of age.

The level of vocational maturity for boys and girls also differ, usually being higher for boys than for girls. Urban or rural school location also affects the vocational maturity 
of students differently in the sense that urban school students generally tend to be more mature than those from rural schools. However, other factors were noticed which would tend to modify how precise or confident we can be in making these categorical statements. For significant interactions occurred between class and sex, class and the geographic location of schools and sex and the geographic location of schools. Thus, any statement about the effect of the class variable on the vocational maturity of ECS students must be qualified by the possible effect of sex and of the geographic lcoation of the class. Any statement about the effect of sex must equally take into consideration the effect of the geographical location of the school in any interpretation of the CMI results, for the students in the ECS of Nigeria.

\section{Implications}

The result of this study has implications for the theory of vocational maturity. For the major proponents of vocational developmental theory (Super, 1957; Crites, 1973) vocational behavior increases as one progresses through different life stages. During adolescence, it should increase by age and grade. This assumption was built into Crites' CMI so that older age groups and classes will exhibit more mature vocational behavior by scoring generally higher than the younger age groups and lower classes. The result of this 
study lends support in a general way to that assumption. However, in the ECS, other factors likely to modify these initial observations have to be considered in predicting the performance of a student on the CMI. With this note of calltion, the results seem to suggest that the developmental theory of vocational maturity has cross cultural possibilities, especially, this is so for cultures which share close affinities with respect to their work ethic and possibly world view.

Test Developinent and Use

The researcher pointed out (Chapter 1) that the type of tests proposed for use by the ECS career oriented guidance program seem too limited in scope. These aptitude, interest and personality measures singled out specifically for development and use in career guidance, are trait measures which tend to view the individual from a very narrow perspective in that they look at him only at a specific point in time and not over time. Besides, they overlook a wide variety of factors which might impinge on his vocational decision. Attitudes and competencies, specifically of a vocational nature, necessary for realistic career decision making are ignored by this trait and factor approach. Besides, the gradual but increasing development of the individual with respect to his vocational behavior is also not explored. 
The ECS student who is expected to make a major career decision at the end of his secondary school or somewhere in the middle, may not even be ready to make these decisions. Since the trait measures do not assess the attitudes, skills and competencies necessary for career decision making, they cannot provide answers to the important question of "how ready" these students are to make realistic vocational decisions. An answer to this question is vital, for in any helping relationship, one needs a "preview" of where the helpee is so that appropriate help can be given.

This study tried to investigate if the developmental assumption of vocational maturity applies to students in the ECS of Nigeria. The findings indicate that the concept as measured by Crites' inventory, albeit the Attitude Scale, Planning subtest, and Occupational Information subtest of the CMI, does have validity with some qualifications, for the ECS sample studied. Since tests are both expensive and take long to develop, the CMI could be modified and the complete irventory tried out for use in the ECS. This way a more developmental picture of the vocational maturity of the studerit can be obtained. Admittedly, further empirical studies will be needed to validate the findings of the present study. However, such validation studies would be considerably cheaper than starting from scratch to construct a new test. 


\section{Career Counseling Practice}

The result of this study indicated differential vocational maturity for boys and girls. Achebe's study (1972) of the vocational aspirations of secondary school students in the East Central State of Nigeria indicated that the boys not only had a higher level of vocational aspiration, but also a broader knowledge of job opportunities. There is thus need for this frequently observed differentiation to be seriously examined and taken note of especially when counseling the students. Especially as the girls enter secondary schools, effort should be made to give them every support and encouragement which will raise their self concept and motivational levels so that they do not become overly constrained by societal prejudices. There is evidence that in the middle years of a secondary school, girls tend to be more vocationally mature than the boys. The considerably higher vocational maturity of girls in urban areas where opportunities for improvement seem most promising, indicates no doubt, the level at which girls can achieve if given the opportunity. Every attempt therefore, should be made when the new program begins, to liberate the potential of the girls. And this point can never be overscored. For human resource development planners have it seems, equated the maximum development of our manpower with male power. One would like to see the word "manpower" used in its generic sense to include females as well. 
Another problem raised by the result of this study, is the relative immaturity of rural boys and girls with respect to vocational matters. Before the civil way when most rural schools were managed by private proprietors who had to equip the schools single-handedly, one could understand and appreciate some of the problems that were encountered. But since the East Central state Government has taken over all secondary schools in the state, sustained effort should be made to expand the vocational horizon of students in rural schools. Interventions like field-trips, and excursions into more industralized cities, invitation of workers to talk to students and provide role models for them, employment of a counselor with vocational orientation to each rural school and perhaps the involvement of rural parents in the school guidance program could be instituted. There is no doubt that parents need to be fully briefed and involved in the new program so that they will give it all the support it needs. Besides, the involvement of parents will also help to spur them to encourage their children to greater heights.

\section{Limitations}

The conclusions arrived at in this study are subject to certain limitations. Among these perhaps is the fact that by using one boy and one girl school from the urban area and one boy and one girl, school from the rural area, it is possible 
that the particular type of schools, rather than the environment may have affected the results. Two of the urban schools were amongst the best of the government owned schools while the other two were mission schools. The urban schools tended to, and possibly still attract some of the best students. A replication is needed however, to check this point.

Besides, this study was undertaken only fours years after the Nigerian Civil War. And the East Central state served as the battlefield. The crippling psychological and economic effects of the war were still very much in evidence when this study was undertaken. It is possible that these war effects may have introduced some bias into the responses of the students. As conditions improve however, and both reconstruction and rehabilitation gets under way, the study should be further verified, since this is hopefully, the first in a series of studies to be undertaken in this area.

An important point to consider in the conclusion is the fact that the CMI measure still needs to be validated, even within the United States. No study other than Crites' standardization data has so far been published regarding the validity of the newer Competence Test of the CMI. Even with the Attitude Scale, inconsistencies exist in some of the findings, specifically with relation to the effect of sex and school location on vocational maturity. Therefore, any conclusions arrived at should be interpreted with caution. 
The researcher is equally aware of the possibility fo experimentor effect in modifying the tests used in this study. One possible factor that might jeopardize an internal validity is "the calibration of a measuring instrument" (Campbell and Stanley, 1966). However as was pointed out earlier, the minor changes made in the tests were mainly stylistic and changes in terminology. These need not affect the ability of the tests, in any significant way to measure vocational maturity.

\section{Suggestions for Future Research}

This is the first known attempt to test out crites' inventory in Nigeria. It will be advisable to replicate the study in order to check the findings. However, care should be taken to ensure at least subcultural similarities to the ECS sample, in order to make the findings comparable.

Subsequent research might consider testing the entire CMI. This task could not be undertaken in the present study because of limited financial resources. Such a study would help establish validity for the CMI, which is so badly needed at this time.

In studies testing out the complete inventory on ECS students a more representative sample might be considred to include all the five secondary school classes and the different types of schools, e.g., grammar, commercial, trade and technical. 
There is need for a follow up study of these students for the next four years, i.e., until the class 1 students leave school. This is important in order to obtain a longitudinal picture of their vocational development. All the studies so far reported, using the CMI are cross sectional studies. This underscores the need for a more developmental study of this construct that is time related.

The peculiar developmental pattern exhibited by girls needs to be examined in subsequent studies. It might well be possible that, vocationally, as well, girls develop much differently from boys. The clarification of this problem should have very important implications for the way girls should be counseled.

Only a few variables which might affect the vocational maturity of ECS students were explored in this study. Future research studies might consider the effect of socio-economic status using fathers' educational level, father's and mother's educational level in combination as well as father's or mother's income or the combination, as indices. The possible effect of school achievement and I.Q. on vocational maturity would also be worth looking into. Achievement motivation is another variable that could affect vocational maturity. Since the government has taken over all secondary schools in the state, it would be interesting to see how the various types of schools respond on the inventory. This should provide 
data to help structure the guidance program.

Since vocational maturity is a multi-dimensional construct, researchers should endeavor to explore as many complex variables as might affect this construct in their specific locale. 
APPENDICES 
APPENDIX A

PART II (KNOWING ABOUT JOBS) SUBTEST OF THE COMFETENCE TEST OE THE CMI 
PART II

\section{KNOWING ABOUT JOBS}

\section{Directions}

In each item of this part, you are given a brief description of a job performed by a person. Following the description are four job titles. Read each job description and then select the correct job title for it. If you have no idea, indicate "don't know."

Mark your answers to this part of the test in section I, of the separate Answer Sheet. Make sure that your marks are heavy and black and that they completely fill the space. Erase completely any answers you wish to change. Make no stray marks on the Answer sheet.

Continue to work until you reach the word STOP. If you complete this part before time is called, you may go back and check your answers. Do not begin the next part until you are told to do so.

1. Obinna went into the newsroom and was given many typewritten sheets of paper which he began to study. At five minutes to six, he took the paper into a studio and sat in front of a microphone and waited, watching the big studio clock. At six o'clock a green light flashed and he began to read.

What is his job? 
1. newspaper reporter

2. news broadcaster

3. studio attendant

4. wireless monitor

5. don't know.

2. Obi watched carefully as the huge press ran at top speed, turning out the Daily Times newspaper. Suddenly, he pushed a bution and stopped the press to repair a tear in the roll of paper that was feeding into one of the rollers. He also checked the ink tanks and filled those that were running low. He started the press again and finished the first part of the newspaper. With new plates in place for the remaining parts, he once again started the press and finished the job.

What is his job?

1. laboratory technician

2. office machine operator

3. printer

4. tool and die makex

5. don't know

3. Afam carefully placed the piece of iron between the jigs on the surface of his drill press. Before going on, he checked his measurements and the exact place where he wanted to drill the hole. He then lowered the drill until it started to spin through the metal. When he finished, he again measured the inside of the hole before placing the iron in the bin next to his bench. This was the last piece in this job; after lunch he would set up his drill to work on connecting rods.

What is his job?

$$
\begin{aligned}
& \text { 1. optician } \\
& \text { 2. instrument assembler } \\
& \text { 3. machinist } \\
& \text { 4. X-ray technician } \\
& \text { 5. don't know }
\end{aligned}
$$

4. Mrs. Okeke sat at her desk which was filled with piles of orders and bills for goods used by her company, the General Machine Company. She was checking the bills when her secretary said that her 10 o'clock appointment was ready to see her. She talked with her visitor, a salesman for the Box Company, for about an hour and placed an order with him for 5,000 large sized cardboard boxes. She spent the rest of the morning writing; she attended a business meeting in the afternoon. 
What is her occupation?

1. bookkeeper
2. production planner
3. purchasing officer
4. vendor
5. don't know

5. Ngozi smiled and handed Mr. Eze two bags of kobo and naira notes. She said "Have a nice day," as he gathered up the coins and notes and left. There was no one else at her winoow; so she took the time to check how much change she had left in her coin drawer and filed some notes she would need to balance her cash at the end of
the day.

What is her occupation?
1. accountant
2. bank teller
3. buyer
4. postal clerk
5. don't know

6. Maria set the camera so that it was pointed at the man's chest. She checked some measurements and then moved him a little to the left of center on the machine's platform before she went behind a lead wall where the controls were. She asked him to hold his breath for a few seconds while she pushed a button which started the machine. Then she was finished, except for developing the film.

What is her occupation?

1. machine tool operator

2. optometrist

3. photographer

4. X-ray technician

5. don't know

7. Mr. Ojo returned home tired from a busy day at his cocoa plantation. He had done some weeding, examined all the trees carefully, and sprayed them against harmful insects and disease. Then he took home a few bunches of bananas from banana trees which were planted to give shade to the cocoa trees.

What is his occupation?

1. Forest inspector

2. agricultural officer

3. fruit merchant

4. farmer

5. don't know 
8. Okafor checked the drawings and nailed the last joist into joists to make a fine panelling sheets of plywood on the room was going to be a study, he on the walls. Since the bookcases and a work surface with file had to build in

What is his occupation?

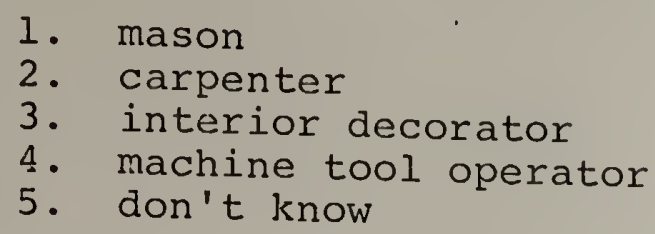

9. Mr. Dike looked at the long lists of numbers on his desk and wondered where he had made the mistake. He could not make the credits and debits balance. As he started to add them again, his secretary buzzed him to say that a customer was in her office waiting to see him. It was Mr. Ekwensi who had just opened a new bookshop and wanted advice on how to keep proper records. During the day, Mr. Dike talked with customers about other money matters, as well as making more general audits of their income and expenditures.

What is his occupation?

$$
\begin{aligned}
& \text { 1. accountant } \\
& \text { 2. bookkeeper } \\
& \text { 3. lawyer } \\
& \text { 4. statistician } \\
& \text { 5. don't know }
\end{aligned}
$$

10. Ifoma worked rapidly on the electrical part which was laid out in front of her on the workbench. Her job was to put the circuit board and base into the case. She then had to solder the two pieces together and wrap the whole piece with a sleeve which protected it from heat and cold. Once the part was finished, it would move along the production line and be put together with other parts to make a vehicle.

What is her occupation?

1. instrument assembler

2. key punch operator

3. machinist

4. optician

5. don't know

11. Chika works for the Welfare Department, where she helps people with many things, such as personal adjustment, money, and jobs. She makes up a case history, talks 
about the family's problem at meetings, and tries to find a solution to it. She arranges child care, hospital care, legal advice, and other services for the family.

What is her occupation?

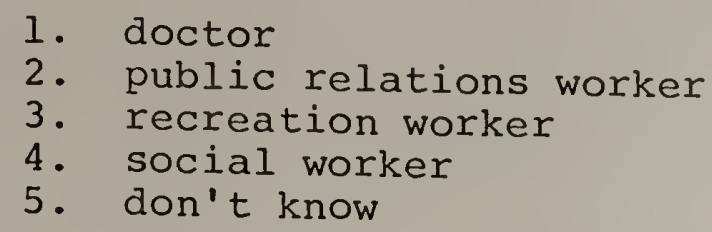

12. Rita was looking forward to another busy day in her job at Presidential Boutique, the largest clothing store in town. She was expecting her orders of women's dresses to arrive, and this meant getting them ready for the Easter sale. She also had to make plans for another trip to Lagos to look at several new fashions for Christmas.

What is her occupation?
1. buyer
2. advertising copywriter
3. public relations worker
4. social worker
5. don't know

13. John goes to work in a uniform. He inspects trees in a forest reserve to find out those that are healthy and those that need attention. He marks those which are about to die with a heavy hammer which hangs from his belt. Last week he caught a man cutting down trees for firewood, and arrested him.

What is his occupation?

$$
\begin{aligned}
& \text { 1. a policeman } \\
& \text { 2. forest guard } \\
& \text { 3. wildlife manager } \\
& \text { 4. botanist } \\
& \text { 5. don't know }
\end{aligned}
$$

14. Cletus looked up from the counter, where he had just placed a place of bacon and eggs, and reached for three other orders which had been left on the counter in front of him. One was for rice and plantain; another was for pounded yam and egusi soup; and the third was for curried rice. He quickly started preparing each of these dishes so that he would have them ready before new orders came in.

What is his occupation? 
$\begin{array}{ll}\text { 1. } & \text { cook } \\ \text { 2. } & \text { orderly } \\ \text { 3. } & \text { dietician } \\ \text { 4. } & \text { vendor } \\ \text { 5. } & \text { don't know }\end{array}$

15. Mrs. Ekoma was at the hospital by $8 \mathrm{a} . \mathrm{m}$. and had finished her rounds by $10 \mathrm{a} . \mathrm{m}$. She was now headed for her office, where she had appointments until $3 \mathrm{p} . \mathrm{m}$. She was then due back at the hospital for a meeting, before taking her whekly turn on the Emergency Service. During the evening, who had been in an accident.

What is her occupation?

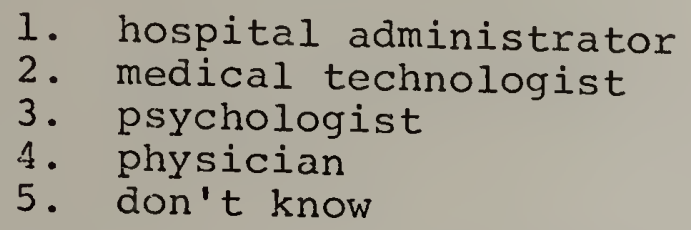

16. Ebele is a pretty, well-dressed young woman who makes a good impression and can talk easily with her customers as she cuts, brushes, washes, and sets their hair. She often has ideas for new haircuts and for fashions that go with them. Sometimes she also gives manicures and scalp massages, and she is trained to find skin diseases even though she cannot treat them.

What is her occupation?
1. beautician
2. fashion designer
3. receptionist
4. personal maid
5. don't know

17. Essien was in a hurry for the loading crew to finish. He vanted to get on the road again; he always enjoyed being on the move, even if it were to places he had been before. This trip, however, was to Kano, and he had never been there. When he was finally ready to go, he made a last min'lte check with the office about his route and time of arrival. Within a few minutes, he was on his way.

What is his occupation?

$$
\begin{aligned}
& \text { 1. bus driver } \\
& \text { 2. routeman } \\
& \text { 3. rigger } \\
& \text { 4. trailer driver } \\
& \text { 5. don't know }
\end{aligned}
$$


18. Loretta examined the menu once more before sending it to to be both good tasting day's meals. She had planned it worry about the cost, since sheritious. She also had to She tried to economize, but she only had a small budget. ever meals had to be prepared She depended on her training in hundreds of workers. paration to satisfy them as much nutrition and food pre-

What is her occupation?

1. chemist

2. cook

3. dietitian

4. food technologist

5. don't know

19. There was cattle disease in the district. Okorie was sent to inspect the animals and vaccinate them. He treated some of the animals and told the farmers that the very sick ones must be destroyed. He also talked to the farmers about the epidemic and gave them advice on how to protect

What is his occupation?

1. physician

2. dentist

3. veterinary worker

4. sanitary inspector

5. don't know

20. Mr. Okoye leaned back in his big, soft chair and listened carefully as the young woman sitting across from him told how she had tried to make a success of her marriage but now wanted to file for a divorce. He explained the state laws about divorce to her and asked her if she wanted to go through with it. She said yes, and he started to gather the information needed to file the first papers.

What is his occupation?

1. lawyer

2. marriage counselor

3. creative writer

4. psychiatrist

5. don't know 


\section{APPENDIX B}

PART IV (PLANNING) SUBTEST OF THE COMPETENCE TEST OF THE CMI 
PART IV

LOOKING AHEAD

\section{Directions}

In each item of this part, you are given an occupational title and three steps that a person could complete to prepare for and enter this job. You are then given four ways in which these steps could be ordered. Read the job title and the steps and then select the correct order for completing the three steps. If you have no idea, indicate "don't know."

Mark your answers to this part of the test in section II of the separate Answer Sheet. Make sure that your marks are heavy and black and that they completely fill the space. Erase completely any answers you wish to change. Make no stray marks on the Answer Sheet.

Continue to work until you reach the work STOP. If you complete this part before time is called, you may go back and check your answers.

41. Obi has decided to be a printer. Three steps he can take to become one are:

1. train as an apprentice printer

2. pass journeyman printer's tests

3. get a job as a printer's "devil" (assistant)

What is the correct order of these steps?
1) 123
2) 2 2 113
3) 3112
4) 321
5) don't know 

42. Ngozi wants to be a secondary school teacher. Three steps
she can take to become one are:

1. find a job as a teacher

2. pass a professional teacher's exam

3. attend a university or teaching training school

What is the correct order of these steps?
1) 132
2) $2 \quad 3 \quad 1$
3) 312
4) 321
5) don't know

43. Nwoye has chosen to be a carpenter. Three steps he can take to become one are:

1. learn to be a carpenter as an apprentice

2. attend a secondary school

3. pass the journeyman test

What is the correct order of these steps?
1) 123
2) 2113
3) 132
4) 321
5) don't know

44. Eze has decided to be a newsbroadcaster. Three steps he can take to become one are:

1. attend a secondary school

2. train in radio staff school

3. attend an interview and pass a voice audition

What is the correct order of these steps?
1) 2113
2) 3 1 112
3) $1 \begin{array}{lll}1 & 3 & 2\end{array}$
4) 231
5) don't know

45. Tom is interested in being a forest officer. Three steps he can take to become one are:

1. take science subjects in seconarary schools

2. take a university degree in forestry

3. go to a school of forestry 
What is the correct order of these steps?
1) 1332
2) $2 \quad 3 \quad 1$
3) 3112
4) 321
5) don't know

46. Elizabeth has chosento be a lawyer. Three steps she can take to become one are:

1. pass bar exams

2. go to law school

3. specialize in history in a university

What is the correct order of these steps?
1) $13 \quad 3$
2) $2 \quad 3 \quad 1$
3) 3112
4) 321
5) don't know

47. Okey wants to be a machinist. Three steps he can take to become one are:

1. get a job as a machinist

2. take technical courses in a secondary or trade school

3. gain experience in setting up machines

What is the correct order of these steps?
1) 2 1 13
2) $2 \quad 3 \quad 1$
3) $3 \begin{array}{lll}1 & 2\end{array}$
4) 321
5) don't know

48. Rose has chosen to be a librarian. Three steps she can take to become one are:

1. get a B.A. or B.Sc. degree

2. get a professional certificate

3. get a job as a librarian

What is the correct order of these steps?
1) 1223
2) 2 1 13
3) $2 \quad 3 \quad 1$
4) 321
5) don't know 
49. Ikem wants to be a policeman. Three steps he can take to
become one are:

1. pass police qualifying tests

2. go to a police academy for training

3. take a general course in secondary school

What is the correct order of these steps?
1) 133
2) 231
3) 3 1 12
4) 3221
5) don't know

50. Ify wants to be a secretary. Three steps she can take to

1. take commercial subjects in a secondary school

2. take business courses in a university

3. interview for a job at some business

What is the correct order of these steps?
1) 1223
2) 1332
3) 2 1 13
4) 312
5) don't know

51. Nanette has decided to be an interior decorator. Three steps she can take to become one are:

1. graduate from a school of design

2. finish an apprenticeship in a decorating studio

3. attend college for a few years and take courses in interior decoration and related subjects

What is the correct order of these steps?
1) 123
2) 2 2 113
3) $2 \quad 3 \quad 1$
4) 312
5) don't know

52. Elom thinks he' 11 be an instrument assembler. Three steps he can take to become one are:

1. check "want ads" for jobs

2. receive on-the-job training as an assembler

3. take technical and shop courses in a secondary school 
What is the correct order of these steps?
1) $122 \quad 3$
2) $2 \quad 3 \quad 1$
3) 3 1 12
4) 321
5) don't know

53. Chinwe has decided to be an architect. Three steps she
can take to become one are:

1. major in architecture in a university

2. pass the state licensing tests for architects

3. finish a three year apprenticeship in an architect's

What is the correct order of these steps?
1) 133
2) 2 2 113
3) 3112
4) 321
5) don't know

54. Edith has decided to be a cook in a large hotel. Three steps she can take to become one are:

1. get promoted to full cook

2. find a full time job as an apprentice cook

3. take home economics courses while in secondary school What is the correct order of these steps?
1) 1223
2) $23 \quad 3 \quad 1$
3) 3 1 12
4) 321
5) don't know

55. Adaeze's goal is to be a department store buyer. Three steps she can take to' become one are:

1. work up to head of stock and assistant buyer

2. get a job as a salesman in a department store

3. earn a degree in business administration in college what is the correct order of these steps?
1) 3251
2) 231
3) 3112
4) $13 \quad 3 \quad 2$
5) don't know 
56. Amos wants to be a lorry driver. Three steps he can take
to become one are:

1. find a job with a transport company

2. get a high grade in driver's training

3. pass the tests for a driver's license (class B)

What is the correct order of these steps?
1) 1223
2) 2 1 13
3) $2 \quad 3 \quad 1$
4) 321
5) don't know

57. Enuma wants to be a doctor. Three steps she can take to become one are:

1. finish an internship

2. go to medical school

3. practice medicine

What is the correct order of these steps?
1) $1 \quad 3 \quad 2$
2) 2 1 13
3) $2 \quad 3 \quad 1$
4) 321
5) don't know

58. Mary wants to be an X-ray technician. Three steps she can take to become one are:

1. complete X-ray technician's courses

2. pass registry tests in $X$-ray technology

3. find a job with a hospital or clinic

What is the correct order of these steps?
1) 312
2) $1 \begin{array}{lll}1 & 3 & 2\end{array}$
3) 2 1 3
4) 123
5) don't know

59. Joan has decided to be an office machine operator. Three steps she can take to become one are:

1. complete secondary school in a conmercial course

2. apply for a job at the state employment office

3. take special traning at a business school in office machines 
What is the correct order of these steps?
1) 123
2) 1312
3) 231
4) 312
5) don't know

50. Alice wants to be a motor mechanic. Three steps she can
take to become one are:

1. take technical subjects in a secondary school

2. obtain technical certificate

3. attend a trade school

What is the correct order of these steps?
1) 1332
2) $2 \quad 1 \quad 3$
3) 3 1 2
4) 321
5) don't know 
APPENDIX C

ATTITUDE SCALE OF THE CMI 


\section{I R E C}

There are a number of statements about carreer choice in this booklet. Career choice means the kind of job or work which you think you will probably be doing when you have finished all of your schooling.

Read the statements and mark your answers in section III and IV (81-1.30) on the separate Answer sheet. If you agree or mostly agree with the statement, use your pencil to blacken No. 1. If you disagree or mostly disagree with the statement, blacken the space marked 2. Be sure that your marks are heavy and black and that they completely fill the spaces. Erase completely any answer you wish to change. Dc not make any stray pencil marks on the Answer Sheet.

81. Orce you choose a job, you can't choose another one.

82. In order to choose a job, you need to know what kind of person you are.

83. I plan to follow the line of work my parents suggest.

84. I suppose everybody has to go to work someday, but I don't look forward to it.

85. A person can do any kind of work he wants as long as he tries hard.

86. I'm not going to worry about choosing an occupation until I'm out of school.

87. Your job is important because it determines how much you can earn.

88. Work is important mainly because it lets you buy the things you want. 
89. The greatest attraction of a job to me is the opportunity
it gives for getting ahead. 90. I often daydream about what I want to be, but I really
haven't chosen a line of work yet.

91. Knowing what you are good at is more important than knowing what you like in choosing an occupation.

92. Your parents probably know better than anybody else which occupation you should enter.

93. If I can just help others in my work, I'll be happy.

94. Work is dull and unpleasant.

95. Everyone seems to tell me something different; as a result I don't know which kind of work to choose. 96. I don't know how to begin to look for the work I want to
do.

97. There is no point deciding on a job when the future is so uncertain.

98. I spend a lot of time wishing I could do work I know I can never do.

99. I don't know what courses I should take in school.

100. It's probably just as easy to be successful in one occupation as it is in another.

101. By the time you are half way through secondary school, you should have almost made up your mind about the job you intend to do.

102. There are so many things to consider in choosing an occupation, it is hard to make a decision.

103. I rarely think about the work I want to do.

104. It doesn't matter which job you choose as long as it pays well.

105. You can't go very far wrong by following your parents' advice about which job to choose.

106. Working is much like going to school.

107. I am having difficulty in preparing myself for the work I want to do. 
108. I know very little about the requirements of jobs.

109. The job I choose has to give me plenty of freedom to do
what I want.

110. The best thing to do is to try out several jobs, and then choose the one you like best.

111. There is only one occupation for each person.

112. Whether you are interested in a particular kind of work is not as important as whether you can do it.

113. I can't understand how some people can be so certain about what they want to do.

114. As far back as I can remember, I've known the kind of : vork I want to do.

115. I want to really accomplish something in my work-to make a great discovery or earn a lot of money or help a great number of people.

116. You get into an occupation mostly by chance.

317. It's who you know, not what you know, that's important in a job.

118. When it comes to choosing a job, I'll make up my own mind.

119. You should choose an occupation which gives you a chance to help others.

120. When I am trying to study, I often find myself daydreaming about what it will be like when I start working.

121. I have little or no idea of what working will be like.

122. You should choose an occupation, then plan how to enter it.

123. I really can't find any work that has much appeal to me.

124. You should choose a job in which you can someday become famous.

125. It you have some doubts about what you want to do, ask your parents or friends for advice and suggestions.

126. You should choose a job which allows you to do what you believe in. 
127. The most important part of work is the pleasure which comes from doing it.

128. I keep changing my occupational choice.

129. As far as choosing an occupation is concerned, something will come along sooner or later.

130. I am not going to worry about choosing a job since one doesn't have anything to say about it anyway. 
NOTE: Al1 numbers in brackets 205

Letters represent the answers. However the used in the present study. the numbers adjacent to each letter. the nature of the answer sheet used.

ANSWER KEY

CAREER MATURITY INVENTORY

\begin{tabular}{|c|c|c|c|c|c|c|c|c|c|c|c|}
\hline & & & & & & & & Con & pete & e Tes & \\
\hline & & & & & & & Part & 2 & & & Irt 4 \\
\hline$(81)$ & 1. $\mathrm{F}$ & (102) & 22. $\mathrm{T}$ & (123) & 43. F & (1) & 21 & B & (2) & $(41)$ & 61. C (3) \\
\hline$(82)$ & 2. $\mathrm{T}$ & (103 & 23. $\mathrm{F}$ & $(124)$ & 44. F & (2) & 22. & $\mathrm{H}$ & (3) & $(42)$ & 62. J (4) \\
\hline (83) & 3. $\mathrm{F}$ & $(104)$ & 24. F & (125) & 45. $\mathrm{T}$ & (3) & 23. & $\mathrm{C}$ & (3) & $(43)$ & 63. B (2) \\
\hline$(84)$ & 4. F & $(105)$ & 25. F & $(126)$ & 46. T & (4) & 24. & $\mathrm{H}$ & (3) & (44) & 64. H (3) \\
\hline$(85)$ & 5. F & $(106)$ & 26. F & (127) & 47. T & (5) & 25 & B & (2) & $(45)$ & 65. A (1) \\
\hline$(86)$ & 6. F & $(107)$ & 27. F & (128) & 48. F & $(6)$ & 26. & $\mathrm{~J}$ & (4) & $(46)$ & 66. J (4) \\
\hline$(87)$ & 7. F & $(108)$ & 28. F & (i29) & 49. F & (7) & 27. & $D$ & (4) & $(47)$ & 67. B (2) \\
\hline$(88)$ & 8. F & $(109)$ & 29. F & $(130)$ & 50. F & $(8)$ & 28 & G & (2) & $(48)$ & 68. F (1) \\
\hline$(89)$ & 9. F & $(110)$ & 30. F & & & (9) & 29. & A & (1) & $(49)$ & 69. D (4) \\
\hline$(90)$ & 10. F & (111) & 31. F & & & $(10)$ & 30. & $F$ & (1) & $(50)$ & 70. F (1) \\
\hline$(91)$ & 11. $\mathrm{F}$ & $(112)$ & 32. $\mathrm{F}$ & & & (11) & 31. & D & (4) & (51) & 71. D (4) \\
\hline$(92)$ & 12. $\mathrm{F}$ & (113) & 33. $\mathrm{F}$ & & & (12) & 32. & F & (1) & $(42)$ & 72. $\mathrm{H}$ (1) \\
\hline$(93)$ & 13. F & $(114)$ & 34. F & & & (13) & 33. & B & (2) & $(53)$ & 73. A (1) \\
\hline$(94)$ & 14. $\mathrm{F}$ & (115) & 35. F & & & $(14)$ & 34. & $\mathrm{~F}$ & (1) & $(54)$ & 74. J (4) \\
\hline (95) & 15. $\mathrm{F}$ & $(116)$ & 36. $\mathrm{F}$ & & & $(15)$ & 35. & $D$ & (4) & (55) & 75. A (1) \\
\hline$(96)$ & 16. $\mathrm{F}$ & $(117)$ & 37. F & & & $(16)$ & 36. & $\mathrm{~F}$ & (1) & (56) & 76. H (3) \\
\hline$(97)$ & 17. $\mathrm{F}$ & $(118)$ & 38. $\mathrm{T}$ & & & $(17)$ & 37. & $\mathrm{D}$ & (4) & $(57)$ & 77. B (2) \\
\hline$(98)$ & 18. $\mathrm{F}$ & (119) & 39. $\mathrm{F}$ & & & $(18)$ & 38. & $\mathrm{H}$ & (3) & $(58)$ & 78. J (4) \\
\hline (99) & 19. $\mathrm{F}$ & $(120)$ & 40. F & & & $(19)$ & 39. & $\mathrm{C}$ & (3) & (59) & 79. B (2) \\
\hline$(100)$ & 20. $\mathrm{F}$ & (121) & 41. F. & & & $(20)$ & 40 & $\mathrm{~F}$ & (1) & $(60)$ & 80. F (1) \\
\hline (101) & 21. F & $(122)$ & 42. $\mathrm{T}$ & & & & & & & & \\
\hline
\end{tabular}


BIBLIOGRAPHY

. 


\section{BIBLIOGRAPHY}

Achebe, C. C. "Vocational Aspirations of Secondary School Students in East Central State of Nigeria," Unpublished master's thesis, University of Nigeria, Nsukka, 1972.

Asbury, F. "Vocational development of rural disadvantaged eighth grade boys." Vocational Guidance Quarterly, 1968, 47, 109-113.

Ansell, E. M. "An Assessment of Vocational Maturity of Lower-Class Caucasians, Lower-Class Negroes and Middle-Class Caucasians in Grades Eight through Twelve." Unpublished doctoral dissertation. State University of New York at Buffalo, May 1970.

Astin, Helen S. "Patterns of career choices over time," Personnel ard Guidance Journal, 1967, 45, 541-546. years." Journal "Career development during the high school

Bartlett, $W$. "Vocational maturity and personality variables of Manpower trainees." Vocational Guidance Quarterly, $1968,47,104-108$.

Bathory, M. J. "Occupational aspirations and vocational maturity." Paper presented at meeting of the American Vocational Association, Cleveland, December, 1967.

Beilin, H. "The Application of general developmental principles to the vocational area." Journal of Counseling Psychology, 1955, 2, 53-57.

Buehler, Charlotte'. Der Menscheliche Labenslauf als psychologiches problem. Liepzig: Herzel, 1933.

Callaway, C. A. School Leavers and the Developing Economy in Nigeria. Nigerian Institute of Social and Economic Research, 1960 .

Carter, H. D. "The Development of vocational attitudes," Journal of Consulting Psychology, 1940, 4, 185-191.

Cooley, W. W. "Interactions among interests, abilities, and career plans." Journal of Applied Psychology, Monograph, $1967,51$. 
Crites, J. O. "A model for the measurement of vocational maturity." Journal of Counseling Psychology, 1961, ${ }^{2}$, research design" "Proposals for a new criterion measure and Boston: Houghton Mifflin, 1964.

adolescence. I. "Measurement of Vocational maturity in inventory." P. Attitude test of the vocational development No. 595).

Hill, 19 $\overline{69 .}$ Vocational Psychology. New York: McGrawInventor $\overline{y, 1973 .} \cdot$ Attitude Scale Form A-1, Career Maturity CMI, CTB MCGraw-Hill, Competence Test Form A-1, Research Edition California, 1973 .

Hil Theory and Research Handbook, CMI CTB/MicGrawHill, Del Monte Research Park, Monterey, California, 1973.

MCGraw- Administration and Use Manual, CMI, CTB/ CRITERIA, 7, CTB " Newsletters, 1974 . , and Semler, I. J. "Adjustment, educational achievement and vocational maturity as dimensions of development in adolescence," Journal of Counseling Psychology 1967, $14,489-496$.

Davis, C. "A Study of Rural and Urban Youth: Their Vocational Maturity, Idealistic Educational Aspirations, Realistic Educational Aspirations, and Occupational Aspirations." Uripublished doctoral dissertation, University of South Carolina, 1972 .

Dilley, J. S. "Decision-making ability and vocational maturity." Personnel and Guidance Journal, 1965, 44 , 423-427.

Dysinger, W. C. "Maturation and vocational guidance." Occupations, 1950, 29., 198-201. 

East Central State, Policy on Public Education: Official
Document. No. 3 of 1971. Ministry of Education, Enugu.

East Central State, Education Statistics and Graphs Ministry of Education, 1970 .

Edwards, A. L. Experimental Design in Psychological Research. Revised edition. Holt, Rinehart and Winston, 1964.

Flanagan, J., and Cooley, W. W. Project Talent: One year followup studies, University of Pittsburgh, 1966.

Ginzberg, E., Ginsberg, S. Alexrod S., and Herma, J. Occupational Choice. New York: Columbia University Press,

Gribbons, W. and Lohnes, P. R. "Relationship among measures of readiness for vocational planning." Journal of Counseling Psychology, 1964, 11, 13-19.

Guidelines for the Third National Development Plan, 1975-80. Central Planning Office. Federal Ministry of Economic Development and Reconstruction 1974.

Havighurst, R. J. Human development and education, New York: Longmans, Green, 1953.

Hays, J. Statistics. New York: Holt, Rinehart \& Winston, 1963.

Levine, 'R. A. "Drearns and Deeds: Achievement Motivation in Nigeria" in Nigeria, Modernization and the Politics of Communalism. Michigan State University Press, 1971.

Lo Cascio, R. "Delayed and impaired vocational development: a neglected aspect of vocational development theory," Personnel and Guidance Journal, 1964, 42, 885-887.

- "Continuity and Discontinuity in vocational development theory." Personnel and Guidance Journal, 1967, 46, $32-36$.

Theory . The Vocational Maturity of Diverse Groups: Counseling and Evaluation, National Vocational Guidance AssociaEion Monograph 1974, p. 123-133.

Maynard, P. "Assessing the Vocational Maturity of InnerCity Youths," Unpublished doctoral dissertation, State University of New York at Buffalo, 1971. 

Miller, D. C. and Form, W. H., Industrial Psychology,
New York: Harper \& Row, 195l.

Montessano, N. and Geist, H. "Differences in occupational choice between ninth and twelfth grade boys." Personnel and Guidance Journal, 1964, 43, 150-154.

National Standard Classification of Occupations. Lagos Printing Division, 1966.

Obiechina, E. An African Popular Literature, A Study of Onitsha Market Pamphlets, Cambridge University Press, 1973.

Osipow, S. H. Theories of Career Development. 2nd ed. Appleton Century Crofts, 1973.

Ottenberg, S. "Ibo Receptivity to Change" in Continuity and Change in African Culture, Bascome \& Herskovits, The University of Chicago Press, 1970.

Popham, W. J., Sirotnck, K. A. Educational Statistics, Use and Interpretation. 2nd Ed. Harper and Row, 1973.

Schmidt, J. L. and Rothney, J. W. M. "Variability of Vocational Choices of High School Students." Personnel and Guidance Journal, 1955, 34, 142-146.

Schmieding, O. A. and Jensen, Shirley P. "American Indian Students: vocational development and vocational tenacity." Vocational Guidance Quarterly, 1968, 17, 120-3.

Schwarz, F. A. and Krug, R. E. Ability Testing in Developing Countries: A Handbook of principles and Techniques. Praeger Publishers, New York, 1972.

Shaffer, W. M. "The Stability of Vocational Interest from grades 8-12." Paper presented at the American Personnel and Guidance Association, New York City, March 25, 1975.

Smith, E. D. and Herr, E. L. "Sex differences in the maturation of vocational attitudes among adolescents." Vocationa l Guidance Quarterly, 1972, 20, 177-182.

Strong E. K., Jr. Vocational interests of men and women. Palo Alto, Stanford University Press, 1943.

- Vocational interests--eighteen vears after college. Minneapolis: University of Minnesota Press, 1955.

Super, D. E. "A theory of vocational development." American Psychologist, 1953, 8, 185-190. 

maturity." The dimensions and measurement of vocational
Teachers College Record, 1955, 57, 151-163.

1957. - The psychology of careers. New York--Harpers,

guidance: recent "A developmental approach to vocational Quarterly, 1964, 13, 1-10.

, Crites, J. O., Hummel, R. C., Moser, Helen P., Overstreet, Phoebe L., and Warnath, C. F. Vocational Development: a framework for research. New York: Teachers College,

, and Overstreet, Phoebe L. The Vocational maturity of ninth grade boys. New York: Teachers College, Columbia University, Bureau of Publications, 1960.

Underwood, B. J. Experimental psychology. New York: Appleton-Century - Crofts, 1949.

Westbrook, B. W., \& Cunningham, J. W. "The Development and Application of Vocational Maturity Measures." Vocational Guidance Quarterly, 1970, Vol. 18, $3,171-175$.

WiIstach, I. M. "Vocational Maturity of MexicanAmerican Youth." Unpublished doctoral dissertation, University of Southern California, 1967.

Wrenn, C. G. The Counselor in a Changing World. American Fersonnel and Guidance Association, 1962.

Yoloye, E. A. "The Predictive Validity of Lorge Thorndike Intelligence Tests for Achievement in Nigerian Granmar Schools," West African Journal of Educational and Jocational Measurement, Vol. 1, No. 1, February 1973. 
. 
